\title{
The Middle Stone Age human fossil record from Klasies River Main Site
}

\section{Frederick E. Grine $^{\text {a*}}$, Sarah Wurz ${ }^{\text {b }}$, Curtis W. Marean ${ }^{c, d}$}

$\mathbf{a}$

Departments of Anthropology and Anatomical Sciences, Stony Brook University, Stony Brook, NY 11794-4364, USA

b

School of Geography, Archaeology and Environmental Studies, University of the Witwatersrand, Johannesburg, South Africa (Sarah.Wurz@wits.ac.za)

c

Institute of Human Origins, School of Human Evolution and Social Change, Arizona State University, Tempe AZ 85287-2402, USA (Curtis.Marean@asu.edu)

d

Centre for Coastal Palaeoscience, Nelson Mandela Metropolitan University, Port Elizabeth, South Africa

* Corresponding author.

E-mail address: frederick.grine@ stonybrook.edu Telephone: +1-631-632-7622 (F.E. Grine) 


\section{ABSTRACT}

The paleoanthropological significance of Klasies River Main Site derives from its abundant Middle Stone Age (MSA) archaeological debris and the hominin fossils that have featured in discussions about modern human emergence. Despite their significance, the human remains have yet to be contextualized within the spatial, stratigraphic and geochronological framework of the site. We provide an updated overview of the stratigraphy and geochronology of the site, and review the human fossil record in this context. We also provide the first anatomical interpretations of many of the cranial vault fragments. Five hominin specimens derive from the Upper Member and six from the lowermost LBS Member. The vast majority - nearly 40 cataloged specimens - come from the SAS Member, many of these are from a single stratigraphic horizon in a relatively small area in Cave 1. There is a strong cranial bias to the sample; just over $70 \%$ of skeletal remains are from the skull. The postcranial skeleton is poorly represented. Excluding the three metatarsals, there are only three long bones in the sample - a clavicle, a proximal radius, and a proximal ulna. Remarkably, humeral, femoral and tibial diaphyses, which are the most durable elements in terms of cortical bone thickness and density, are absent. However, the proportional representation of hominin remains is reminiscent of the "Klasies Pattern" shown by the MSA large bovid skeletal parts. To some degree, this may reflect the excavation and recovery methods that were employed. The vast bulk of the human fossils represent adults. Only three undoubted juvenile individuals are represented - each by a deciduous tooth. This contrasts with other MSA sites along the southern coast of South Africa, where human remains are predominantly juvenile, usually in the form of (possibly exfoliated) deciduous teeth. However, this apparent dissimilarity may also reflect different excavation techniques.

\section{Keywords:}

human; cranial; vault; postcranial; adult; juvenile 


\section{Introduction}

The "site" of Klasies River, also referred to as Klasies River Mouth (Singer and Wymer 1982), comprises five caves or rock shelters located along a $2.5 \mathrm{~km}$ stretch of the Tsitsikamma Coast in the Eastern Cape Province of South Africa (Figure 1). Three of the caves preserve archaeological deposits. The westernmost Main Site (34 $\left.6^{\prime} 29.69^{\prime \prime} \mathrm{S}, 24^{\circ} 23^{\prime} 25.95^{\prime \prime} \mathrm{E}\right)$, which is situated approximately $0.5 \mathrm{~km}$ from the mouth of the Klasies River, was the focus of 14 months of intensive excavations by J. Wymer in 1967-1968 (Singer and Wymer, 1982). It was subsequently excavated seasonally by H. Deacon from 1984 to 1995 (Deacon, 1989, 1995, 2001b; Deacon and Wurz, 2005), and one of us (SW) has been excavating the site since 2013. The Main Site preserves ca. $21 \mathrm{~m}$ depth of deposits spread across a series of interrelated recesses in the Table Mountain sandstone cliff that are referred to as Caves 1, 1A, 1B and 2 (Figure 2). Most of the work has focused on the Cave 1 and Cave 1A deposits.

\section{FIGURE 1 ABOUT HERE}

\section{Print Full Page Width}

The palaeoanthropological significance of the Main Site derives from its abundant Middle Stone Age (MSA) archaeological debris and human fossils. These artifacts and faunal remains have featured prominently in discussions over the emergence of modern human behaviors (e.g., Klein, 1976, 1989; Deacon, 1989, 1992, 1993, 2001a; Klein and Cruz-Uribe, 1996; Milo, 1998; Wurz, 1999, 2002, 2008; Deacon and Wurz, 2001; McCall, 2006; Dusseldorp, 2010; d'Errico et al., 2012). Despite their generally fragmentary nature, the hominin fossils have played a significant role in interpretations of Homo sapiens evolution (e.g., Singer and Wymer, 1982; Bräuer et al., 1992; Smith, 1992; Frayer et al., 1993; Stringer and Bräuer, 1994; Bräuer and Singer, 1996a, 1996b; Churchill et al., 1996; Lam et al., 1996; Ahern and Smith, 2004; Royer et al., 2009).

\section{FIGURE 2 ABOUT HERE}

Print Full Page Width 
Wymer's initial excavations resulted in the recovery of the bulk of the human fossils nearly 40 specimens - that have been found to date, and most of these were documented to some degree by Singer and Wymer (1982). Four others (a lumbar vertebra, a fragment of temporal bone, a partial atlas, and a left hallucial metatarsal) were identified subsequently by Richard Klein from among the faunal remains recovered from those excavations. These have been documented by Grine et al. (1998) and Rightmire et al. (2006). Deacon's excavations resulted in the discovery of another dozen human fossils. These have been described by Rightmire and Deacon (1991, 2001), Bräuer et al. (1992a), Churchill et al. (1996), Rightmire et al. (2006) and Grine (2012).

While some of these hominin fossils display manifestly modern morphologies, others exhibit somewhat more archaic traits, and the degree of size dimorphism seems unmatched among recent human populations (Royer et al., 2009). While it is possible that these specimens do not derive from a single population or lineage, but rather represent different, unrelated populations who utilized the site at different times, it is also possible that some of the differences might relate to the temporal depth of the sample, which spans most of Marine Isotope Stage (MIS) 5 and all of MIS 4 (Grine, 2016). However, it is perhaps worth noting that some of the most dimorphic fossils derive from the same or adjacent levels. Overall, the evidence, albeit limited, seems to suggest a pattern of general but incomplete morphological modernity. As observed by Smith (1992: 148), the "somewhat primitive aspects of certain features in some specimens" might be expected in an otherwise morphologically modern population of this geological antiquity.

Despite the significance that the Klasies Main Site hominin fossils have assumed in the interpretation of human evolution and the observations that some appear to possess somewhat more archaic morphologies than others, they have yet to be contextualized within the spatial and strato-chronological framework of the site. Moreover, while several of the pieces of cranial vault have been positioned anatomically (e.g., the KRM 16425 frontal, the KRM 15397 temporal, and the KRM 41658 fronto-parietal fragments) by Singer and Wymer (1982) and Grine et al. (1998), there has been no attempt to date to place the remaining dozen or so vault pieces $\mathbf{1}$ in correct anatomical position. Such placement is critical to any attempt to ascertain the minimum number of individuals that are represented at the site or to assess patterns of postmortem taphonomic damage to the collection. 
Footnote 1 (page 4)

At present, 18 cranial fragments are present in the Iziko South African Museum collection, and all but three of these derive from the vault. As discussed below, Singer and Wymer (1982) listed an additional 30 or so vault fragments that were catalogued from their excavations. Singer noted that some of these were missing from the collection at the time it was described by him in the late 1970s, while others were listed by him as being "possibly human." None of these additional fragments is currently present in the museum collection.

Here we provide an overview of the human fossil record from the Klasies Main Site, placing the specimens in their stratigraphic and spatial context, and noting those that have been described and/or discussed by previous workers. We also provide the first morphological interpretation and anatomical placement of almost all of the numerous vault fragments that comprise the current collection.

A number of initiatives have served to develop a reasonable, if not wholly resolved, geochronological record for the bulk of the thickness of the MSA deposits, and Deacon's work has provided an improved stratigraphic framework for the Main Site. In particular, the stratigraphic scheme provided by Deacon and Geleijnse (1988) recognized a number of members, and they managed to place most of the units described by Singer and Wymer (1982) into this context. In order to provide an overview of the human fossils, it is necessary to appreciate their stratigraphic and geochronological context.

\section{Stratigraphy, archaeology and age of the Main Site}

The Main Site deposits are spread across a series of interrelated recesses referred to as Caves 1, 1A, 1B and 2, with most of the archaeological investigation having focused on those in Cave 1 and Cave 1A. The sediments in Cave 1A are substantially thicker (ca. $16 \mathrm{~m}$ ) than in Cave 1 (ca. 4 m). John Wymer's 1967-1968 excavations (Figure 3) recovered human remains from Caves 1, 1A and 1B, with the majority coming from Cave 1.

With reference to the Middle Stone Age archaeological record of the Main Site, Singer and Wymer (1982) identified a number of lithic phases in the sequence, numbered from below upwards as MSA I, II, III and IV, with the Howiesons Poort intercalated between MSA II and 
III. The lithic assemblage referred to as MSA I by Singer and Wymer (1982) has been termed MSA 2a by Volman (1984), and the Klasies River technological sub-stage by Wurz (2002). The assemblage referred to as MSA II by Singer and Wymer (1982) has been called MSA 2b by Volman (1984). Wurz (2002), on the other hand, recognized a greater difference between them than did Volman (1984), referring the MSA II to the Mossel Bay sub-stage. The Howiesons Poort witnesses a major shift in raw material usage with a marked increase in non-quartzite rocks, and is characterized here, as elsewhere, by the presence of backed artefacts and blade technology (Wurz, 2002). The subsequent MSA III assemblage contains a higher usage of nonlocal raw materials than the MSA I and MSA II, but not as high as in the Howiesons Poort, and the configuration of some of the MSA III cores appears to be similar to that in the underlying Howiesons Poort (Wurz, 2002). The MSA IV, as recognized by Wymer (Singer and Wymer, 1982) is restricted in occurrence to Layer 13 (i.e., the WS Member of Deacon and Geleijnse, 1988) in Cave 1. It was described as exhibiting a low incidence of flake-blades but a comparatively high frequency of small convergent flake-blades compared to the MSA III.

\section{FIGURE 3 ABOUT HERE}

\section{Print Full Page Width}

Singer and Wymer (1982) enumerated some seven or eight MSA artefact-bearing horizons in Cave 1 (numbered from top to bottom 13 through 39), with the bottom of the sequence (Layer 40) being clean beach gravel and shingle. They recognized 39 MSA layers in Cave 1A (numbered 1 - 39 from top to bottom), 15 MSA layers in Cave 1B (numbered 1 - 15 from top to bottom), and five MSA layers in Cave 2. Human fossils were recovered by them from layers 6, 25, 34 and 36 in Cave 1A, Layers 14, 15, 16, 17, 37 and 38 in Cave 1, and Layer 10 in Cave 1B.

Work by Hilary Deacon from 1984 to 1995 (Figure 3) provided an improved appreciation of the relationships of the archaeological deposits, together with a small number of human fossils, mostly from Cave 1A. Importantly, Deacon and Geleijnse (1988) developed a stratigraphic framework in which levels with broadly similar lithological characteristics were combined into members. Deacon and Geleijnse (1988) combined the various MSA artefactbearing layers identified by Singer and Wymer (1982) into five named members - from bottom 
to top designated the LBS (Light Brown Sand), SAS (Shell and Sand), RF (Rock Fall), Upper, and WS (White Sand). No single repository in the Main Site complex preserves all five. The LBS, SAS and WS members are represented in Cave 1, the LBS, SAS, RF and Upper in Cave 1A, the LBS and SAS in Cave 1B, and the RF and Upper in Cave 2. The stratigraphic units (i.e., Members and sub-members) identified by Deacon and Geleijnse (1988) and their correlations with the layers designated by Singer and Wymer (1982) and the lithic stages identified by them are summarized in Figure 4 and Table 1.

FIGURE 4 ABOUT HERE

Print Full Page Width

TABLE 1 ABOUT HERE

Print Landscape Orientation

The stratigraphy of the Main Site as defined by Deacon and Geleijnse (1988) is discussed below with any evidence that has been put forward pertaining to the geochronological age of each unit. In this context, it should be stressed that while all attempts to determine the ages of the deposits are recorded here, we recognize that the various methods that have been employed differ in their reliability, accuracy and precision. In particular, some of these methods have been improved with time. Uranium - thorium (U-Th) on clean speleothem is perhaps the most accurate and precise of these methods, but its use in dating archaeological sediments is restricted to those that are clearly intercalated with speleothem, which tends to be rare in archaeological sites. Single grain optically stimulated luminescence (SG-OSL) has improved substantially over time, and at the Pinnacle Point site of Crevice Cave, intercalated speleothems and sands dated with UTh and SG-OSL have produced concordant ages (Bar-Mathews et al., 2010). The Klasies Main Site stratigraphic units are discussed here from lowest to uppermost.

\subsection{The LBS (Light Brown Sand) Member}

The lowermost sedimentary unit overlying bedrock was referred to as the LBS ("Light Brown Sand") Member by Deacon and Geleijnse (1988). It is represented in Caves 1, 1A and 
$1 B$.

Layers 37 - 40 of Singer and Wymer (1982) in Caves 1 and 1A and their Layers 10 - 15 in Cave 1B correspond to the LBS Member (Wurz, 2000; Deacon, 2008). Layer 10 in Cave 1B is the equivalent of Layer 37 in Cave 1 (Deacon and Geleijnse, 1988), and they form the top of the LBS Member. These two layers were initially regarded as representing the base of the SAS Member due to their presumed age, with amino acid racemization (Bada and Deems, 1975) and relative ESR estimates (Goede and Hitchman, 1987) suggesting them to be considerably younger than the LBS. As such, they were initially interpreted by Deacon and Geleijnse (1988) as comprising a separate entity, the RBS (Rubble Brown Sand) sub-member of the SAS Member. However, as the lithology of the RBS strata shows more similarity to the underlying layers, the RBS was subsequently reinterpreted as comprising the top of the LBS Member (Wurz, 2000; Deacon, 2008). This reinterpretation accords with the description by Singer and Wymer (1982). ${ }^{2}$

Deacon and Geleijnse (1988) observed that the artefacts from the RBS appear to belong to the MSA I of Singer and Wymer (1982) and are therefore more similar to those of the LBS Member than the remainder of the SAS Member. The lithics from the LBS Member have been designated MSA I by Singer and Wymer (1982), MSA 2a by Volman (1984) and the Klasies River sub-stage by Wurz (2002). The distinguishing element in lithic technology from this phase is a well-developed, recurrent strategy aimed at obtaining relatively thin, elongate blades and points through controlling the platform features and the convexity of the active surface (Wurz, 2002, 2015). Retouch is mostly informal, with 'elegant' denticulates marking the MSA 1 or Klasies River sub-stage (Singer and Wymer 1982).

Footnote 2 (page 8)

The designations of the RBS by Wurz (2002) accord with the grouping of layers she outlined in her table 2. However, her illustration (2002: figure 2) of the stratigraphic scheme is an adaptation of the figures by Deacon and Geleijnse (1988: figures 5 and 6) in which the RBS in Cave 1 (= Layer 37) is erroneously indicated as a sub-member of the SAS, and Layer 37 in Cave 1A is also wrongly included as the lowermost unit of the SAS Member. In Wurz (2002: table 2) the layers for the RBS Member in Cave 1B should be 10-11, and SAS Lower in Cave 1 B should correspond to layers 6-9. 
2.1.1 Age of the LBS Member According to Deacon et al. (1988), the sand of the LBS Member is similar to that of the modern beach, and was most likely deposited when the sea level was very close to the present. This would be consistent with Shackleton's (1982: 196) observation that shells from the "MSA I midden" have $\delta^{18} \mathrm{O}$ values that "can only have formed during isotope substage 5e." Marine Isotope Stage (MIS) 5e has been variably dated between about 130 - 106 ka, with the most recent determination at between 130 - 119 ka (Hearty et al., 2007). ${ }^{\mathbf{3}}$ Given the presence of several peak sea levels during MIS 5e, the beach sands of the LBS Member are most likely the result of regression at the end of MIS 5e. This would place this regressive beach at the end of MIS 5e in the interval between 119 - 106 ka by the estimates of Hearty et al. (2007) and Bassinot et al. (1994) respectively. Wurz (2002) has identified Shackleton's (1982) samples as having derived from Layer 38 in Cave 1 and Layer 12 of Cave 1B.

A uranium-series date of ca. 109 ka obtained by Vogel (2001) for speleothem carbonates from Layer 40 in Cave 1, which should be considered as a minimum age estimate if the speleothem grew atop the sediments, is consistent with this interpretation. So, too, is an optically stimulated luminescence date of ca. $107 \mathrm{ka}$ (with a very wide estimate range) recorded by Feathers (2002) for a single sample of sand from Layer 38 in Cave 1A. Feathers (2002: 128), however, has noted that the Klasies sediments represent a very complex environment of uranium dissolution and enrichment, suggesting that the Main Site represents "about the worst case imaginable" for luminescence dating. Bada and Deems (1975) recorded amino acid racemization dates of ca. $110 \mathrm{ka}$ for samples from Layer 38. Millard (2008) has concluded that the LBS

Footnote 3 (page 9)

The onset of MIS 5e has been determined at 124 ka by Martinson et al.

(1987: table 2) and 122 ka by Imbrie et al. (1984: table 6) and Bassinot et al. (1994: table 4). The onset of MIS 5d has been set at 111 ka by Martinson et al. (1987), 107 ka by Imbrie et al. (1984) and 106 ka by Bassinot et al. (1994). Most recently, Hearty et al. (2007) defined the post-glacial MIS 6/5e Termination sea-level rise at $130 \mathrm{ka}$, and the rapid descent of sea-level into MIS 5d as being just after $119 \mathrm{ka}$. 
Member can be described as being older than $100 \mathrm{ka}$. These ages for the LBS Member in Caves $1,1 \mathrm{~A}$ and $1 \mathrm{~B}$, which are all roughly concordant given the error estimates involved, are summarized in Table 2.

TABLE 2 ABOUT HERE

\section{Print Landscape Orientation}

\subsection{The SAS (Shell and Sand) Member}

The LBS Member is overlain by the SAS (Shell and Sand) Member. ${ }^{4}$ The SAS Member is represented in Caves 1, 1A and 1B, and comprises the bulk of the deposit in Caves 1 and 1A (Deacon and Geleijnse, 1988). The SAS Member has been divided into several sub-members in Cave 1 to retain consistency with the levels recognized by Singer and Wymer (1982). Deacon and Geleijnse (1988) designated sub-members L (Lower) (= B [Base]), ${ }^{\mathbf{5}} \mathrm{U}$ (Upper), W (Wedge) and R (Rubble) of the SAS Member in Cave 1 as corresponding to Layers 17, 16, 15 and 14 respectively. Deacon and Geleijnse (1988) defined the top of the SAS Member

Footnote 4 (page 10) The SAS Member also has been referred to as the "Sands-Ash-Shell" Member (Grün et al., 1990: 427), although this nomenclature appears to have been abandoned in favor of the original usage of "Shell and Sand" by Deacon in subsequent publications.

Footnote 5 (page 10)

Deacon and Geleijnse (1988) designated the stratigraphic unit immediately overlying the RBS sub-member in Cave 1 as sub-member "B." The name for this sub-member was altered to "L" by Deacon (2001b) in an unpublished "Guide to Klasies River 2001." Although "B" continued to be used by him in some contexts (e.g., Rightmire et al., 2006), "L" was also employed (e.g., Deacon, 2008). Because "L" has been employed consistently by Wurz (2002, 2012; Wurz et al., 2003) and appears to have been preferred by Deacon (e.g., 2008), it is used here. 
in Cave 1A as being equivalent to Layer 23 of Singer and Wymer (1982) and its lowermost layer above the RBS sub-member (i.e., Layer 37) as equivalent to Layer 36.

Singer and Wymer (1982) viewed the SAS Member in Cave 1 as representing a series of separate occupational layers (15 and most of 17) interspersed with layers of rubble (part of 17, 16 and 14) that had rolled down from the large pile of occupational debris that had built up near Cave 1A. In agreement, Deacon and Geleijnse (1988) described SAS-L (=B) (Layer 17) as an occupation level, and SAS-R (Layer 14) as a talus slope deposit. However, Deacon and Geleijnse (1988) consider SAS-U (Layer 16) as an occupational layer, and SAS-W (Layer 15) as deriving from a talus slope deposit that blocked off the mouth of Cave 1 rendering it uninhabitable through SAS-W and SAS-R times. Subsequently, however, Rightmire and Deacon $(1991,2001)$ suggested that all the material in the SAS Member could have derived from the same depositional event, although the reason for this conclusion was not given.

Rightmire and Deacon (2001) concluded that Singer and Wymer (1982) may have given unwarranted significance to facies changes between sedimentary units and, as an example, point to Figure 3.3 of Singer and Wymer (1982), in which sediments apparently attributed to Layer 14 appear both over and under Layer 15. However, figure 3.3 of Singer and Wymer (1982) is an enlargement of a portion of their figure 3.1 (1982), which clearly depicts Layer 16 underlying Layer 15. It is reasonably clear that the label for Layer 16 was merely omitted from Figure 3.3. However, figure 3.3 has "loose" written in the rubble between Layers 14 and 16, suggesting that there is not a clear separation of these layers here, and Singer and Wymer (1982) acknowledge that the provenience of material recovered from this particular area is questionable. Thus, Rightmire and Deacon (1991) argue that the context of the finds from SAS W (Layer 15) is geological rather than deriving from an in situ archaeological deposit, and that SAS R (Layer 14) in Cave 1 occupies a broad channel-like feature (i.e., a drainage sump) against the back slope of SAS W. As such, the top of SAS W in Cave 1 is seen to correspond with the top of Layer 25 in Cave 1A, with SAS W representing slope wash from Cave 1A.

The lithic assemblages from the SAS Member have been described variously as MSA II (Singer and Wymer, 1982), MSA 2b (Volman, 1984), and the Mossel Bay sub-stage (Wurz, 2002). Layers 1 - 15 in Cave 1B were recognized by Singer and Wymer (1982) as representing MSA I, but analysis by Wurz (2000) confirmed Thackeray's (1989) contention that the material in the upper part of the Cave 1B sequence belongs to the MSA II sub-stage. Due to its thickness 
and the subtle changes in the stone tool technology that it evidences, the SAS Member has been divided into the "MSA II Upper” and “MSA II Lower” by Wurz (Wurz 2002) (Table 2), although both units form part of the Mossel Bay techno-complex. The "MSA II Upper" includes the SAS R and SAS W sub-members in Cave 1, and most of the SAS Member in Cave 1A. The "MSA II Lower" includes the SAS U and SAS L sub-members in Cave 1 and the lowermost part of the sequence in Cave 1A (i.e., Layer 36 and possibly Layers 35 and 34 of Singer and Wymer [1982]).

2.2.1 Age of the SAS Member Based on $\delta^{18} \mathrm{O}$ values for shell from Layer 15 (=W) of Cave 1, the SAS Member appears to have begun accumulation during MIS 5c (Shackleton, 1982; Deacon et al., 1988); that is, somewhere between ca. 105 - 96 ka according to the SPECMAP dates (Imbrie et al., 1984) and the chronologies of Wright (2000: figure 4) and Lisiecki and Raymo (2005).

With regard to the lower part of the SAS Member, Bada and Deems (1975) reported aspartic acid ages of ca. 89 ka for the SAS-U sub-member (Layer 16) in Cave 1. However, as noted by Rightmire and Deacon (1991), there are uncertainties surrounding the calibration of these ages. Grün et al. (1990) reported ESR estimates of $93.5 \pm 10.4$ and $88.3 \pm 7.8 \mathrm{ka}$ using a linear uptake (LU) model for two samples of a tooth fragment from Layer 17 at the base of the SAS Member. Although this was their preferred interpretation, the early uptake (EU) model yielded corresponding dates of $67.9 \pm 7.2$ and $63.9 \pm 5.3 \mathrm{ka}$ (Grün et al., 1990). Millard (2008) has recalculated the ESR ages from data in Grün et al. (1990) to produce a wider range of dates for the SAS member: 102 - 63 ka using an EU model and 104 - 64 ka using a LU model. Eggins et al. (2005) have applied laser ablation MC-ICPMS to reanalyze this same specimen of tooth enamel, obtaining a U-series/ESR estimate of $101 \pm 12 \mathrm{ka}$. As with virtually all ESR estimates on open systems such as tooth enamel, any one of the three potential models can be employed to seemingly provide any date that is preferred. However, the application by Eggins et al. (2005) of U-series (U-Th) disequilibrium to enamel that is also subjected to ESR enables better determination of the uptake model, and the age estimate they produced is consistent with Vogel's (2001) U-Th results for speleothem samples from concordant levels.

Vogel (2001) obtained U-Th estimates of 85.2 $\pm 2.1 \mathrm{ka}, 94.6 \pm 3.2 \mathrm{ka}$ and $100.8 \pm 7.5 \mathrm{ka}$ for three stalagmite samples from SAS-R (Layer 14) (Table 2). He also reported an age range of 
$77.4 \mathrm{ka}$ for a sample of carbonate crust from the upper SAS (Layer 30) in Cave 1A (Vogel, 2001). Although Vogel (2001) also obtained a U-Th age of only $36.6 \mathrm{ka}$ for shell from SAS W (Layer 15) in Cave 1, he noted that shells produce unreliable U-series dates owing to their tendency to absorb uranium from percolating water long after deposition. This results in an age that is substantially younger than the shell itself. Grün et al. (1990) obtained three ESR estimates from a specimen of tooth enamel from the upper part of the SAS member (Layer 27) in Cave 1A; the mean EU value was $51.2 \pm 4.3 \mathrm{ka}$ and the mean LU date was $66.4 \pm 6.1 \mathrm{ka}$. Eggins et al. (2005) have applied laser ablation MC-ICPMS to reanalyze this same specimen of tooth enamel, and seem to have obtained a revised estimate that is within the range indicated by the earlier LU model, although the actual values were not reported by them.

Feathers (2002) reported a range of OSL dates for a sample from SAS-U (Layer 16) of between $61.7 \pm 9.0$ and 107.3 \pm 34.7 , with a preferred OSL/IRSL estimate of $70.9 \pm 5.1 \mathrm{ka}$. These comfortably bound the estimate of 89 ka reported by Bada and Deems (1975) for an AAR sample from this same layer. Feathers (2002) also published a wide range of OSL ages (67.4 \pm 6.6 to $154.5 \pm 15.5 \mathrm{ka}$ ) for a sample from SAS-W (Layer 15) from Cave 1, with a preferred OSL/IRSL estimate of $68.4 \pm 6.5 \mathrm{ka}$. The ages that have been estimated for the SAS Member in Caves 1 and $1 \mathrm{~A}$ are summarized in Table 2 .

\subsection{The RF (Rock Fall) Member}

In Cave 1A, the relatively thin (ca. 0.5 meter thick) RF ("Rock Fall”) Member overlies the SAS Member. It is equivalent to Layer 22 of Singer and Wymer (1982). The RF Member was identified by Deacon and Geleijnse (1988) as forming the base of the sedimentary sequence in Cave 2, although the only layers (numbered 1 through 5) in that recess discussed by Singer and Wymer (1982) are described as being lithologically very similar to one another and containing Howiesons Poort artefacts. These layers have been designated as corresponding to the Upper Member by Deacon and Geleijnse (1988). Deacon's sieving platform, which was a step cut into the entrance deposits of Cave 2, exposes the RF Member.

The assemblage of lithic artefacts from the RF Member shows no significant distinction from that in the underlying SAS Member, and has similarly been referred to MSA II (Singer and Wymer, 1982), MSA 2b (Volman, 1984), and the Mossel Bay sub-stage (Wurz, 2002). 
2.3.1 Age of the RF Member The oxygen isotope profile of the RF Member correlates with MIS 5a (i.e., 84 - $74 \mathrm{ka}$ ) according to Deacon et al. (1988). Vogel (2001) reported a U-series age of only $28 \pm 2.2 \mathrm{ka}$ for a sample of shell from Layer 22 in Cave 1A; but here, too, he was at pains to point out that shells produce unreliable U-series dates. Feathers (2002) obtained an OSL/IRSL estimate of $80.6 \pm 17.6 \mathrm{ka}$ and reported a U-series estimate of $77.4 \pm 7.0 \mathrm{ka}$ for a single sample from this level. Millard (2008) has recalculated Feathers' reported estimates for this horizon to obtain a range of ca. 71 - $53 \mathrm{ka}$. Jacobs et al. (2008) obtained single-grain OSL ages from two sand samples from the RF member. One from Layer 22 yielded a date of $72.1 \pm 3.4 \mathrm{ka}$; the second produced an age of $71.6 \pm 2.9 \mathrm{ka}$. These two determinations average to $71.9 \pm 3.2 \mathrm{ka}$ for the upper part of the RF member.

Feathers (2002) and Tribolo et al. (2013) have cautioned that OSL ages determined on sediment particles of unknown moisture history are open to question, an issue that potentially affects other trapped charge techniques, such as TL and ESR, as well. Jacobs et al. (2008), who employed SG-OSL dating, estimated the moisture content of the site to have been equivalent to that at present, which is perhaps open to question in light of the climatic fluctuations that have been documented for the end of MIS 5 (Carr et al., 2016; Grine, 2016; Scott, 2016). However, Jacobs et al. (2008) built moisture variation into the error estimates, noting that the uncertainty attached to the total dose rate is sufficient to accommodate likely variations in sample moisture content throughout the period of burial, where the total dose rates decrease and the optical ages increase by $\sim 1 \%$ for each $1 \%$ increase in water content (Jacobs et al., 2008: SI, pp. 14-19). Thus, these ages would seem to be reasonably bounded.

The various dates that have been estimated for the RF Member in Cave 1 are summarized in Table 2.

\subsection{The Upper Member}

The Upper Member overlies the RF Member, capping the stratigraphic profile in Cave 1A. The bulk of its thickness (i.e., Layers 10 - 21 of Singer and Wymer [1982]) contains Howiesons Poort lithics; the stone tools from its uppermost levels (Layers 1 - 9) have been described as conforming to a distinctive post-Howiesons Poort MSA III by Singer and Wymer (1982; see also Wurz, 2002; Villa et al., 2010). The Upper Member is also represented in Cave 
2, where it is equivalent to Layers 1 - 5 of Singer and Wymer (1982). Here, too, it contains Howiesons Poort artefacts. According to Deacon and Geleijnse (1988), the Upper Member directly overlies the RF Member in Cave 2.

2.4.1 Age of the Upper Member The oxygen isotopes from shells in the Upper Member are consistent with its deposition during MIS 4. Shackleton (1982) suggested concordance anywhere between MIS 5b and MIS 3, while Deacon et al. (1988) suggested consistency with the transition from MIS 5a to MIS 4. This range would correspond to an age of between about 80 - 60 ka based on the dates for these isotope stages (Imbrie et al., 1984; Martinson et al., 1987; Bassinot et al., 1994; Aitken and Stokes, 1997; Wright, 2000; Lisiecki and Raymo, 2005). The ages that have been estimated for the Howiesons Poort and the post-Howiesons Poort levels provide more detailed determinations for the Upper Member.

2.4.1.1 The Howiesons Poort Grün et al. (1990) obtained three ESR estimates for a single tooth from the Howiesons Poort strata of the Upper Member. The EU model values average to only $31.9 \mathrm{ka}$. Because this is within the range of ${ }^{14} \mathrm{C}$-dating, and prior analyses had indicated the material from the MSA strata at Klasies to be beyond this limit, Grün et al. (1990) obviously preferred the LU model values, which average to $45.6 \pm 6.7 \mathrm{ka}$. Even their preferred data would indicate a potential ESR range of some 39 - $52 \mathrm{ka}$ for this level. Vogel (2001) reported ${ }^{14} \mathrm{C}$ dates for two samples of charcoal from Layers 17 and 18 in excess of $50 \mathrm{ka}$ and 40 ka respectively. Millard (2008) recalculated the ESR ages from Grün et al. (1990) for the Howiesons Poort, obtaining an EU range of 42 - $60 \mathrm{ka}$, and a LU range of 47 - $60 \mathrm{ka}$. Eggins et al. (2005) have applied laser ablation MC-ICPMS to reanalyze the same tooth examined by Grün et al. (1990), obtaining a U-series/ESR estimate between 53 - $64 \mathrm{ka}$. An attempt to employ amino acid racemization of ostrich egg shell from the Howieson's Poort deposits by Brooks et al. (1993) yielded an estimate in excess of $80 \mathrm{ka}$.

Vogel (2001) obtained a U-series estimate of $65.6 \pm 5.3 \mathrm{ka}$ for a calcite crust from the Howiesons Poort strata (Layer 14) in Cave 1A, and reported infinite ${ }^{14} \mathrm{C}$ radiocarbon dates for charcoal samples from Layer 17 (> $50 \mathrm{ka}$ ) and Layer 18 (> $40 \mathrm{ka}$ ). Feathers (2002) reported OSL ages for two samples from the Howiesons Poort levels. The first, from Layer 1/2 of Cave 2, yielded an age range of $50.6 \pm 4.9$ to $64.0 \pm 6.0 \mathrm{ka}$, with a preferred OSL/IRSL estimate of 52.4 $\pm 4.0 \mathrm{ka}$. The second, from Layer 15 of Cave 1A, produced an age range of $42.1 \pm 4.7$ to $63.6 \pm$ 
19.0 ka, with a preferred OSL/ISRL estimate of $46.7 \pm 3.3 \mathrm{ka}$. Tribolo et al. (2005a, 2005b) applied thermoluminescence (TL) analyses to a sample of 13 pieces of burnt quartzite from the Howiesons Poort deposit, and obtained a weighted average of some $56.3 \pm 6.5$ with an overall range between 48 - $58 \mathrm{ka}$. Re-assessment of the dose rates for these burnt lithics provided a slightly younger mean age of $53.3 \pm 3 \mathrm{ka}$, with an overall range of 48 - $58 \mathrm{ka}$ (Tribolo et al., 2013: table S2). Jacobs et al. (2008a) reported single-grain OSL estimates for three sand samples from the Howiesons Poort that ranged between $63.4 \pm 2.6$ and $65.5 \pm 2.3$, and average to $64.3 \pm$ $2.5 \mathrm{ka}$. While this is concordant with the dates for the Howiesons Poort reported by Jacobs et al. (2008) at other sites in South Africa, these age determinations have not been without debate (e.g., Guérin et al., 2013; Tribolo et al., 2013; Galbraith, 2015; Jacobs and Roberts, 2015).

\subsubsection{The post-Howiesons Poort Grün et al. (1990b) obtained three ESR} estimates for a single tooth from the post-Howiesons Poort strata of the Upper Member. The EU model values average to only $37.7 \mathrm{ka}$, which is marginally within the range of conventional ${ }^{14} \mathrm{C}$ dating; hence, they preferred the linear uptake model values, which average to $50.8 \pm 6.6 \mathrm{ka}$. This value and its attendant range (44-57 ka) are slightly older than that obtained by them for the stratigraphically lower Howiesons Poort level. Eggins et al. (2005) applied laser ablation MC-ICPMS to reanalyze the same tooth examined by Grün et al. (1990), and although they failed to record the actual values, it is apparent from their illustration (Eggins et al., 2008: figure 8) that the range almost entirely overlaps that for the Howiesons Poort sample, and that the average is also a little older than that for the Howiesons Poort specimen. Millard (2008) recalculated the ESR dates from Grün et al. (1990) for the post-Howiesons Poort specimen, obtaining an EU age of $<48 \mathrm{ka}$, and a LU age of $<52 \mathrm{ka}$. Vogel (2001) reported a ${ }^{14} \mathrm{C}$ date in excess of 45,200 years for a charcoal sample from Layer 6 in cave 1A.

Feathers (2002) obtained an OSL/IRSL estimate for a single sample of $43.4 \pm 3.0 \mathrm{ka}$ from a level (Layer 9) in the post-Howiesons Poort MSA III strata of the Upper Member. Unlike the ESR values (Grün et al., 1990b; Eggins et al., 2005), the OSL ages determined by Feathers are at least concordant with the stratigraphic derivation of the samples. Tribolo (2003) determined a TL age of $60 \pm 5 \mathrm{ka}$ from a single burnt stone from the same square (E50) sampled by Feathers (2002). Re-assessment of the dose rate for this specimen provided a slightly younger mean age of $57 \pm 4$ ka (Tribolo et al., 2013: table S2). Jacobs et al. (2008a) reported a single-grain OSL age 
of $57.9 \pm 2.3 \mathrm{ka}$ for a sediment sample immediately overlying the Howiesons Poort levels in Cave 1A.

The published ages for the Howiesons Poort and post-Howiesons Poort layers of the Upper Member in Cave 1A and Cave 2 are summarized in Table 2.

\subsection{The WS (White Sand) Member}

In Cave 1, the SAS member is capped by the WS (White Sand) Member (Deacon and Geleijnse, 1988). It is equivalent to Layer 13 of Singer and Wymer (1982). Its lithic artefacts have been described as MSA IV (Singer and Wymer, 1982).

2.5.1 Age of the WS Member Bada and Deems (1975) obtained an aspartic acid estimate of ca. $65 \mathrm{ka}$, and Feathers (2002) reported an OSL/TL date of $70.7 \pm 7.4 \mathrm{ka}$ based on a single sample from this layer. Most recently, Feathers has produced SG-OSL dates of $66.5 \pm 4.8$ and $56.3 \pm 4.6$ ka for two samples taken at depths of 150 and $450 \mathrm{~mm}$ below the top of the WS Member (Nami et al., 2016: table 2). Although these two ages are stratigraphically inverted, the means are nearly within their $1 \sigma$ error terms, and they bracket the aspartic acid estimate.

Nami et al. (2016) also reported on two paleomagnetic sample cores taken from the WS Member. While most of the samples within the WS components of the cores that display normal geomagnetic field positions, corresponding to the Bruhnes Chron, the lowermost samples exhibit anomalous directions. Nami et al. (2016) consider that these may be related to the excursion estimated at $61 \pm 2$ ka from cores in the Norwegian-Greenland Sea, or to an undated excursion (5a) that is placed somewhere between 40 and $125 \mathrm{ka}$. The age estimates that have been obtained for the WS Member are summarized in Table 2.

\section{Stratigraphic and spatial distribution of the human fossils}

As noted above, the excavations by John Wymer produced the bulk of the human fossils that have been recovered to date. More than 40 human specimens were documented by Singer and Wymer (1982). Four other human bones excavated by Wymer, but not initially recognized as such, were identified subsequently by Richard Klein from among the faunal remains. These four - a lumbar vertebra, a fragment of temporal bone, a partial atlas, and a left hallucial metatarsal - 
have been described by Grine et al. (1998) and Rightmire et al. (2006). Deacon's excavations resulted in another 13 human fossils. These have been documented by Rightmire and Deacon (1991, 2001), Bräuer et al. (1992a), Churchill et al. (1996), Rightmire et al. (2006) and Grine (2012).

The human remains from the Middle Stone Age deposits at Klasies River Main Site are listed in Table 3. Three separate identification systems have been applied to the hominin remains from the Klasies Main Site. In the first instance, Singer and Wymer (1982) provided the specimens that they recovered and described (or at least listed) with the prefix "KRM" (Klasies River Mouth) appended to a specimen excavation number (e.g., KRM 13400). Those specimens, or at least most of those present in the collection in 1986 were given Iziko South African Museum (SAM-AP) acquisition numbers. Thus, for example, KRM 13400 is catalogued as SAM-AP 6223. Specimens that were recovered by Wymer, but recognized only later among the faunal remains as hominin by R.G. Klein do not necessarily have a KRM number; but these have been given SAM-AP accession numbers. Finally, most (but not all) of the human fossils recovered by Deacon were published by him and G.P. Rightmire with their excavation coordinate designations (e.g., "E50/AV" or "01/C1/SMB” or "“"AA43/SAS4 SHB”). In his description of Deacon's fossils, Grine (2012) employed the excavation grid coordinates, where these were known. All of the specimens excavated by Deacon have been accessioned recently (February 2015) into the Iziko South African Museum collection, and their SAM-AP catalogue numbers are provided in Table 3.

\section{TABLE 3 ABOUT HERE Print Landscape Orientation}

The majority of specimens carry KRM numbers, and not all of the KRM fossils have been accessioned by the Iziko South African Museum (i.e., provided with SAM-AP numbers). In addition, all of the articles published to date on the hominin specimens from Klasies have utilized KRM numbers. Thus, we here employ KRM numbers in preference to the SAM-AP numbers, although the latter are noted where they have been applied. In those instances in which there is no KRM number associated with a specimen, the SAM-AP number is utilized when discussing the fossil. 
While the facial bones, mandibles and the postcranial bones have been afforded at least reasonable, if not detailed description, only three pieces from the neurocranium have been described in any detail. Similarly, whereas the postcranial and facial bones have been identified by element and side, the cranial vault fragments have not been given the same treatment. Identification and anatomical positioning of these vault pieces is critical to any assessment of the minimum number of individuals (MNIs) that derive from a given stratigraphic unit. This information is also critical in the assessment of possible patterning with reference to human induced surface modification. For these reasons, the cranial vault fragments are described here in greater detail than provided by Singer and Wymer (1982) and, where feasible, anatomical landmarks are used to position these pieces as precisely as possible.

The following overview of the human remains from the various stratigraphic levels of the Main Site provides the reference sources for those fossils that have been afforded description and/or analysis. The cranial vault pieces that have not been documented are here described and illustrated.

\subsection{WS Member human remains}

The deposits that comprise the WS Member in Cave 1 are devoid of human remains.

\subsection{Upper Member human remains}

Five human specimens derive from the Upper Member in Cave 1A (Table 3). Two (cranial vault fragments) were recovered by Wymer and three (isolated teeth) by Deacon. All but one of these five appear to come from the post-Howiesons Poort strata, although there is some degree of uncertainty with regard to the stratigraphic derivation of the teeth found by Deacon. No human remains have been recovered from the Upper Member strata in Cave 2.

KRM 40243 - 40244. These are two small parietal fragments from Layer 6. They were mentioned briefly by Singer and Wymer (1982: 139), who noted that "both appear charred," 6 with KRM 40244 more so than KRM 40243. They also observed that "the inner aspects show faint vascular grooves." Unfortunately, both pieces are currently missing from the human fossil collection of the Iziko South African Museum. Given their derivation, comparable thickness (maxima of $6.5 \mathrm{~mm}$ and $6.0 \mathrm{~mm}$ according to Singer and Wymer, 1982) and apparently similar 
Footnote 6 (page 19).

Although numerous hearths have been documented in the deposits (Singer and Wymer, 1982; Deacon and Geleijnse, 1988), their relationship to the apparently charred hominin bones cannot be determined on the basis of currently available data.

state of preservation, it is conceivable that they derive from a single individual.

Although these two pieces were not illustrated by Singer and Wymer (1982), copies of Singer's photographs of their endocranial and ectocranial aspects were made available to us, and casts of both specimens are available in the museum collection. KRM 40243 is a triangular fragment (ca. 25 x $37 \mathrm{~mm}$ ) with deeper meningeal grooves than KRM 40244 (ca. 24 x $30 \mathrm{~mm}$ ), which has a more nearly rectangular outline. KRM 40243 and KRM 40244 are illustrated here in Figure 5. KRM 40244 presents some half dozen indentations along its shortest side that may be sutural. The presence of meningeal grooves on the endocranial surfaces suggest that both are pieces of parietal, as described by Singer and Wymer (1982). It is not possible to determine their anatomical locations more precisely.

\section{FIGURE 5 ABOUT HERE}

Print Column Width

SAM-AP 6373 - 6375. These three isolated teeth were recovered by Deacon; two (SAMAP 6374 and 6375) are from square E50 and one (SAM-AP 6373) is from square H51 (Table 3). Rightmire and Deacon (1991) briefly mentioned the teeth, misidentifying SAM-AP 6375 as a $\mathrm{P}_{3}$, but provided no contextual information for them. The three have been described and illustrated by Grine (2012).

The $\mathrm{Ldi}^{1}$ (SAM-AP 6374) and a RP 4 (SAM-AP 6375) from square E50 almost certainly do not represent a single individual inasmuch as the former is expected to have been shed well in advance of the eruption of the premolar. At the same time, it is very unlikely that SAM-AP 6374 from square E 50 and the fragment of $\mathrm{Rdm}^{1}$ (SAM-AP 6373) from square H51 could have derived from the same individual, because square E50 is at the very top of the Upper Member, while H51 is about midway through the thickness of the Upper Member deposit. 
Singer and Wymer (1982) noted that no human remains were found by them in the Howiesons Poort layers. The two teeth from square E50 (SAM-AP 6374 and 6375) would also appear to be attributable to post-Howiesons Poort levels. Thus, the maxillary deciduous molar fragment (SAM-AP 6373) from square H51 is the only specimen that is associated with the Howiesons Poort at Klasies River Main Site.

\subsection{RF Member human remains}

The RF Member deposits in Cave 1A and Cave 2 have not yielded any human remains.

\subsection{SAS Member human remains}

The vast majority of the human fossils come from the SAS Member (Table 3). Most of these were attributed to Layer 14 by Singer and Wymer (1982). A number of the human remains attributed to Layer 14 (SAS-R) are clustered in a small area in Cave 1. According to Singer and Wymer (1982: figure 3.20), mandibles and teeth of at least four individuals (KRM 13400, KRM 14695 and KRM 16424) and a clavicle (KRM 27076) were found within a $5 \mathrm{~m}^{2}$ area near the

mouth of the cave. ${ }^{7}$ This cluster of fossils includes the most gracile and robust mandibular corpora within the human assemblage (Royer et al., 2009). Singer and Wymer (1982: table 8.1) also list the KRM 16651 zygomatic and the KRM 16720 os coxae fragment (now missing from the museum collection) as deriving from Layer 14. Although the position of neither was indicated by Singer and Wymer (1982: figure 3.20) in their plan of the Layer 14 excavation, Deacon (2008: figure 6) seems to have been able to place KRM 16651 in this context. An additional four cranial vault fragments (KRM 27574 - 27577) are listed by Singer and Wymer

Footnote 7 (page 21). The same illustration in Singer and Wymer (1982: figure 3.20) also depicts specimens "KRM 16491 - 2" immediately adjacent to the cross for KRM 13400. However, these two numbers do not appear anywhere in their description of the human remains, and nor are they present in the museum collection; thus, it is likely that they are typographical errors for 14691-2, which comprise the left mandibular fragment containing an $\mathrm{M}_{1}$ and an isolated $\mathrm{LP}_{4}$ that are associated with the KRM 13400 corpus (Grine, 2012). 
(1982: table 8.1) as deriving from Layer 14. Although the positions of these pieces were not indicated by Singer and Wymer (1982: figure 3.20) in their plan of the Layer 14 excavation, Deacon (2008: figure 6) was able to place them in this context. Thus, at least nine or 10 fossils from Layer 14 appear to have been found within a $6 \mathrm{~m}^{2}$ area of Cave 1.

Singer and Wymer (1982: figures 3.21 - 3.24) also noted the proximate spatial (horizontal plan) locations of human fossils from Layer 15 (KRM 27038), Layer 16 (KRM 16425), Layer 17 (KRM 21776) and Layer 37 (KRM 26909) in relation to the front of Cave 1. The positions of many of these fossils are indicated in Figure 6. In total, some 13 or 14 human specimens derive from the SAS deposits within a comparatively constrained area of Cave 1. Three individually numbered human (or possibly human) fossils were recovered by Wymer from Layer 17 in Cave 1. Of these, the edentulous KRM 21776 mandibular corpus was found within a few meters of a number of the specimens from Layer 14. The two skull fragments (KRM 24006 and KRM 24007) from the same "Main Cutting A" were unfortunately missing from the museum collection at the time it was described by Singer (Singer and Wymer, 1982).

\section{FIGURE 6 ABOUT HERE}

\section{Print Full Page Width}

Because human remains are relatively scarce at Klasies River Main Site, Rightmire and Deacon (1991; see also Deacon, 2008) argued that a group of this many individuals would be unlikely to have accumulated secondarily in sloping rubble deposits. Thus, they posited that "some if not all of these finds can be in primary context and be associated with the lower (17-16) [depositional] rather the upper (15-14) [rubble] phases of deposition" (1991: 136). They argued that this pattern would be unlikely if the bones had been deposited in different environments at different times, and raised the possibility that all the hominid material in the SAS Member represents a single depositional event, which Deacon (1995) had suggested to have been associated with layer 16 (SAS U). Indeed, the illustration by Singer and Wymer (1982: figure 3.20) indicates mixture with both Layers 15 and 16 in the area immediately adjacent to the fossils, and this bears upon the provenience of the human material, particularly in the area of the "West Cutting," from which 11 specimens are recorded by Singer and Wymer (1982: table 8.1) as coming from Layer 14 - 15 (= Deacon's SAS Rubble-Wedge units). 
Rightmire and Deacon $(1991,2001)$ have raised interesting questions regarding the provenience of the hominid remains, but the evidence they marshaled for their being related to a single depositional event needs to be revisited.

Of the 18 individually catalogued fossils recovered in the 1967-1968 excavations that are held to derive from Layer 14 in Cave 1, a number can definitely be associated with one another. Thus, the KRM 13400 mandibular corpus is certainly associated with the four KRM 14691-4 teeth (Grine, 2012). Singer and Wymer (1982) noted that the KRM 27575 and 27576 vault fragments can be joined to each other in a good fit. Singer and Wymer (1982) also ventured that the KRM 27574 parietal fragment and the three other vault fragments in this numerical sequence (i.e., KRM $27575+27576$ and KRM 27577) may possibly belong to a single individual. In addition, the KRM 14695 symphysis and 14696 molar, which were found immediately adjacent to one another, possibly represent a single individual. Of the five specimens excavated by Deacon from a level equivalent to layer 16 (= SAS U) in Cave 1A (Table 3), the SAM-AP 6379 and 6380 upper molars are certainly associated (Rightmire and Deacon, 2001), and it is likely that the heavily worn SAM-AP $6381 \mathrm{I}^{2}$ is associated with these molars (Grine, 2012).

Singer and Wymer (1982: table 8.1) suggested that the three cranial vault fragments (KRM 26730, KRM 26731 and KRM 26732) from Layer 34 in Cave 1A were associated with one another, and that two of these pieces (KRM 26731 and KRM 26732) are blackened "probably by fire." Thus, some 39 individually catalogued human fossils have been recovered the SAS Member in Caves 1, 1A and 1B. At least four individuals are represented by more than one element that can be associated with certainty (or near certainty).

3.4.1 SAS R (Cave 1) remains A total of 18 individually catalogued specimens derive from deposits in Cave 1 that comprise sub-member R. At least three individuals are represented by more than one catalogued element.

KRM 20927(A) (SAM-AP 6113A). This lumbar vertebra was discovered among the faunal remains by R.G. Klein. Rightmire and Deacon (1991) provided a cursory description of its state of preservation and a series of measurements for the bone. They did not identify its position. We regard it as either a L2 or a L3, with the weight of evidence suggestive of a L2 (G. Russo, pers. comm.). This assessment it based on the shape of the vertebral canal, which is less triangular in outline than is characteristic of lower lumbar vertebrae, laminar width and height 
(narrow and tall), and the orientation of the postzygapophyses, which face more sagittally than would be expected for articulation with a L4.

The specimen carries the same KRM number as the left hallucial metatarsal from Layer 16 in Cave 1. As a result, the vertebra has been catalogued in the Iziko South African Museum as SAM-AP 6113A, whereas the metatarsal has been accessioned as SAM-AP 6113B. Following this, it is proposed here to refer to the vertebra as KRM 20927(A).

SAM-AP 6268. This partial atlas was discovered among the faunal elements by R.G. Klein. Grine et al. (1998) provided its description, illustration and morphometric analysis.

KRM 13400 (SAM-AP 6223). This is an incomplete mandibular symphysis and right corpus that is clearly associated with four isolated teeth (KRM 14691-14694 = SAM-AP 62276230) recovered nearby (Grine, 2012). It has been described and illustrated by Singer and Wymer (1982), Rightmire and Deacon (1991), and Grine (2012), who provided radiographic images. It has also featured in discussions by Lam et al. (1996) and Royer et al. (2009).

KRM 14695 (SAM-AP 6100). This edentulous piece of mandibular symphysis was described briefly and illustrated by Singer and Wymer (1982: 142; plate 59), who noted that the "mental eminence is not markedly developed." The specimen has been discussed also by Lam et al. (1996).

Singer and Wymer (1982) provided a brief description and illustration of the isolated KRM 14696 (SAM-AP 6266) LM $_{1}$, noting that it was found adjacent to the mandibular fragment. They are likely associated.

KRM 16424 (SAM-AP 6225). This is a very small, gracile right mandibular corpus. It was described and illustrated by Singer and Wymer (1982: 142), who noted that "the front part of the corpus is discolored (including the $\mathrm{M}_{1}$ ), possibly charred," although they also observed that there "are no signs of fire shrinkage." This specimen has been discussed and illustrated by Rightmire and Deacon (1991), Lam et al. (1996) and Royer et al. (2009).

KRM 16651 (SAM-AP 6098). This left zygomatic was described and illustrated by Singer and Wymer (1982: 145), who noted that it "is large but within the range of size variation in modern African populations." Rightmire and Deacon (1991: 143) provided a brief description of the specimen, noting that it "is large by modern standards but not noticeably archaic," and that it "seems less robust" than the corresponding element from Florisbad. The size of this element 
was the subject of protracted discussion in the 1990s (Smith, 1992; Frayer et al., 1993; Bräuer and Singer 1996a, 1996b; Wolpoff and Caspari, 1996).

KRM 16720. This fragment of os coxae was afforded an excruciatingly brief description by Singer and Wymer (1982: 146), who simply noted that it "could belong to the pubic portion of the acetabular rim." It was not illustrated by them. Unfortunately, it is missing from the museum collection.

KRM 26076 (SAM-AP 6104). This nearly complete left clavicle was briefly described and illustrated by Singer and Wymer (1982), and mentioned by Rightmire and Deacon (1991). All have commented upon its small size and light construction.

KRM 27038 (SAM-AP 6107). This is a moderately large (68 $\mathrm{mm} \times 53 \mathrm{~mm})$ piece of cranial vault (Figure 7). Singer and Wymer (1982: plates 61 and 62) identified it as a piece of the right parietal. It is of relatively uniform thickness $(8.0-8.8 \mathrm{~mm})$, and preserves a $65.0 \mathrm{~mm}$ segment of a patent and highly digitiform suture. The suture is paralleled endocranially by arachnoid fovea adjacent to it, and a parasagittal ridge that thickens posteriorly along the superior sagittal sinus. These serve to identify the suture as the sagittal. The fragment exhibits slight sagittal-parasagittal flattening; because this is most commonly manifest somewhat anterior to lambda, the piece can be positioned somewhat behind the coronal suture. The orientation of the two meningeal grooves preserved on the endocranial surface indicates that this piece comes from the right side, which is consistent with Singer's (Singer and Wymer, 1982) interpretation. Its anatomical position can be determined with a high degree of confidence (Figure 7). The ectocranial surface exhibits possible evidence of burning.

\section{FIGURE 7 ABOUT HERE}

\section{Print Column Width}

KRM 27574 (SAM-AP 6093). This is a moderately large (ca. $55 \mathrm{~mm}$ x $68 \mathrm{~mm}$ ) piece of cranial vault (Figure 8). Singer and Wymer (1982: plates 61 and 62) suggested that it could belong to a juvenile, although no reason for this was provided. Possibly it relates to the fact that this piece is somewhat thinner than the KRM 27575-6 and KRM 27577 vault fragments from the same cutting and horizon. Its endocranial aspect preserves a prominent groove for the posterior branch of the middle meningeal artery. There is a shallow depression some $15 \mathrm{~mm}$ behind the 
groove and adjacent to the broken inferior margin. The bone is thin $(3.5 \mathrm{~mm})$ in this region, and although much of the ectocranial surface has been eroded, the endocranial surface is intact. This piece is interpreted with high confidence as representing the inferoposterior corner of a right parietal (Figure 8). Discoloration, possibly due to burning, is evident on the ectocranial surface of this piece. Although KRM 27574 probably derives from a point adjacent to KRM 27577, the two pieces do not make contact.

\section{FIGURE 8 ABOUT HERE \\ Print Column Width}

KRM 27575-27576 (SAM-AP 6097-6094). These two moderately large cranial vault fragments (Figure 9) were recognized by Singer and Wymer (1982: plates 63 and 64) as being conjoint. Together, they measure some 87 x $56 \mathrm{~mm}$, and both are thicker than KRM 27574 (KRM 27576 is $10.1 \mathrm{~mm}$ thick at the suture, and KRM 27575 is $8.5 \mathrm{~mm}$ thick near its center), suggesting that they derive from different individuals. KRM 27576 preserves $35.0 \mathrm{~mm}$ of patent suture along the edge opposite its fit with KRM 27575. Endocranial anatomical markers are scarce on both specimens, but KRM 27575 exhibits five or six small depressions that could represent arachnoid fovea. The interpretation of the suture as coronal places these foveae adjacent to the midsagittal line. Although Singer tentatively identified KRM 27575 as a piece of parietal, the conjoined fragments are interpreted here with high confidence as the left frontal with part of the left coronal suture preserved (Figure 9). The absence of discernible meningeal grooves, save for the possibility of one barely perceptible furrow on KRM 27575 , further supports the identification of these pieces as frontal rather than parietal.

\section{FIGURE 9 ABOUT HERE}

\section{Print Column Width}

KRM 27577 (SAM-AP 6095). This is a small (ca. 44 x $22 \mathrm{~mm}$ ) fragment of cranial vault (Figure 10). Although Singer and Wymer (1982: plates 63 - 64) regarded this piece as undiagnostic, one edge preserves a slightly eroded, but obviously patent lambdoid suture. A low ridge of bone on the endocranial aspect adjacent to the suture represents the superior lip of the 
transverse-sigmoid sinus. It is interpreted here with high confidence as representing the inferoposterior corner of a right parietal near asterion (Figure 10). The maximum thickness of this piece is $7.9 \mathrm{~mm}$.

FIGURE 10 ABOUT HERE

Print Column Width

3.4.2 SAS W(Cave 1) remains Two specimens derive from sediments in Cave 1 that have been considered to comprise sub-member W. Both are postcranial bones.

KRM 27889 (SAM-AP 6108). This is the proximal end of a left radius. Singer and Wymer (1982: 146) provided a very cursory description, noting it to be "suggestive of a small, lightly built individual." It was illustrated and described in greater detail by Pearson and Grine (1997), who commented upon its relatively thick cortical bone and comparatively stout neck. Their comparative morphometric analysis revealed similarities to both recent and archaic human homologues, suggesting a mosaic of primitive and derived traits.

SAM-AP 6387. This is an isolated manual distal phalanx. It was recovered by Deacon from the SAS W (i.e., Layer 15) talus deposit, which Rightmire and Deacon (2001: 538) interpreted to mean that it had derived from "a horizon higher in the sequence." This would suggest Layer 14 (= SAS R). Unfortunately, this specimen was neither described nor illustrated by Rightmire and Deacon (2001). Its size suggests that it may derive from the index finger (i.e., ray II) (W. Black, pers. comm.). The side from which it derived cannot be determined, but for illustrative purposes only (see below), it is treated as a right.

\subsubsection{SAS Layer 25 (Cave 1A) remains Only a single specimen has been documented} from Layer 25 in Cave 1A.

KRM 21696. This is a fragment of cranial vault. Singer and Wymer (1982: table 8.1) list this specimen as a "skull? fragment". Unfortunately, it was already missing from the collection at the time it was described by Singer. As a result, we have no information relating to its morphology or state of preservation. 
3.4.4 SAS Layer 34 (Cave 1A) remains Three pieces of cranial vault were recovered by Wymer from Layer 34 in Cave 1A. All were illustrated and afforded very brief descriptions by Singer and Wymer (1982), who suggested that they could be associated with one another. All three are said to derive from a single clay layer.

KRM 26730 (SAM-AP 6110). This is the largest ( $72 \mathrm{~mm}$ x $49 \mathrm{~mm}$ ) of the three fragments (Figure 11). It was considered by Singer and Wymer (1982: 145; plates 63 and 64) to probably represent a right parietal. It preserves several shallow and one reasonably prominent meningeal groove and about $35 \mathrm{~mm}$ of a patent suture (which Singer interpreted as the lambdoid). Adjacent to the suture is a small, faint depression on the endocranial aspect, which probably represents an arachnoid fossa. The position of the fossa, together with the orientations of the meningeal grooves is inconsistent with the identification of this fragment as being from a right parietal. Instead, the endocranial morphology suggests that it is a piece of left parietal that preserves part of the sagittal (rather than lambdoid) suture. A medium confidence interpretation of its anatomical placement is shown in Figure 11. This piece measures $7.1 \mathrm{~mm}$ in thickness at the suture, and has a maximum thickness of $7.5 \mathrm{~mm}$. Most of the ectocranial surface is preserved intact.

\section{FIGURE 11 ABOUT HERE Print Column Width}

KRM 26731 - 26732 (SAM-AP 6111-6112). These are two small pieces (ca. $38 \mathrm{~mm}$ x 35 $\mathrm{mm}$ and $38 \mathrm{~mm}$ x $29 \mathrm{~mm}$, respectively) of cranial vault (Figure 12). They are likely to be parts of the parietal inasmuch as each preserves a portion of a deep meningeal groove on its endocranial aspect. However, because neither has a sutural edge, it is not possible to position them anatomically. The ectocranial surfaces of both are spalled. As noted by Singer and Wymer (1982: 145), they are blackened, probably by fire. They also appear shrunken, possibly due to the effects of burning. It seems reasonable to assume, as did Singer and Wymer (1982), that these two fragments are very likely to be associated with one another.

FIGURE 12 ABOUT HERE

Print Column Width 
3.4.5 SAS U (Cave 1) remains Four individually catalogued specimens were recovered by Wymer in the deposits that constitute SAS U in Cave 1. Another six were found by Deacon in his excavation of the "Witness Baulk" in Cave 1; four of these are represented by isolated teeth, of which two are definitely associated with one another.

KRM 20927 (B) (SAM-AP 6113B). This left hallucial metatarsal was identified among the faunal elements by R.G. Klein. Rightmire and Deacon (1991) provided a brief description and several measurements, observing it to be indistinguishable from modern human homologues. Rightmire et al. (2006) provided a bit more descriptive information for the bone, but curiously also failed to illustrate it. They commented upon its comparatively short length in relation to Late Pleistocene specimens from the Levant, suggesting an individual whose stature fell within the range of modern KhoeSan.

As noted above, this specimen carries the same KRM number as the lumbar vertebra from Layer 14 in Cave 1. As a result, the hallucial metatarsal has been catalogued in the Iziko South African Museum as SAM-AP 6113B. Following this, it is proposed here to refer to the bone as KRM 20927(B).

KRM 15387 (SAM-AP 6296). This is a small (ca. 40 x $35 \mathrm{~mm}$ ) piece of cranial vault preserving a $15.5 \mathrm{~mm}$ long segment of a patent suture (Figure 13). It was neither described nor illustrated by Singer and Wymer (1982), and nor was it listed by them in their table of human fossils. Endocranially, a moderately broad $(4.0 \mathrm{~mm})$ furrow that represents the superior sagittal sinus extends along the length of the suture about $3.0 \mathrm{~mm}$ from its edge. The fragment is $6.0 \mathrm{~mm}$ thick at the suture, and has a maximum thickness of $9.0 \mathrm{~mm}$. It certainly represents a piece of parietal, although the side from which it derives cannot be determined. It can be positioned with medium confidence (Figure 13); it can be placed either slightly anterior or posterior to the position indicated here, but this will not affect its interpretation. The ectocranial aspect is intact, and exhibits a white-gray discoloration, suggestive of burning.

FIGURE 13 ABOUT HERE

Print Column Width 
KRM 15397 (SAM-AP 60269). This small fragment preserves the glenoid region of a right temporal bone. It was discovered among the faunal elements by R.G. Klein, and described and illustrated by Grine et al. (1998). It derives from a comparatively small individual, and Grine et al. (1998) suggested that its proximity to the KRM 16425 frontal together with their comparable state of size and preservation might indicate derivation from a single individual.

KRM 16425 (SAM-AP 6103). This well-known frontal fragment was described and illustrated by Singer and Wymer (1982: plate 59), and by Rightmire and Deacon (1991), all of whom stressed its morphological modernity. White (1987) was the first to observe stone tool cutmarks crossing its squamous surface. The ontogenetic status of this specimen, which some have argued might account for its lack of archaic morphology, has been a matter of some discussion (Singer and Wymer, 1982; Habgood, 1989; Smith, 1992; Ahern and Smith, 2004; Grine, 2012).

SAM-AP 6378. This is the mesial end of a worn right mandibular second deciduous molar. It was recovered by Deacon from the "Witness Baulk" in Cave 1. It has been described and illustrated by Grine (2012).

SAM-AP 6379 - 6380. These isolated left maxillary second and third molars were recovered by Deacon from the "Witness Baulk" in Cave 1. They have been described and illustrated by Rightmire and Deacon (2001). They are probably associated with the SAM-AP $6381 \mathrm{I}^{2}$.

SAM-AP 6381. This is a very heavily worn maxillary lateral incisor. It was recovered by Deacon from the "Witness Baulk" in Cave 1. It has been described and illustrated by Grine (2012). It is probably associated with the SAM-AP 6379 and SAM-AP 6380 maxillary molars.

SAM-AP 6385. This is a nearly complete right fifth metatarsal recovered by Deacon from the "Witness Baulk" in Cave 1. It was described and illustrated by Rightmire et al. (2006). The bone is large, exceeding the fiducial limits for recent South African human groups in all dimensions. The shaft is intact, but the ends are weathered. Rightmire et al. (2006) have suggested that the end might have been gnawed upon.

SAM-AP 6386. This is a complete left second metatarsal recovered by Deacon from the "Witness Baulk" in Cave 1. It was described and illustrated by Rightmire et al. (2006). The bone is gracile but long, exceeding recent human fiducial limits for length. Rightmire et al. (2006: 98) noted that "in several regions, the cortex is blackened, and the specimen gives the appearance of having been burned." 
3.4.6 SAS L (Cave 1) remains There are three fossils from SAS L (i.e., Layer 17) in Cave 1. All were excavated by Wymer. There are two from this sub-member in Cave 1A (i.e., Layer 36); one of the latter was excavated by Wymer, and the other by Deacon.

KRM 21776 (SAM-AP 6101). This is the edentulous symphysis and left corpus of a mandible from Cave 1. It was found in three parts. It was described and illustrated by Singer and Wymer (1982: plate 60). As noted by them (1982: 144-145), the specimen is "blackened, possibly charred," and its "cracked appearance suggests firing." This piece of jaw has featured in discussions of size dimorphism and mental eminence development at the site (Lam et al., 1996; Groves and Thorne, 2000; Royer et al., 2009).

KRM 24006 and KRM 24007. These two cranial vault fragments from Cave 1 were already missing from the collection at the time it was described by Singer and Wymer (1982). Unfortunately, therefore, we have no information relating to their morphology or preservation.

3.4.7 SAS Layer 36 (Cave 1A) remains There are two fossils from this unit of Cave 1A. The large cranial vault fragment was excavated by Wymer, while the proximal ulna was recovered by Deacon from the very top of this layer.

KRM 41658 (SAM-AP 6224). This is the largest cranial vault fragment from the Main Site (Figure 14). It measures ca. $96 \mathrm{~mm}$ x $108 \mathrm{~mm}$. It was described and illustrated by Singer and Wymer (1982: 145; plate 66), who were able to determine its anatomical position with a high degree of certainty owing to a number of anatomical landmarks. It has also been discussed by Rightmire and Deacon (1991:). The endocranial surface is intact, and preserves well-developed meningeal grooves, a short segment of an obliterated coronal suture, the remnant of which takes the form of a line of small pits on the endocranial aspect, and part of the obliterated sagittal suture, which is represented by a small wedge of bone at bregma. As noted by Singer and Wymer (1982), these landmarks allow for an extremely high confidence identification of this fragment as a large piece of right parietal with smaller parts of the left parietal and right frontal (Figure 14). The bone is thick $(9.5 \mathrm{~mm})$ laterally but thins superiorly, where the diploë become less extensive. The superior half of the ectocranial surface is eroded. Singer and Wymer (1982) suggested that this specimen is indicative of an individual with a relatively long and narrow cranial vault, whereas Rightmire and Deacon (1991) argued that while vault shape cannot be 
determined, the specimen shows some evidence of parietal bossing. Any such bossing is less evident to us.

\section{FIGURE 14 ABOUT HERE \\ Print Column Width}

SAM-AP 6384. This is a partial right ulna recovered by Deacon from the bottom of the SAS Member at the base of the deposits of Cave 1A where they intersect with those of Cave 1. These deposits are equivalent to those that directly overlie the shelly SCB 1 horizon in Cave 1/1A (Deacon and Geleijnse, 1988; Deacon and Rightmire, 1991). Because this is described as forming the base of the SAS Member in Cave 1A ( $\approx$ the top of Layer 36) by Deacon and Geleijnse (1988), the ulna may derive from SAS L. The specimen was illustrated and briefly described by Rightmire and Deacon (1991); a much more comprehensive treatment was provided by Churchill et al. (1996). The proximal end exhibits some archaic traits, such as a large olecranon process and a relatively short coronoid process resulting in an anteriorly facing trochlear notch, and it possesses thick cortical bone. The affinities of the ulna have been debated by Groves (1998) and Pearson et al. (1998).

\subsection{LBS Member human remains}

Wymer recovered three cranial vault fragments (KRM 26909, KRM 26910 and KRM 267070) from Layer 37 (= RBS sub-member) at the top of the LBS Member in Cave 1. He also recovered a mandible and condylar fragment (KRM 41815 and KRM 41820) from this same unit (Layer 10) in Cave 1B. Singer and Wymer (1982: 146) considered the KRM 26910 fragment to be the "companion piece" to the KRM 26909 parietal, and they (1982: 147) noted that the KRM 41820 condylar fragment was found "immediately next to [the] KRM 41815 [mandible] and probably belongs to its right ramus." Unfortunately, the condyle, which Singer and Wymer (1982) regarded as being suggestive of a "massive" ramus and which was almost certainly associated with the KRM 41815 jaw, is currently missing from the museum collection, as is the KRM 26910 vault fragment.

Singer and Wymer (1982: table 8.1) noted that " 27 skull fragments some of which are ? human" were found in Layer 38 in Main Cutting A of Cave 1. However, these were "missing 
from the South African Museum collection and not described" at the time of Singer's documentation of the human remains (Singer and Wymer, 1982: table 8.1, footnote 1).They opined that "it is possible that they were identified as being nonhominid and moved." However, one specimen in this series, KRM 24396, was present in the collection when it was studied by us. It is described here.

Deacon's excavations yielded two fragmentary maxillae (SAM-AP 6376 and 6377) from the LBS Member in Cave 1A. According to Deacon and Geleijnse (1988: 8), these specimens "are from separate individuals although they were found in the same basal shell midden horizon only a metre apart."

KRM 26909 (SAM-AP 6105). This piece of parietal was illustrated and afforded very brief description by Singer and Wymer (1982: 146; plate 61). The specimen, as currently preserved (Figure 15), appears to have lost some $5 \mathrm{~mm}$ to $10 \mathrm{~mm}$ of bone along one edge since its description by Singer. It currently measures ca. 45 x $45 \mathrm{~mm}$. The piece is heavily eroded, with a maximum thickness of $10.3 \mathrm{~mm}$. The endocranial surface preserves two meningeal grooves. Following Singer and Wymer (1982), it is considered here to be a piece of parietal, but it is not possible to determine either its side or its exact anatomical position. A low medium confidence interpretation of its anatomical position is depicted in Figure 15. This piece is clearly burnt.

\section{FIGURE 15 ABOUT HERE \\ Print Column Width}

KRM 27070 (SAM-AP 6106). This is a moderately large piece of cranial vault, measuring about $58 \mathrm{~mm} \times 45 \mathrm{~mm}$, with a maximum thickness of $6.6 \mathrm{~mm}$ (Figure 16). It was afforded a very brief description by Singer and Wymer (1982: plate 61), who referred to it as a "nondescript fragment of cranium." One corner preserves a very short $(7.3 \mathrm{~mm})$ segment of a patent suture, and there is a small, shallow depression on the endocranial aspect near the corner of the fragment that is in line with the suture; the depression likely represents an arachnoid fossa. No meningeal grooves are evident on KRM 27070. The suture may be a portion of the sagittal suture, which would identify this as a piece of parietal from either the left or right side. Alternatively, if the depression represents an arachnoid fovea it would also be reasonable to 
identify the specimen as a piece of right frontal preserving a segment of the coronal suture. Two possible anatomical placements for KRM 27070 are shown in Figure 16.

\section{FIGURE 16 ABOUT HERE \\ Print Column Width}

KRM 41815 (SAM-AP 6222). This is a nearly complete, robust mandible with very heavily worn teeth. Singer and Wymer (1982: 146; plate 68) provided a reasonably detailed description and metrical assessment of the jaw. It has also been discussed by Rightmire and Deacon (1991) and others with reference to dimorphism and expression of the chin in the Klasies assemblage (Smith, 1992, 1994; Lam et al., 1996; Royer et al., 2009). As noted above, Singer and Wymer (1982: 147) noted that the presently missing KRM 41820 condylar fragment was found "immediately next to [the] KRM 41815 [mandible] and probably belongs to its right ramus." Singer and Wymer (1982) regarded it as being suggestive of a "massive" ramus.

KRM 24396 (SAM-AP 6297). This is a small (ca. $37 \mathrm{~mm}$ x $27 \mathrm{~mm}$ ) piece of human cranial vault that preserves a short (ca. $19 \mathrm{~mm}$ ) segment of a patent suture, the edge of which has well-developed digitations (Figure 17). A small region of the endocranial surface has flaked away near the sutural edge; otherwise, the fragment is reasonably well-preserved. The piece is $8.8 \mathrm{~mm}$ thick some $5 \mathrm{~mm}$ from the suture (where both tables are intact), and thins to $6.3 \mathrm{~mm}$ at the opposite edge. The endocranial aspect preserves no identifying features. Hence, the suture could represent either the sagittal or the lambdoid, which would position this fragment either as a piece of parietal or supraoccipital. Two possible low medium confidence interpretations of the anatomical placement of this fragment are shown in Figure 17. The ectocranial surface evinces an abundance of natural impressions.

\section{FIGURE 17 ABOUT HERE}

Print Column Width

SAM-AP 6376. This is a piece of edentulous left maxilla. It was afforded very brief description by Rightmire and Deacon (1991: 145), who considered it to be "large by modern standards" and comparable to that of Laetoli Hominid 18 from the ca. 130 ka-old Ngaloba Beds 
in Tanzania (Magori and Day, 1983; Hay, 1987). It was illustrated by Bräuer et al. (1992), who also provided greater descriptive detail, and who presented metrical evidence indicating that its size falls "within or close to the range" (p. 421) for a sample of recent African maxillae. Rightmire and Deacon (1991) observed that the specimen is blackened.

SAM-AP 6377. This is a tiny fragment of the alveolus of a left maxilla containing a worn $\mathbf{M}^{1}$. It has been briefly described by Rightmire and Deacon (1991) and illustrated by Bräuer et al. (1992). Rightmire and Deacon (1991: 145) observed it to be small by comparison to the SAMAP 6376 maxilla, suggesting that this might attest to "a substantial level of sexual dimorphism" in the population.

\section{Skeletal element representation}

The human fossils discussed above are listed by element in Table 3. Singer and Wymer (1982: 147) observed that "in comparison with the faunal fragments, the hominid remains are scanty." The non-hominin large mammal faunal remains from Wymer's excavations were reported by Klein (1976) and those from Deacon's 1984 excavations by van Pletzen (2000). It is difficult to do direct comparisons of element abundance because Klein's (1976) data are presented only as MNIs, but it is possible to comment on the basic distribution across the strata.

Mammalian faunal remains are well-preserved throughout the Klasies River Main site sequence and a diverse array of taxa are represented. These are dominated by bovids though many other species are represented. Hominin remains are rare relative to bovids, but comparable in abundance to the many other non-bovid taxa such as baboon (Papio ursinus), clawless otter (Aonyx capensis), and leopard (Panthera pardus). While the non-hominin faunal remains are well-represented throughout the strata, the hominin remains are not so equally represented, being particularly abundant in SAS R (Layer 14) and SAS U (Layer 16), and possibly the LBS Member (Layer 38) if all of the cranial fragments mentioned by Singer and Wymer (1982) are hominin (Table 3). Layer 16 also has a large sample of non-hominin faunal remains, and Layer 38 has a moderate sample. Relative to the non-hominin faunal sample, the hominin faunal sample is less evenly distributed.

The representation of these skeletal elements (i.e., excluding isolated teeth) reveals a strong bias towards cranial remains, even when the ca. 30 catalogued vault fragments mentioned 
by Singer and Wymer (1982) that are currently missing from the collection are excluded (Table 4). Of the nearly 40 specimens present in the current collection, just over $70 \%$ are cranial, and nearly $70 \%$ of these are vault fragments. In contrast to the face and vault, the basicranium is poorly represented. In contrast to the abundance of cranial pieces, there are relatively few pieces of the postcranial skeleton (Table 4 and Figure 18). This disparity was noted by Singer and Wymer (1982: 117 and 147), who observed that "it can hardly be coincidental."

TABLE 4 ABOUT HERE

Print Landscape Width

FIGURE 18 ABOUT HERE

Print Full Page Width

With reference to the postcrania, only two vertebrae are present, and one of these is an atlas, which is adjacent to the skull. Excluding the three metatarsals, there are only three long bones represented in the sample - a left clavicle from SAS R in Cave 1, a left proximal radius from SAS W in Cave 1, and a right proximal ulna from SAS L in Cave 1A. Remarkably, the humeral, femoral and tibial diaphyses are entirely lacking from this assemblage. Singer and Wymer (1982: 117) considered the lack of femora to be "particularly remarkable." These are the most durable elements from the viewpoint of cortical bone thickness and density. Although several studies have suggested that bone density may not necessarily be directly related to archaeological preservation (e.g., Lam and Pearson, 2004, 2005; Conard et al., 2008), there is a considerable body of evidence to support the notion that larger, thicker diaphyses should differentially survive attrition (e.g., Waldron., 1987; Galloway et al., 1997; Willey et al., 1997; Lam et al., 1999, 2003; Stojanowski et al., 2002; Pickering et al., 2003; Symmons, 2004; Lyman, 2013). Interestingly, the pedal and manual elements are represented by relatively complete metatarsals and phalanges, while the wrist and ankle elements are entirely lacking.

However, it should be noted that, to a certain extent, the proportional over-representation of human cranial elements is somewhat reminiscent of the pattern of skeletal part representation displayed by the Klasies Main Site MSA large bovid remains. This pattern, described some 40 years ago by Richard Klein (1976) on the basis of his analysis of the archaeofauna from the 
Wymer excavations, finds the large-bodied bovids such as the greater kudu (Tragelaphus strepsiceros), wildebeest (Connochaetes gnou and C. taurinus), eland (Taurotragus oryx), Cape buffalo (Syncerus caffer), and hippopotamus (Hippopotamus amphibious) are generally represented by skull parts (mainly teeth and jaws) and distal extremities (carpals, tarsals, metapodials and phalanges), while the long bones (humerus, radius, ulna, femur and tibia) are very poorly represented. This has been referred to as the "Klasies Pattern" by Bartram and Marean (1999). Klein (1989; Klein et al., 1999) and Outram (2001, 2004) have argued that it reflects the likelihood that particular carcass parts of these large species will be transported from a kill/scavenge site to a base camp and that these parts will survive in an identifiable condition owing principally to their being fragmented in the procurement of marrow. Turner (1989) and Bartram and Marean (1999), on the other hand, have argued that the pattern reflects instead collection bias. Essentially, they argue that the large bones are fragmented in the process of marrow procurement and the epiphyseal portions are destroyed by scavengers or other processes, and that the diaphyseal fragments are systematically discarded in the field inasmuch as they are regarded as non-identifiable.

van Pletzen (2000) examined the bovid material recovered from Deacon's 1984 excavation (bovid bones account for over $70 \%$ of the faunal sample from this excavation). Deacon's excavation procedures differed from those employed by Wymer, with fine mesh screens ( 2 and $3 \mathrm{~mm}$ ) used for sieving and the retention of all osseous material. She observed that "most of the faunal sample consists of bone fragments and fragmentation is very high," with fragments ranging in size from $<5 \mathrm{~mm}$ to $>100 \mathrm{~mm}$ (van Pletzen, 2000: 42). However, a simple count of limb bone fragments of large and large-medium-sized bovids led van Pletzen (2000: tables 11 and 12) to document essentially the same "head and foot" pattern as described by Klein (1976, 1989; Klein et al, 1999) for the fauna from Wymer's excavations, although she tabulated a greater abundance of vertebral elements. van Pletzen's (2000) study did not entail a detailed analysis or attempted refitting of limb bone shaft fragments to construct identifiable pieces (e.g. Marean and Kim, 1998), and it was completed prior to the publication of methods that permit the calculation of minimum numbers of elements from those shafts (e.g., Marean et al., 2000, 2001).

Thus, the high percentage of long bone fragmentation recorded in Deacon's faunal sample combined with the effects of the excavation and sorting techniques employed by Wymer have almost certainly served to bias the distribution of human skeletal elements. It is possible, 
therefore, that the preservation of human remains at Klasies is at least partially a function of recovery and identification techniques.

In addition to the distribution pattern noted above, the vast majority of the human fossils from Klasies are representative of adult individuals. This contrasts with penecontemporaneous and geographically proximate MSA coastal sites such as Die Kelders Cave 1, Blombos and Klipdrift Shelter, where the human remains are predominantly or wholly representative of juveniles, usually in the form of (possibly exfoliated) deciduous teeth (Grine et al., 1991; Grine 1998, 2000; Grine et al., 2000; Grine and Henshilwood, 2002; Harvati et al., 2015). Only three individuals at Klasies are represented by undoubted juvenile remains, and each of these is an isolated deciduous tooth - SAM-AP 6374 and SAM-AP 6373 from the Upper Member deposits in Cave 1A, and SAM-AP 6378 from the SAS U deposit in Cave 1. All of the other dental remains, including those in maxillae and mandibles, are consistent with derivation from fully adult individuals, and many suggest advanced adulthood to judge from the degree of occlusal wear. The postcranial bones are similarly indicative of adult individuals insofar as they preserve fused epiphyses.

In this regard, the ontogenetic status of the KRM 16425 frontal fragment has been the subject of some discussion. Singer and Wymer (1982: 142) describe it as possessing an "almost obliterated" frontonasal suture. A survey of 100 known-age individuals in the Terry Collection (National Museum of Natural History) indicates that fusion of this suture is rare, occurring in only some $20 \%$ of individuals over 70 years of age (D. Ubelaker, pers. comm.). On the other hand, Frayer et al. (1993) have argued that this fragment derives from a juvenile because it has a weakly developed brow ridge. They have argued that it represents a juvenile archaic hominin inasmuch as its "innerorbital area is markedly broad and distinctly nonmodern" (1993: 35-36). However, it is questionable whether a weakly developed brow should be considered evidence of immaturity even if the Klasies hominins are viewed as being archaic.

Ahern and Smith (2004) have argued erroneously that the notable lateral thinning of the KRM 16425 supraorbital is similar to that of juvenile Neandertals such as Le Moustier 1, Vindija 224 and Vindija 279. The latter simply do not evince the thinning that is manifest on KRM 16425. Moreover, studies of archaic hominin (i.e., Neanderthal) craniofacial growth have shown that their characteristic features (e.g., browridges) arise early in ontogeny (Ponce de León and Zollikofer, 2001; Krovitz, 2003; Bastir et al., 2007). In this regard, the apparently small size of 
the frontal sinus (Ahern and Smith, 2004) of KRM 16425 would seem to be inconsistent with the view that this specimen is a juvenile of a form with an archaic frontal morphology such as Florisbad. We interpret the gracile, modern-like brow of KRM 16425 as being representative of an adult with modern morphology rather than an ontogenetically young, morphologically archaic individual who had yet to develop the brow and frontal sinus by the time of its death. The interorbital breadth and size of the frontal sinus in KRM 16425 require further analysis, but even if it should be demonstrated that this fragment derives from a juvenile, it would not dramatically alter the age profile of the Klasies hominin assemblage. Adults are curiously common at Klasies River Main Site in comparison to other MSA hominin-bearing sites along the southern coast of South Africa.

In the context of excavation techniques noted above, the use of fine mesh sieving screens ( 2 and $3 \mathrm{~mm}$ ) and the retention of all material by Deacon may account for the relative abundance of isolated teeth in his sample. Indeed, seven of the 12 individual hominin specimens recovered by Deacon are isolated teeth and, of these, three are deciduous. If one considers only the 12 specimens that comprise the Deacon sample from Klasies, the percentage of juvenile remains is $25 \%$. If the excavation, sieving and recovery methods employed by Deacon at Klasies are comparable to those used at Klipdrift, Blombos and Die Kelders, this might serve to explain the closer correspondence of proportional juvenile representation (as manifest by isolated deciduous teeth) in the Deacon/Klasies and other MSA coastal samples. However, even considering the Deacon sample alone, there is still a seemingly higher representation of adult human fossils in the MSA layers at Klasies Main Site.

\section{Conclusions}

The paleoanthropological significance of the Klasies River Main Site derives from its abundant Middle Stone Age (MSA) archaeological debris and human fossils that have featured prominently in discussions over modern human emergence. Despite the significance that these fossils have assumed in the interpretation of human evolution, they have yet to be contextualized within the spatial and strato-chronological framework of the site. We here provide an overview of the human fossil record from Klasies Main Site, placing it in stratigraphic and spatial context. We also provide the first morphological interpretation and anatomical placement of many of the 
numerous cranial vault fragments that comprise the current collection. Five specimens derive from the Upper Member; one of these is associated with the Howiesons Poort. The vast majority of the fossils - some 39 individually catalogued specimens - come from the SAS Member in Caves 1, 1A and 1B; many derive from a single stratigraphic horizon (SAS-R) and are clustered in a relatively small area in Cave 1. Four specimens are known from the top of the LBS Member in Cave 1 and 1B, and Deacon's excavations yielded two fragmentary pieces from the LBS Member in Cave 1A.

The representation of these skeletal elements (i.e., excluding isolated teeth) reveals a strong bias towards cranial remains. Of the specimens present in the current collection, just over $70 \%$ are cranial, and nearly $70 \%$ of these are vault fragments. In contrast, there are relatively few pieces of the postcranial skeleton. Excluding the three metatarsals, there are only three long bones represented in the sample - a left clavicle, a left proximal radius, and a right proximal ulna from different levels of the SAS Member in Cave 1 and 1A. Remarkably, humeral, femoral and tibial diaphyses, which are the most durable elements from the standpoint of cortical bone thickness and density, are absent. The pedal and manual elements are represented by relatively complete metatarsals and phalanges, while wrist and ankle elements are lacking. It is possible, however, that the preservation of human remains at Klasies is at least partially a function of recovery and identification techniques given the excavation and sorting techniques employed by Wymer, and the high percentage of long bone fragmentation in the MSA deposits recorded in Deacon's faunal sample.

In addition, the vast bulk of the human fossils from Klasies Main Site are representative of adult individuals. This is in contrast with penecontemporaneous and geographically proximate sites such as Die Kelders Cave 1, Blombos and Klipdrift Shelter, where the human remains are predominantly or wholly representative of juveniles, usually in the form of (possibly exfoliated) deciduous teeth. Only three individuals at Klasies are represented by undoubted juvenile remains, and each of these is an isolated deciduous tooth. All of the other dental remains are consistent with derivation from fully adult individuals, and many suggest advanced adulthood to judge from the degree of occlusal wear. The postcranial bones are similarly indicative of adult individuals insofar as they preserve fused epiphyses.

While it would appear that differences in excavation, sieving and recovery techniques might account for some of the difference in proportional juvenile at Klasies Main Site, adults are 
curiously common here in comparison to other MSA hominin-bearing sites along the southern coast of South Africa.

\section{Acknowledgements}

Research support to F.E. Grine was provided by the Leakey Foundation and the College of Arts and Sciences, Stony Brook University. S. Wurz's work is based on research supported by the National Research Foundation of South Africa; any opinion, finding, conclusion or recommendation expressed in this article is that of the authors and the NRF does not accept any liability in this regard. Research support to C.W. Marean was provided by National Science Foundation grants BCS-9912465 and BCS-0130713. We thank Graham Avery and Wendy Black, Curator of Precolonial Archaeology, Iziko South African Museum, for access to the specimens and for information pertaining to the human fossil catalogues. We thank the Editor, the Associate Editor, and two anonymous reviewers for their careful reading of the manuscript and their helpful comments and suggestions. The illustrations were masterfully executed by Ms. Luci Betti-Nash.

\section{References}

Ahern, J.C.M., Smith, F.H., 2004. Adolescent archaic or adult moderns? Le Moustier 1 as a model for estimating age at death of fragmentary supraorbital fossils in the modern human origins debate. Homo 55, 1-19.

Aitken, M.J., Stokes, S., 1997. Climatostratigraphy. In: Taylor, R.E., Aitken, M.J. (Eds), Chronometric Dating in Archaeology. Plenum, New York, pp. 1-30.

Bada, J.L., Deems, L., 1975. Accuracy of dates beyond the 14-C dating limit using the aspartic acid racemization reaction. Nature 255, 218-219.

Bar-Matthews, M., Marean, C.W., Jacobs, Z., Karkanas, P., Fisher, E.C., Herries, A.I.R., Brown, K., Williams, H.M., Bernatchez, J., Ayalon, A., Nilssen, P.J., 2010. A high resolution and continuous isotopic speleothem record of paleoclimate and paleoenvironment from 90 to 53 ka from Pinnacle Point on the south coast of South Africa. Quaternary. Sci. Rev. 29, 2131-2145.

Bartram, L.E., Marean, C.W., 1999. Explaining the "Klasies pattern": Kua ethnoarchaeology, the 
Die Kelders Middle Stone Age archaeofauna, long bone fragmentation and carnivore ravaging. J. Archaeol. Sci. 26, 9-29.

Bassinot, F. C., Labeyrie, L.D., Vincent, E., Quidelleur, X., Shackleton, N.J., Lancelot, Y., 1994. The astronomical theory of climate and the age of the Brunhes-Matuyama magnetic reversal. Earth Planet. Sci. Lett. 126, 91-108.

Bastir, M., O’Higgins, P., Rosas, A., 2007. Facial ontogeny in Neanderthals and modern humans. P. R. Soc. B 274, 1125-1132.

Bräuer, G., Singer, R., 1996a. The Klasies zygomatic bone: archaic or modern? J. Hum. Evol. 30, 161-165.

Bräuer, G., Singer, R., 1996b. Not outside the modern range. J. Hum. Evol. 30, 173-174.

Bräuer, G., Deacon, H.J., Zipfel, F., 1992. Comment on the new maxillary finds from Klasies River, South Africa. J. Hum. Evol. 23, 419-422.

Brooks A.S., Hare P.E., Kokis J.E., 1993. Age of anatomically modern human fossils from the cave of Klasies River Mouth, South Africa. Carnegie Inst. Wash. Yearb. 92, 95-96.

Carr, A.S., Chase, B.M., Mackay, A., 2016. Mid to Late Quaternary landscape and environmental dynamics in the Middle Stone Age of southern South Africa. In: Jones, S.C., Stewart, B.A. (Eds.), Africa from MIS 6-2: Population Dynamics and Paleoenvironments. Vertebrate Paleobiology and Paleoanthropology. Springer, Dordrecht, pp. 23-47.

Churchill, S.E., Pearson, O.M., Grine, F.E., Trinkaus, E., Holliday, T.W., 1996. Morphological affinities of the proximal ulna from Klasies River Main Site: archaic or modern? J. Hum. Evol. 31, 213-237.

Conard, N.J., Walker, S.J., Kandel, A.W., 2008. How heating and cooling and wetting and drying can destroy dense faunal elements and lead to differential preservation. Palaeogeogr. Palaeoclimatol. Palaeoecol. 266, 236-245.

Deacon, H.J., 1989. Late Pleistocene palaeoecology and archaeology in the southern Cape, South Africa. In: Mellars, P., Stringer, C.B. (Eds), The Human Revolution. Edinburgh University Press, Edinburgh, pp. 547-564.

Deacon, H.J., 1992. Southern Africa and modern human origins. Phil. Trans. R. Soc. London B $337,177-183$. 
Deacon, H.J., 1993. Southern Africa and modern human origins. In: Aitken, M.J., Stringer, C.B., Mellars, P.A. (Eds), The Origin of Modern Humans and the Impact of Chronometric Dating. Princeton University Press, Princeton, pp. 104-117.

Deacon, H.J., 1995. Two Late Pleistocene-Holocene archaeological depositories from the southern Cape, South Africa. S. Afr. Archaeol. Bull. 50, 121-131.

Deacon, H.J., 2001a. Modern human emergence: an African archaeological perspective. In: Tobias, P.V., Raath, M.A., Moggi-Cecchi, J., Doyle, G.A. (Eds), Humanity from African Naissance to Coming Millennia - Colloquia in Human Biology and Palaeoanthropology. Florence University Press, Florence, pp. 217-226.

Deacon, H.J., 2001b. Guide to Klasies River 2001. http://academic.sun.ac.za/archaeology/ krguide2001.pdf, pp. 1-12.

Deacon, H.J., 2008. The context of the 1967-8 sample of human remains from Cave 1 Klasies River Main Site. S. Afr. Archaeol. Soc. Goodwin Ser. 10, 143-149.

Deacon, H.J., Geleijnse, V.B., 1988. The stratigraphy and sedimentology of the Main Site sequence, Klasies River, South Africa. S. Afr. Archaeol. Bull. 43, 5-14.

Deacon, H.J., Wurz, S., 2001. Middle Pleistocene populations and the emergence of modern behaviour. In: Barham, L., Robson Brown, K. (Eds), Human Roots: Africa and Asia in the Middle Pleistocene. Western Academic \& Specialist Press, Bristol, pp. 55-63.

Deacon, H.J., Wurz, S., 2005. A Late Pleistocene archive of life at the coast, Klasies River. In: Brower Stahl, A. (Ed.), African Archaeology: A Critical Introduction. Blackwell Publishing, Oxford, pp. 130-149.

Deacon, H.J., Talma, A.S., Vogel, J.C., 1988. Biological and cultural development of Pleistocene people in an Old World southern continent. In: Prescott, J.R. (Ed.), Early Man in the Southern Hemisphere. Department of Physics and Mathematical Physics, University of Adelaide, Adelaide, pp. S23-S31.

d'Errico, F., Moreno, R.G., Rifkin, R.F., 2012. Technological, elemental and colorimetric analysis of an engraved ochre fragment from the Middle Stone Age levels of Klasies River Cave 1, South Africa. J. Archaeol. Sci. 39, 942-952.

Dusseldorp, G.L., 2010. Prey choice during the South African Middle Stone Age: avoiding dangerous prey or maximizing returns? Afr. Archaeol. Rev. 27, 107-133. 
Eggins, S.M., Grün, R., McCulloch, M.T., Pike, A.W.G., Chappell, J., Kinsley, L., Mortimer, G., Shelley, M., Murray-Wallace, C.V., Spötl, C., Taylor, L., 2005. In situ U-series dating by laser-ablation multi-collector ICPMS: new prospects for Quaternary geochronology. Quaternary Sci. Rev. 24, 2523-2538.

Feathers, J.K., 2002. Luminescence dating in less than ideal conditions: case studies from Klasies River Main Site and Duinefontein, South Africa. J. Archaeol. Sci. 29, 177-194.

Frayer, D.W., Wolpoff, M.H., Thorne, A.G., Smith, F.H., Pope, G.G., 1993. Theories of modern human origins: the paleontological test. Am. Anthropol. 95, 14-50.

Galbraith, R.F., 2015. On the mis-use of mathematics: a comment on "How confident are we about the chronology of the transition between Howieson's Poort and Still Bay?” by Guérin et al. (2013). J. Hum. Evol. 80, 184-186.

Galloway, A., Willey, P., Snyder, L. 1997. Human bone mineral densities and survival of bone elements: a contemporary sample. In: Haglund, W.D., Sorg, M.H. (Eds), Forensic Taphonomy: the Postmortem Fate of Human Remains. CRC Press, Boca Raton, pp. 295317.

Goede, A., Hitchman, M.A., 1987. Electron spin resonance analysis of marine gastropods from coastal archaeological sites in southern Africa. Archaeometry 29, 163-174.

Grine, F.E., 1998. Additional human fossils from the Middle Stone Age of Die Kelders Cave 1, South Africa: 1995 excavations. S. Afr. J. Sci. 94, 229-235.

Grine, F.E., 2000. Middle Stone Age human fossils from Die Kelders Cave 1, Western Cape Province, South Africa. J. Hum. Evol. 38, 129-145.

Grine, F.E., 2012. Observations on Middle Stone Age human teeth from Klasies River Main Site, South Africa. J. Hum. Evol. 63, 750-758.

Grine, F.E., 2016. The Late Quaternary hominins of Africa: the skeletal evidence from MIS 6-2. In: Jones, S.C., Stewart, B.A. (Eds), Africa from MIS 6-2: Population Dynamics and Paleoenvironments. Springer, Dordrecht, pp. 323-381.

Grine, F.E., Henshilwood, C.S., 2002. Additional human remains from Blombos Cave, South Africa: (1999-2000 excavations). J. Hum. Evol. 42, 293-302.

Grine, F.E., Klein, R.G., Volman, T.P., 1991. Dating, archaeology and human fossils from the Middle Stone Age Layers of Die Kelders Cave 1, South Africa. J. Hum. Evol. 21, 363395. 
Grine, F.E., Pearson, O.M., Klein, R.G., Rightmire, G.P., 1998. Additional human fossils from Klasies River Mouth, South Africa. J. Hum. Evol. 35, 95-107.

Grine, F.E., Henshilwood, C.S., Sealy, J.C., 2000. Human remains from Blombos Cave, South Africa: (1997-1998 excavations). J. Hum. Evol. 38, 755-765.

Groves, C.P., 1998. The proximal ulna from Klasies River. J. Hum. Evol. 34, 119-121.

Groves, C., Thorne, A., 2000. The affinities of the Klasies River Mouth remains. In: Chisholm, J. (Ed.), Perspectives in Human Biology, Vol. 5. Center for Human Biology, University of Western Australia, pp 43-53.

Grün, R., Shackleton, N.J., Deacon, H.J., 1990. Electron-spin-resonance dating of tooth enamel from Klasies River Mouth. Curr. Anthropol. 31, 427-432.

Guérin, G., Murray, A.S., Jain, M., Thomsen, K.J., Mercier, N., 2013. How confident are we in the chronology of the transition between Howieson's Poort and Still Bay? J. Hum. Evol. 64, 314-317.

Habgood, P.J., 1989. The examination of regional features on middle and early Late Pleistocene sub-Saharan African hominids. S. Afr. Archaeol. Bull. 44, 17-22.

Harvati, K., Bauer, C.C., Grine, F.E., Benazzi, S., Ackermann, R.R., van Niekerk, K.L., Henshilwood, C.S., 2015. A human deciduous molar from the Middle Stone Age (Howiesons Poort) of Klipdrift Shelter, South Africa. J. Hum. Evol. 82, 190-196.

Hay, R.L., 1987. Geology of the Laetoli area. In: Leakey, M.D., Harris, J.M. (Eds.), Laetoli: A Pliocene Site in Northern Tanzania. Oxford University Press, Oxford, pp. 23-47.

Hearty, P.J., Hollin, J.T., Neumann, A.C., O’Leary, M.J., McCulloch, M., 2007. Global sealevel fluctuations during the last interglaciation (MIS 5e). Quaternary Sci. Rev. 26, 20902112.

Imbrie, J., Hays, J.D., Martinson, D.G., McIntyre, A., Mix, A.C., Morley, J.J., Pisias, N.G., Prell, W.L., Shackleton, N.J., 1984. The orbital theory of Pleistocene climate: support from a revised chronology of the marine $\delta^{18} \mathrm{O}$ record. In: Berger, A. (Ed.), Milankovitch and Climate, Part 1. D. Reidel, Hingham, MA, pp. 269-305.

Jacobs, Z., Roberts, R.G., 2015. An improved single grain OSL chronology for the sedimentary deposits from Diepkloof Rockshelter, Western Cape, South Africa. J. Archaeol. Sci. 63, 175-192. 
Jacobs, Z., Roberts, R.G., Galbraith, R.F., Deacon, H.J., Grün, R., Mackay, A., Mitchell, P., Vogelsang, R., Wadley, L., 2008. Ages for the Middle Stone Age of southern Africa: implications for human behavior and dispersal. Science 322, 733-735.

Klein, R.G., 1976. The mammalian fauna of the Klasies River Mouth sites, Cape Province, South Africa. S. Afr. Archaeol. Bull. 31, 75-98.

Klein, R.G., 1989. Why does skeletal part representation differ between smaller and larger bovids at Klasies River Mouth and other archaeological sites? J. Archaeol. Sci. 6, 363-381.

Klein, R.G., Cruz-Uribe, K., 1996. Exploitation of large bovids and seals and Middle and Later Stone Age sites in South Africa. J. Hum. Evol. 31, 315-334.

Klein, R.G., Cruz-Uribe, K., Milo, R.G., 1999. Skeletal part representation in archaeofaunas: comments on “Explaining the 'Klasies Pattern': Kua ethnoarchaeology, the Die Kelders Middle Stone Age archaeofauna, long bone fragmentation and carnivore ravaging” by Bartram \& Marean. J. Archaeol. Sci. 26, 1225-1234.

Krovitz, G., 2003. Shape and growth differences between Neandertals and modern humans: grounds for a species level distinction? In: Thompson, J.L., Krovitz, G.E., Nelson, A.J. (Eds), Patterns of Growth and Development in the Genus Homo. Cambridge University Press, Cambridge, pp. 320-342.

Lam, Y.M., Pearson, O.M., 2004. The fallibility of bone density values and their use in archaeological analyses. J. Taphonomy 2, 99-115.

Lam, Y.M., Pearson, O.M., 2005. Bone density studies and the interpretation of the faunal record. Evol. Anthropol. 14, 99-108.

Lam, Y.M., Pearson, O.M., Smith, C.M., 1996. Chin morphology and sexual dimorphism in the fossil hominid mandible sample from Klasies River Mouth. Am. J. Phys. Anthropol. 100, 545-557.

Lam, Y.M., Chen, X., Pearson, O.M., 1999. Intertaxonomic variability in patterns of bone density and the differential representation of bovid, cervid, and equid elements in the archaeological record. Am. Antiq. 64, 343-362.

Lam, Y.M., Pearson, O.M., Marean, C.W., Chen, X., 2003. Bone density studies in zooarchaeology. J. Archaeol. Sci. 30, 1701-1708. 
Lisiecki, L.E., Raymo, M.E., 2005. A Plio-Pleistocene stack of 57 globally distributed benthic $\delta^{18}$ O records. Paleoceanography 20, PA1003, doi:10.1029/2004PA001071.

Lyman, R.L., 2013. Bone density and bone attrition. In: Pokines, J.T., Symes, S.A. (Eds), Manual of Forensic Taphonomy. CRC Press/ Taylor \& Francis, New York, pp. 51-72.

Magori, C.C., Day, M.H., 1983. Laetoli Hominid 18: an early Homo sapiens skull. J. Hum. Evol. $12,747-754$.

Marean, C.W., Abe, Y., Nilssen, P., Stone, E., 2001. Estimating the minimum number of skeletal elements (MNE) in zooarchaeology: a review and a new image-analysis GIS approach. Am. Antiq. 66, 333-348.

Marean, C.W., Abe, Y., Frey, C.J., Randall, R., 2000. Zooarchaeological and taphonomic analysis of the Die Kelders Cave 1 Layers 10 and 11 Middle Stone Age larger mammal fauna. J. Hum. Evol. 38, 197-233.

Marean, C.W., Kim, S.Y., 1998. Mousterian faunal remains from Kobeh Cave (Zagros Mountains, Iran): behavioral implications for Neanderthals and early modern humans. Curr. Anthropol. 39, S79-S114.

Martinson, D.G., Pisias, N.G., Hays, J.D., Imbrie, J., Moore, T.C., Shackleton, N.J., 1987. Age dating and the orbital theory of the ice ages: development of a high resolution 0 to 300,000-year chronostratigraphy. Quaternary Res. 27, 1-29.

McCall, G.S., 2006. Multivariate perspectives on change and continuity in the Middle Stone Age lithics from Klasies River Mouth, South Africa. J. Hum. Evol. 51, 429-439.

Millard, A.R., 2008. A critique of the chronometric evidence for hominid fossils. I. Africa and the Near East 500-50 ka. J. Hum. Evol. 54, 848-874.

Milo, R.G., 1998. Evidence for hominid predation at Klasies River Mouth, South Africa, and its implications for the behaviour of early modern humans. J. Archaeol. Sci. 25, 99-133.

Nami, H.G., De la Peña, P., Vásquez, C.A., Feathers, J., Wurz, S., 2016. Palaeomagnetic results and new dates of sedimentary deposits from Klasies River Cave 1, South Africa. S. Afr. J. Sci. 112 (11/12), Art. \#2016-0051, 12 pages. http://dx.doi.org/10.17159/sajs.2016/20160051

Outram, A.K., 2001. The scapula representation could be the key: a further contribution to the 'Klasies Pattern' debate. J. Archaeol. Sci. 28, 1259-1263.

Outram, A.K., 2004. Applied models and indices vs. high-resolution, observed data: detailed 
fracture and fragmentation analyses for the investigation of skeletal part abundance patterns. J. Taphonomy 2, 167-184.

Pearson, O.M., Churchill, S.E., Grine, F.E., Trinkaus, E., Holliday, T.W., 1998. Multivariate analyses of the hominid ulna from Klasies River Mouth. J. Hum. Evol. 34, 653-656.

Pearson, O.M., Grine, F.E., 1997. Re-analysis of the hominid radii from Cave of Hearths and Klasies River Mouth, South Africa. J. Hum. Evol. 32, 577-592.

Ponce de León, M., Zollikofer, C., 2001. Neandertal cranial ontogeny and its implications for late hominid diversity. Nature 412, 534-538

Rightmire, G.P., Deacon, H.J., 1991. Comparative studies of Late Pleistocene human remains from Klasies River Mouth, South Africa. J. Hum. Evol. 20, 131-156.

Rightmire, G.P., Deacon, H.J., 2001. New human teeth from the Middle Stone Age deposits at Klasies River, South Africa. J. Hum. Evol. 41, 535-544.

Rightmire, G.P., Deacon, H.J., Schwartz, J.H., Tattersall, I., 2006. Human foot bones from Klasies River Main Site, South Africa. J. Hum. Evol. 50, 96-103.

Royer, D.F., Lockwood, C.A., Scott, J.E., Grine, F.E., 2009. Size variation in early human mandibles and molars from Klasies River, South Africa: comparison with other Middle and Late Pleistocene assemblages and with modern humans. Am. J. Phys. Anthropol. 140, 312-323.

Scott, L., 2016. Fluctuations of vegetation and climate over the last 75000 years in the Savanna Biome, South Africa: Tswaing Crater and Wonderkrater pollen sequences reviewed. Quaternary Sci. Rev. 145, 117-133.

Shackleton, N.J., 1982. Stratigraphy and chronology of the Klasies River Mouth deposits: oxygen isotope evidence. In: Singer, R., Wymer, J. (Eds.), The Middle Stone Age at Klasies River Mouth in South Africa. University of Chicago Press, Chicago, pp. 194-199.

Singer, R., Wymer, J.J., 1982. The Middle Stone Age at Klasies River Mouth in South Africa. University of Chicago Press, Chicago.

Stojanowski, C.M., Seidman, R.M., Doran, G.H., 2002. Differential skeletal preservation at Windover Pond: causes and consequences. Am. J. Phys. Anthropol. 119, 15-26.

Stringer, C.B., Bräuer, G., 1994. Methods, misreading, and bias. Am. Anthropol. 96, 416-424.

Smith, F.H., 1992. Models and realities in modern human origins: the African fossil evidence. Phil. Trans. R. Soc. B 337, 243-250. 
Symmons, R., 2004. Digital photodensitometry: a reliable and accessible method for measuring bone density. J. Archaeol. Sci. 31, 711-719.

Thackeray, A.I., 1989. Changing fashions in the Middle Stone Age: the stone artefact sequence from Klasies River Main Site, South Africa. Afr. Archaeol. Rev., 7, 33-57.

Tribolo, C., 2003. Apport des méthods de la luminescence à la chronologie de techno-faciès du Middle Stone Age associés aux premiers Hommes Modernes du sud de l'Afrique. Ph.D. Dissertation, Université Bordeaux I.

Tribolo, C., Mercier, N., Valladas, H., 2005a. Chronology of the Howieson's Poort and Still Bay techno-complexes: assessment and new data from luminescence. In: d'Errico, F., Backwell, L. (Eds.), From Tools to Symbols. From Early Hominids to Modern Humans. Wits University Press, Johannesburg, pp. 493-511.

Tribolo, C., Mercier, N.,Valladas, H., 2005b. Chronologie des technofaciès Howieson's Poort et Still Bay (Middle Stone Age, Afrique du Sud): bilan et nouvelles données de la luminescence. Bull. Soc. Préhist. Fr. 102, 855-866.

Tribolo, C., Mercier, N., Douville, E., Joron, J.L., Reyss, J.L., Rufer, D., Cantin, N., Lefrais, Y., Miller, C.E., Porraz, G., Parkington, J., Rigaud, J.P., Texier, P.J., 2013. OSL and TL dating of the Middle Stone Age sequence at Diepkloof Rock Shelter (South Africa): a clarification. J. Archaeol. Sci. 40, 3401-3411.

Turner, A., 1989. Sample selection, schlepp effects and scavenging: the implications of partial recovery for interpretations of the terrestrial mammal assemblage from Klasies River Mouth. J. Archaeol. Sci. 16, 1-11.

van Pletzen, L, 2000. The large mammal fauna from Klasies River. M.A. Thesis, University of Stellenbosch.

Vogel, J.C., 2001. Radiometric dates for the Middle Stone Age in South Africa. In: Tobias, P.V., Raath, M.A., Moggi-Cecchi, J., Doyle, G.A. (Eds.), Humanity from African Naissance to Coming Millennia - Colloquia in Human Biology and Palaeoanthropology. Firenze University Press, Firenze, pp. 261-268.

Volman, T.P., 1984. Early prehistory of southern Africa. In: Klein, R.G. (Ed.), Southern African Prehistory and Palaeoenvironments. Balkema, Rotterdam, pp. 169-220.

Waldron, T. 1987. The relative survival of the human skeleton: implications for paleopathology. In: Boddington, A., Garland, A.N., Janaway, R.C. (Eds), Death, Decay and 
Reconstruction. Manchester University Press, Manchester, pp. 55-64.

White, T.D., 1987. Cannibals at Klasies? Sagittarius 2, 7-9.

Willey, P., Galloway, A., Snyder, L., 1997. Bone mineral density and survival of elements and element portions in the bones of the Crow Creek massacre victims. Am. J. Phys. Anthropol. 104, 513-528.

Wolpoff, M.H., Caspari, R., 1996. The modernity mess. J. Hum. Evol. 30, 167-172.

Wright, J.D., 2000. Global climate change in marine stable isotope records. In: Noller, J.S., Sowers, J.M., Lettis, W.R. (Eds), Quaternary Geology: Methods and Applications American Geophysical Union, Washington, D.C., pp. 427-433.

Wurz, S., 1999. The Howiesons Poort backed artefacts from Klasies River: an argument for symbolic behavior. S. Afr. Archaeol. Bull. 54, 38-50.

Wurz, S., 2000. The Middle Stone Age at Klasies River. Ph.D. Dissertation, University of Stellenbosch.

Wurz, S, 2002. Variability in the Middle Stone Age lithic sequence, 115,000 - 60,000 years ago at Klasies River, South Africa. J. Archaeol. Sci. 29, 1001-1015.

Wurz, S., 2008. Modern behavior at Klasies River. S. Afr. Archaeol. Soc. Goodwin Ser. 10, $150-156$.

Wurz, S., 2012. The significance of MIS 5 shell middens on the Cape coast: a lithic perspective from Klasies River and Ysterfontein 1. Quaternary Int. 270, 61-69.

Wurz, S., le Roux, N.J., Gardner, S., Deacon, H.J., 2003. Discriminating between the end products of the earlier Middle Stone Age sub-stages at Klasies River using biplot methodology. J. Archaeol. Sci. 30, 1107-1126.

\section{Figure Legends}

Figure 1. Location of the Klasies Main Site. Inset = Google Map satellite image of southern Africa; top = Google Map satellite image showing the location of the site (red balloon); bottom = contour map of the Eastern Cape coast east of the Klasies River Mouth to Druipkelder Point; stippling = beach sand (modified from Deacon and Geleijnse, 1988: fig. 1). 
Figure 2. Photograph of the Klasies Main Site indicating the numbered caves and recesses. The individual in the red shirt atop the ladder in Cave 2 is Hilary Deacon. Photograph taken from the beach by FEG.

Figure 3. Excavation grid of the main site showing the areas excavated by Wymer (red) and Deacon (blue). The northern and southern extents of Wymer's "Witness Baulk" were excavated by Deacon. Adapted from Deacon and Geleijnse (1988: fig. 4), Deacon (2001: fig. 4), and Deacon (2008: fig. 2).

Figure 4. Schematic of stratigraphic relationships in the Main Site repositories. Adapted from Deacon and Geleijnse (1988: fig. 5), Deacon (2001: fig. 5), Rightmire and Deacon (1991: fig. 2) and Wurz (2002: fig. 2). Numbers in parentheses are the Layer numbers of Singer and Wymer (1982). The letter designations to the left of the stratigraphic columns are the Members, and those to the right of the stratigraphic columns are the sub-members of Deacon and Geleijnse (1988).

Figure 5. Ectocranial aspects of the KRM 40243 (left) and KRM 40244 (right) vault fragments. Scale bar $=1 \mathrm{~cm}$.

Figure 6. Schematic drawing of fossil distribution in the SAS and LBS Member deposits of Cave 1. The placement of the KRM 16720 os coxae fragment from SAS R is not shown; it presumably comes from close to KRM 13400 and KRM 16651 at the very front of the cave. The positions of KRM 16651 and KRM 2757427577 were not illustrated by Singer and Wymer (1982), but were provided by Deacon (2008: figure 6). Adapted from Singer and Wymer (1982: figs 3.20 3.24) and Deacon (2008; fig. 6).

Color codes: SAS R (Layer 14) = red

SAS W (Layer 15) = brown

SAS U (Layer 16) = dark blue

SAS L (Layer 17) = light blue

LBS RBS (Layer 37) = green. 
Figure 7. The KRM 27038 parietal fragment. Drawing of the ectocranial aspect and illustration of its anatomic position (high confidence placement). Scale bar in cms.

Figure 8. The KRM 27574 parietal fragment. Drawing of the ectocranial aspect and illustration of its anatomic position (high confidence placement). Scale bar in cms.

Figure 9. The KRM 27575 and 27576 frontal fragments. Drawing of the ectocranial aspect and illustration of their anatomic position (high confidence placement). Scale bar in cms.

Figure 10. The KRM 27577 parietal fragment. Drawing of the ectocranial aspect and illustration of its anatomic position (high confidence placement). Scale bar in cms.

Figure 11. The KRM 26730 parietal fragment. Drawing of the ectocranial aspect and illustration of its anatomic position (medium confidence placement). Scale bar in cms.

Figure 12. Ectocranial aspects of the KRM 26731 and KRM 26732 parietal fragments. Scale bar $=1 \mathrm{~cm}$.

Figure 13. The KRM 15387 parietal fragment. Drawing of the ectocranial aspect and illustration of two possible anatomic positions (medium confidence placements). Scale bar in cms.

Figure 14. The KRM 41658 vault fragment. Drawing of the ectocranial aspect and illustrations of its anatomic position (high confidence placement). Scale bar in cms. 
Figure 15. The KRM 26909 parietal fragment. Drawing of the ectocranial aspect and illustration of its anatomic position (low medium confidence placement). Scale bar in cms.

Figure 16. The KRM 27070 vault fragment. Drawing of the ectocranial aspect and illustration of two possible anatomic positions as either a fragment of frontal or a fragment of parietal (low medium confidence placements). Scale bar in cms.

Figure 17. The KRM 24396 vault fragment. Drawing of the ectocranial aspect and illustration of two possible anatomic positions (low medium confidence placements). Scale bar in cms.

Figure 18. Skeletal element representation in the Middle Stone Age human sample from Klasies River Main Site. The KRM 16720 os coxae fragment, described by Singer (Singer and Wymer, 1982) as a fragment of the pubic acetabular region, is indicated even though it is currently missing from the collection. 
Table 1. Klasies Main Site stratigraphic correlations and archaeological associations.

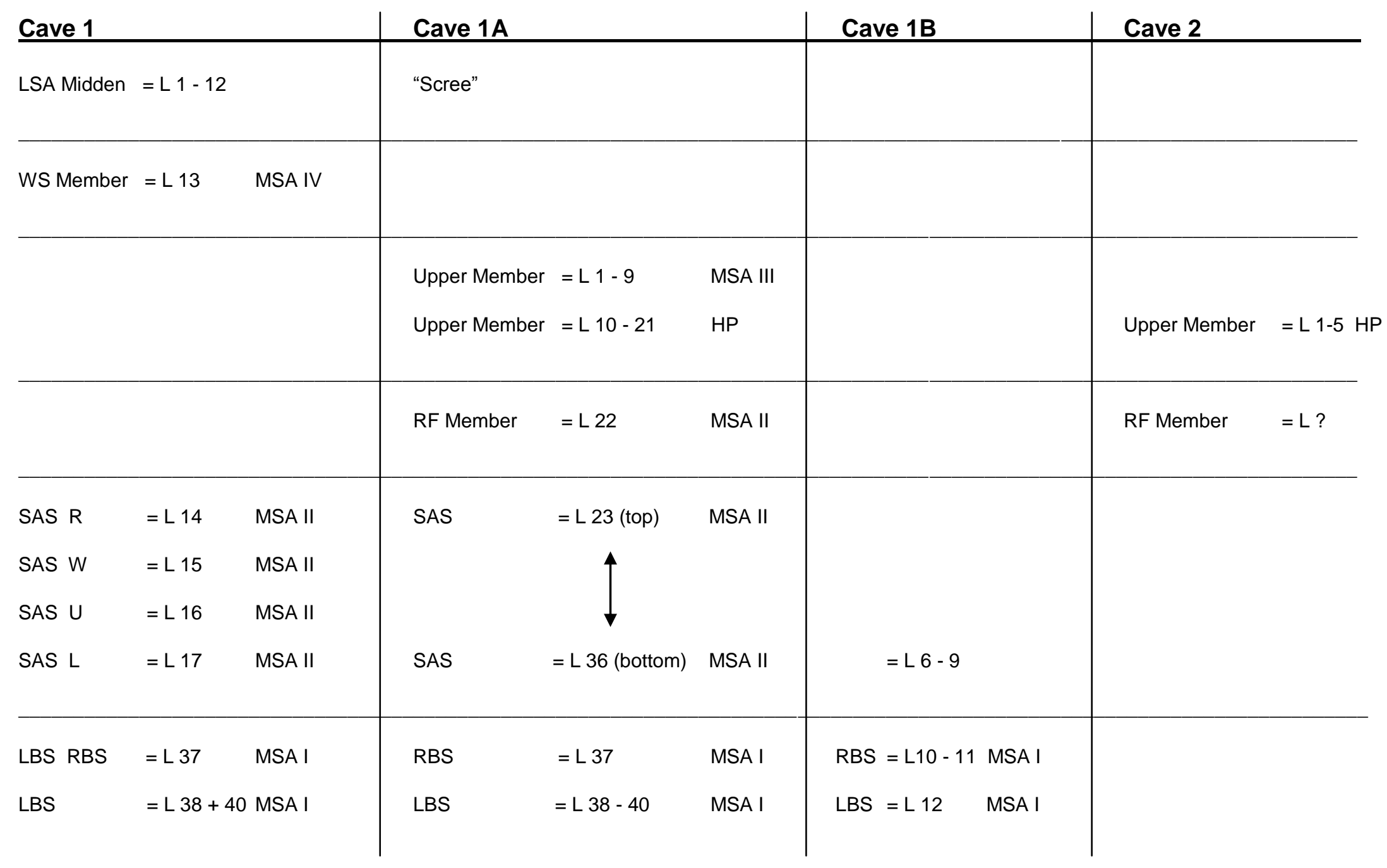

( $L 40$ is clean beach gravel) 
Table 2. Ages determined for Klasies River Main Site.

\begin{tabular}{|c|c|c|c|c|c|c|}
\hline Cave & Member Sub-mb. & \multicolumn{2}{|c|}{ Layer Lithics } & Date (ka) & Method & Reference \\
\hline 1 & WS & 13 & MSA IV & 65 & AAR & Bada and Deems (1975) \\
\hline 1 & WS & 13 & MSA IV & $70.7 \pm$ & TL-OSL & Feathers (2002) \\
\hline 1 & WS & 13 & MSA IV & $66.5 \pm 4.8$ & SG-OSL & Nami et al. (2016) \\
\hline 1 & WS & 13 & MSA IV & $56.3 \pm 4.6$ & SG-OSL & Nami et al. (2016) \\
\hline 1 & WS & 13 & MSA IV & ? ca. 61 & Paleomag & Nami et al. (2016) \\
\hline $1 \mathrm{~A}$ & Upper & & & MIS $5 b-3$ & $\delta^{18} \mathrm{O}$ shell & Shackleton (1982) \\
\hline $1 \mathrm{~A}$ & Upper & & & MIS 5a - 4 & $\delta^{18} \mathrm{O}$ shell & Deacon et al. (1988) \\
\hline $1 \mathrm{~A}$ & Upper & 6 & post-HP MSA III & $>45.2$ & ${ }^{14} \mathrm{C}$ charcoal & Vogel (2001) \\
\hline $1 \mathrm{~A}$ & Upper & & post-HP MSA III & $50.8 \pm 6.6$ & LU ESR * & Grün et al. (1990) \\
\hline $1 \mathrm{~A}$ & Upper & & post-HP MSA III & $<52$ & LU ESR * & Millard (2008) \\
\hline $1 \mathrm{~A}$ & Upper & 9 & post-HP MSA III & $43.4 \pm 3.0$ & OSL & Feathers (2002) \\
\hline $1 \mathrm{~A}$ & Upper & 9 & post-HP MSA III & $60.0 \pm 5.0$ & $\mathrm{TL}$ & Tribolo (2003) \\
\hline $1 \mathrm{~A}$ & Upper & & post-HP MSA III & $57.9 \pm 2.3$ & SG OSL & Jacobs et al. (2008) \\
\hline $1 \mathrm{~A}$ & Upper & 9 & post-HP MSA III & $57.0 \pm 4.0$ & $\mathrm{TL} * * *$ & Tribolo et al. (2013) \\
\hline & Upper & & HP & $>80$ & AAR & Brooks et al. (1993) \\
\hline $1 \mathrm{~A}$ & Upper & 14 & HP & $65.6 \pm 5.3$ & U-series & Vogel (2001) \\
\hline & Upper & & HP & $45.6 \pm 6.7$ & LU ESR * & Grün et al. (1990) \\
\hline & Upper & & HP & $53-64$ & U-series + ESR & Eggins et al. (2005) \\
\hline & Upper & & HP & $60-47$ & LU ESR * & Millard (2008) \\
\hline & Upper & & HP & $56.3 \pm 6.5$ & $\mathrm{TL}$ & Tribolo et al. (2005a) \\
\hline & Upper & & HP & $53.3 \pm 3.0$ & $\mathrm{TL} * * *$ & Tribolo et al. (2013) \\
\hline $1 \mathrm{~A}$ & Upper & 15 & HP & $46.7 \pm 3.3$ & OSL & Feathers (2002) \\
\hline 2 & Upper & $1 / 2$ & HP & $52.4 \pm 4.0$ & OSL & Feathers (2002) \\
\hline & Upper & & HP & $64.3 \pm 2.5$ & SG OSL & Jacobs et al. (2008) \\
\hline $1 \mathrm{~A}$ & Upper & 17 & HP & $>50$ & ${ }^{14} \mathrm{C}$ charcoal & Vogel (2001) \\
\hline $1 \mathrm{~A}$ & Upper & 18 & $\mathrm{HP}$ & $>40$ & ${ }^{14} \mathrm{C}$ charcoal & Vogel (2001) \\
\hline
\end{tabular}


Table 2 continued. Ages determined for Klasies River Main Site.

\begin{tabular}{|c|c|c|c|c|c|c|c|}
\hline Cave & Member & Sub-mb. & Layer & Lithics & Date (ka) & Method & Reference \\
\hline $1 \mathrm{~A}$ & $\mathrm{RF}$ & & 22 & MSA II & $28.1 \pm 2.2$ & U-Th shell $* *$ & Vogel (2001) \\
\hline $1 \mathrm{~A}$ & RF & & 22 & MSA II & $77.4 \pm 7.0$ & U-series & Feathers (2002) \\
\hline $1 \mathrm{~A}$ & $\mathrm{RF}$ & & 22 & MSA II & $80.6 \pm 17.6$ & OSL/IRSL & Feathers (2002) \\
\hline $1 \mathrm{~A}$ & $\mathrm{RF}$ & & 22 & MSA II & $71-53$ & OSL & Millard (2008) \\
\hline $1 \mathrm{~A}$ & $\mathrm{RF}$ & & 22 & MSA II & $71.9 \pm 3.2$ & SG OSL & Jacobs et al. (2008) \\
\hline & $\mathrm{RF}$ & & & MSA II & MIS 5a & $\delta^{18} \mathrm{O}$ shell & Deacon et al. (1988) \\
\hline $1 \mathrm{~A}$ & SAS & & 27 & MSA II & $66.4 \pm 6.1$ & LU ESR * & Grün et al. (1990) \\
\hline $1 \mathrm{~A}$ & SAS & & 30 & MSA II & $77.4 \pm 7.0$ & U-Th & Vogel (2001) \\
\hline 1 & SAS & $\mathrm{R}$ & 14 & MSA II & $85.2 \pm 2.1$ & U-Th & Vogel (2001) \\
\hline 1 & SAS & $\mathrm{R}$ & 14 & MSA II & $94.6 \pm 3.2$ & U-Th & Vogel (2001) \\
\hline 1 & SAS & $\mathrm{R}$ & 14 & MSA II & $100.8 \pm 7.5$ & U-Th & Vogel, 2001 \\
\hline 1 & SAS & $\mathrm{W}$ & 15 & MSA II & $36.6 \pm 3.2$ & U-Th shell $* *$ & Vogel (2001) \\
\hline 1 & SAS & $\mathrm{W}$ & 15 & MSA II & $70.9 \pm 5.1$ & TL-OSL & Feathers (2002) \\
\hline 1 & SAS & $\mathrm{W}$ & 15 & MSA II & MIS $5 \mathrm{c}$ or $5 \mathrm{a}$ & $\delta^{18} \mathrm{O}$ shell & Shackleton (1982) \\
\hline 1 & SAS & & & MSA II & MIS 5c & $\delta^{18} \mathrm{O}$ shell & Deacon et al. (1988) \\
\hline 1 & SAS & $\mathrm{U}$ & 16 & MSA II & 89 & AAR & Bada and Deems (1975) \\
\hline 1 & SAS & $\mathrm{U}$ & 16 & MSA II & $68.4 \pm 6.5$ & OSL/TL & Feathers (2002) \\
\hline 1 & SAS & $\mathrm{L}$ & 17 & MSA II & $88.3-93.5$ & LU ESR $*$ & Grün et al. (1990) \\
\hline 1 & SAS & $\mathrm{L}$ & 17 & MSA II & $101 \pm 12$ & U-series + ESR & Eggins et al. (2005) \\
\hline 1 & SAS & $\mathrm{L}$ & 17 & MSA II & $104-64$ & LU ESR $*$ & Millard (2008) \\
\hline
\end{tabular}


Table 2 continued. Ages determined for Klasies River Main Site.

\begin{tabular}{|c|c|c|c|c|c|c|}
\hline Cave & Member & Sub-mb. & Layer Lithics & Date (ka) & Method & Reference \\
\hline 1 & LBS & RBS & MSA I & 90 & AAR & Bada and Deems (1975) \\
\hline 1 & LBS & & MSA I & 110 & AAR & Bada and Deems (1975) \\
\hline 1 & LBS & & MSA I & MIS 5e & $\delta^{18} \mathrm{O}$ shell & Shackleton (1982) \\
\hline 1B & LBS & & MSA I & MIS 5e & $\delta^{18} \mathrm{O}$ shell & Shackleton (1982) \\
\hline 1 & LBS & & MSA I & $108.6 \pm 3.4$ & U-Th & Vogel (2001) \\
\hline 1 & LBS & & MSA I & $>110$ & U-series & Deacon et al. (1988) \\
\hline 1 & LBS & & MSA I & MIS $5 e-5 d$ & $\delta^{18} \mathrm{O}$ shell & Deacon et al. (1988) \\
\hline $1 \mathrm{~A}$ & LBS & & MSA I & $106.8 \pm 12.6$ & TL-OSL & Feathers (2002) \\
\hline $1 \mathrm{~A}$ & LBS & & MSA I & $>101$ & LU ESR * & Millard (2008) \\
\hline
\end{tabular}

$\mathrm{AAR}=$ amino acid racemization; $\mathrm{TL}=$ thermoluminescence; $\mathrm{OSL}=$ optically stimulated luminescence; $\mathrm{LU}$ ESR $=$ linear uptake model electron spin resonance; SG OSL = single grain optically stimulated luminescence; U-Th = uranium - thorium.

* Only the linear uptake (LU) model estimates are reported here, as these were preferred by the authors. The early uptake (EU) model estimates are substantially younger in all instances.

** These dates were discounted by Vogel (2001) because shell tends to absorb uranium from percolating water long after its deposition, which may result in an age that is substantially too young.

*** This age is based on a re-assessment of the dose rate for the burnt stone that was dated by Tribolo et al. (2005a). 
Table 3. MSA Human Remains from Klasies River Main Site.

Cave Mb. Sub-mb. Layer Excavation

Specimen Number

Specimen Description

Reference

Provenience Excavation \# SAM-AP \#

\begin{tabular}{|llllllll|}
\hline 1A & Upper & 6 & $?$ & KRM 40243* & ---- & parietal frag. \\
1A & Upper & 6 & $?$ & KRM 40244* & ---- & 1 \\
parietal frag. & 1 \\
1A & Upper & $?$ & square E50 & E50/AV & 6375 & $\mathrm{RP}_{4}$ & 2,3 \\
1A & Upper & $?$ & square E50 & E50/TSAS & 6374 & Ldi $^{1}$ & 3 \\
1A & Upper & $?$ & square H51 & H51/CP1 & 6373 & Rdm $^{1}$ frag. & 3
\end{tabular}

\begin{tabular}{|c|c|c|c|c|c|c|c|c|}
\hline 1 & SAS & $\mathrm{R}$ & 14 & $?$ & KRM 20927(A) & $6113 \mathrm{~A}$ & lumbar vertebra (cf. L2) & 2 \\
\hline 1 & SAS & $\mathrm{R}$ & 14 & Main Cutting A & --------------- & 6268 & atlas vertebra (partial) & 4 \\
\hline 1 & SAS & $\mathrm{R}$ & 14 & West Cutting F & KRM 13400 & 6223 & right mandibular corpus with $\mathrm{P}_{4}-\mathrm{M}_{2}$ & 1,2 \\
\hline 1 & SAS & $\mathrm{R}$ & 14 & West Cutting F & KRM 14691 & 6228 & left mandibular frag. with $\mathrm{M}_{1}$ & 1,2 \\
\hline 1 & SAS & $\mathrm{R}$ & 14 & West Cutting F & KRM 14692 & 6227 & $\mathrm{LP}_{4}$ & $1,2,3$ \\
\hline 1 & SAS & $\mathrm{R}$ & 14 & West Cutting F & KRM 14693 & 6229 & $\mathrm{LM}_{2}$ & 1,2 \\
\hline 1 & SAS & $\mathrm{R}$ & 14 & West Cutting F & KRM 14694 & 6230 & $\mathrm{LM}_{3}$ & 1.2 \\
\hline 1 & SAS & $\mathrm{R}$ & 14 & West Cutting F & KRM 14695 & 6100 & anterior mandible frag. & 1,2 \\
\hline 1 & SAS & $\mathrm{R}$ & 14 & West Cutting F & KRM 14696 & 6266 & $\mathrm{LM}_{1}$ & 1,2 \\
\hline 1 & SAS & $\mathrm{R}$ & $14 / 16$ & West Cutting F & KRM 16424 & 6225 & right mandibular corpus & 1,2 \\
\hline 1 & SAS & $\mathrm{R}$ & 14 & West Cutting F & KRM 16651 & 6098 & left zygomatic & $1,2,5$ \\
\hline 1 & SAS & $\mathrm{R}$ & 14 & West Cutting F & KRM $16720 *$ & ----- & os coxae frag. & 1 \\
\hline 1 & SAS & $\mathrm{R}$ & 14 & West Cutting $\mathrm{H}$ & KRM 26076 & 6104 & left clavicle & 1 \\
\hline 1 & SAS & $\mathrm{R}$ & $14 / 15$ & West Cutting H & KRM 27038 & 6107 & right parietal frag. & 1 \\
\hline 1 & SAS & $\mathrm{R}$ & 14 & West Cutting K-L & KRM 27574 & 6093 & right parietal frag. & 1 \\
\hline 1 & SAS & $\mathrm{R}$ & 14 & West Cutting K-L & KRM 27575 & 6097 & left frontal frag. & 1 \\
\hline 1 & SAS & $\mathrm{R}$ & 14 & West Cutting K-L & KRM 27576 & 6094 & left frontal frag. & 1 \\
\hline 1 & SAS & $\mathrm{R}$ & 14 & West Cutting K-L & KRM 27577 & 6095 & right parietal frag. & 1 \\
\hline
\end{tabular}


Table 3 continued (page 2).

\begin{tabular}{|c|c|c|c|c|c|c|c|c|}
\hline \multirow[t]{2}{*}{ Cave } & \multirow[t]{2}{*}{ Mb. } & \multirow[t]{2}{*}{ Sub-mb. } & \multirow[t]{2}{*}{ Layer } & \multirow{2}{*}{$\begin{array}{l}\text { Excavation } \\
\text { Provenience } \\
\end{array}$} & \multicolumn{2}{|c|}{ Specimen Number } & \multirow[t]{2}{*}{ Specimen Description } & \multirow[t]{2}{*}{ Reference } \\
\hline & & & & & Excavation \# & SAM-AP \# & & \\
\hline 1 & SAS & $\mathrm{W}$ & 15 & Main Cutting A & KRM 27889 & 6108 & left proximal radius & 1,6 \\
\hline & SAS & $\mathrm{W}$ & 15 & Witness Baulk & --------------- & 6387 & manual distal phalanx & 7 \\
\hline $1 \mathrm{~A}$ & SAS & & 25 & Initial Cutting & KRM $21696^{*}$ & ------ & ? skull frag. & 1 \\
\hline $1 \mathrm{~A}$ & SAS & & 34 & Initial Cutting & KRM 26730 & 6110 & left parietal frag. & 1 \\
\hline $1 \mathrm{~A}$ & SAS & & 34 & Initial Cutting & KRM 26731 & 6111 & parietal frag. & 1 \\
\hline $1 \mathrm{~A}$ & SAS & & 34 & Initial Cutting & KRM 26732 & 6112 & parietal frag. & 1 \\
\hline 1 & SAS & $\mathrm{U} ?$ & 16 & $?$ & KRM 20927(B) & 6113B & left metatarsal I & 2,10 \\
\hline 1 & SAS & $\mathrm{U}$ & 16 & Main Cutting A & KRM 15387 & 6296 & parietal frag. & \\
\hline 1 & SAS & $\mathrm{U}$ & 16 & Main Cutting A & KRM 15397 & 6269 & right temporal frag. & 4 \\
\hline 1 & SAS & $\mathrm{U}$ & 16 & Main Cutting A & KRM 16425 & 6103 & frontal frag. & 1,2 \\
\hline 1 & SAS & $\mathrm{U}$ & 16 & Witness Baulk & $01 / \mathrm{C} 1 / \mathrm{SMB}$ & 6378 & $\mathrm{Rdm}_{2}$ frag. & 3 \\
\hline 1 & SAS & $\mathrm{U}$ & 16 & Witness Baulk & $\mathrm{A} 1 / 4 / \mathrm{SMB}$ & 6379 & $\mathrm{LM}^{3}$ (same ind. as AP 6380) & 7 \\
\hline 1 & SAS & $\mathrm{U}$ & 16 & Witness Baulk & $\mathrm{A} 2 / 3 / \mathrm{SMB}$ & 6380 & $\mathrm{LM}^{2}$ (same ind. as AP 6379) & 7 \\
\hline 1 & SAS & $\mathrm{U}$ & 16 & Witness Baulk & $\mathrm{A} 2 / 1 / \mathrm{SMB}$ & 6381 & $\mathrm{I}^{2}$ & 3 \\
\hline 1 & SAS & $\mathrm{U}$ & 16 & Witness Baulk & $\mathrm{B} 1 / 3 / \mathrm{SMB}$ & 6385 & right metatarsal V & 10 \\
\hline 1 & SAS & $\mathrm{U}$ & 16 & Witness Baulk & $\mathrm{A} 2 / 2 / \mathrm{SMB} 2$ & 6386 & left metatarsal II & 10 \\
\hline 1 & SAS & $\mathrm{L}$ & 17 & Main Cutting A & KRM 21776 & 6101 & left mandibular corpus edentulous & 1,2 \\
\hline 1 & SAS & $\mathrm{L}$ & 17 & Main Cutting A & KRM 24006* & ------ & ? skull frag. & 1 \\
\hline 1 & SAS & $\mathrm{L}$ & 17 & Main Cutting A & KRM 24007* & ------ & ? skull frag. & 1 \\
\hline $1 \mathrm{~A}$ & SAS & $\mathrm{L}$ & 36 & East Cutting T & KRM 41658 & 6224 & right fronto-parietal frag. & 1,2 \\
\hline $1 \mathrm{~A}$ & SAS & $\mathrm{L}$ & +36 & $?$ & --------------- & 6384 & right proximal ulna & 2,8 \\
\hline
\end{tabular}


Table 3 continued (page 3 ).

\begin{tabular}{llllllll} 
Cave & Mb. & Sub- Mb. Layer & Excavation & \multicolumn{2}{c}{$\begin{array}{c}\text { Specimen Number } \\
\text { Provenience }\end{array}$} & Excavation \# & Specimen Description \\
\hline & & & & & & \\
\hline 1 & LBS & RBS & 37 & Main Cutting A & KRM 26909 & 6105 & ? parietal frag. \\
1 & LBS & RBS & 37 & Main Cutting A & KRM 26910* & ------ & ? parietal frag. assoc. with 26909 \\
\hline 1 & LBS & RBS & 37 & West Cutting H & KRM 27070 & 6106 & parietal frag. \\
\hline
\end{tabular}

\begin{tabular}{|llllllll|}
\hline 1B & LBS & RBS & 10 & $?$ & KRM 41815 & 6222 & $\begin{array}{l}\text { mandible with } \mathrm{LM}_{1}-\mathrm{M}_{2} ; \mathrm{RP}_{4}-\mathrm{M}_{1} \\
\text { condyle probably belongs to } 41815\end{array}$ \\
1B & LBS & RBS & 10 & $?$ & KRM 41820* & ----- & 1,2 \\
1
\end{tabular}

Table 3 Legend:

* = currently missing from the Iziko South African Museum collection. Specimens that are grouped in boxes are regarded as deriving from a single individual on anatomical grounds.

Reference numbers: (1) Singer and Wymer, 1982; (2) Rightmire and Deacon, 1991; (3) Grine, 2012; (4) Grine et al., 1998; (5) Bräuer and Singer, 1995; (6) Pearson and Grine, 1997; (7) Rightmire and Deacon, 2001; (8) Churchill et al., 1996; (9) Bräuer et al., 1992;

(10) Rightmire et al., 2006. 
Table 4. Summary of Skeletal Element Distribution by Stratigraphic Unit in the Klasies Main Site

\begin{tabular}{|c|c|c|c|c|c|c|c|c|c|c|}
\hline \multirow{2}{*}{$\begin{array}{l}\text { Member } \\
\text { sub-member/layer* }\end{array}$} & \multirow[t]{2}{*}{ Upper } & \multicolumn{7}{|c|}{ 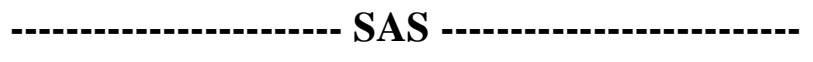 } & \multicolumn{2}{|c|}{----- LBS ---- } \\
\hline & & $\mathbf{R}$ & $\mathbf{W}$ & 25 & 34 & $\mathbf{U}$ & $\mathbf{L}$ & 36 & RBS & 38 \\
\hline \multicolumn{11}{|l|}{ Skull } \\
\hline Vault & 2 & 4 & & 1 & 4 & 3 & 2 & 1 & 2 & $1+$ \\
\hline Upper face ${ }^{* *}$ & & 1 & & & & & & & & 2 \\
\hline Mandible & & 3 & & & & & 1 & & 1 & \\
\hline \multicolumn{11}{|l|}{ Postcranium } \\
\hline vertebra & & 2 & & & & & & & & \\
\hline clavicle & & 1 & & & & & & & & \\
\hline ulna & & & & & & & & 1 & & \\
\hline radius & & & 1 & & & & & & & \\
\hline os coxae $* * *$ & & 1 & & & & & & & & \\
\hline metatarsal & & & & & & 3 & & & & \\
\hline phalanx & & & 1 & & & & & & & \\
\hline
\end{tabular}

This table excludes isolated teeth. * Letters designate Deacon's sub-member categories; numbers designate Wymer's layers. ** Upper face is equivalent here to maxilla and zygomatic. *** The KRM 16720 os coxae fragment from Layer 14 (SAS R) of Cave 1 is included here even though it is currently missing from the collection. + Excluding the numerous (ca. 26) skull fragments listed by Singer and Wymer (1982: table 8.1) as "some? human" that are currently missing from the collection. 


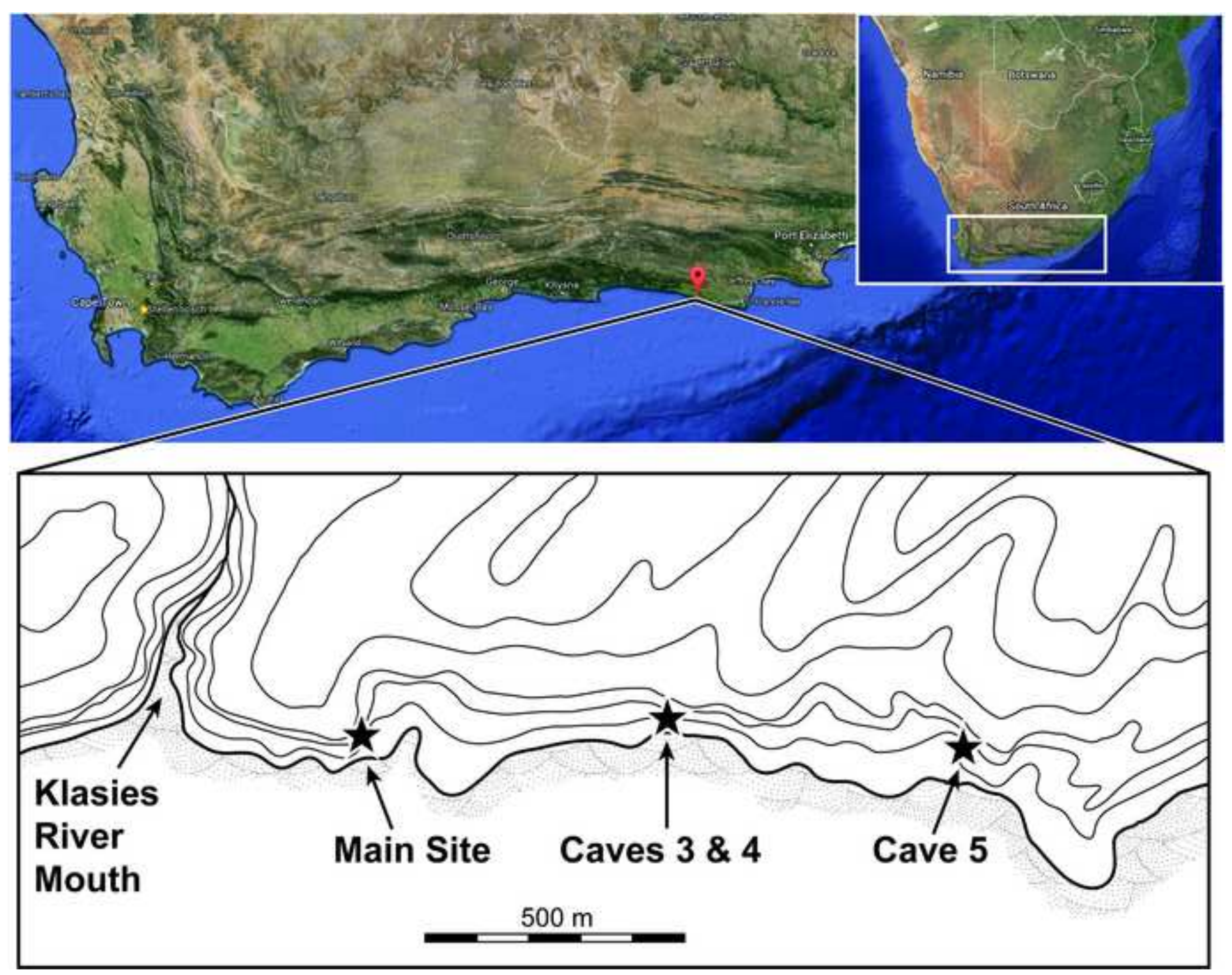




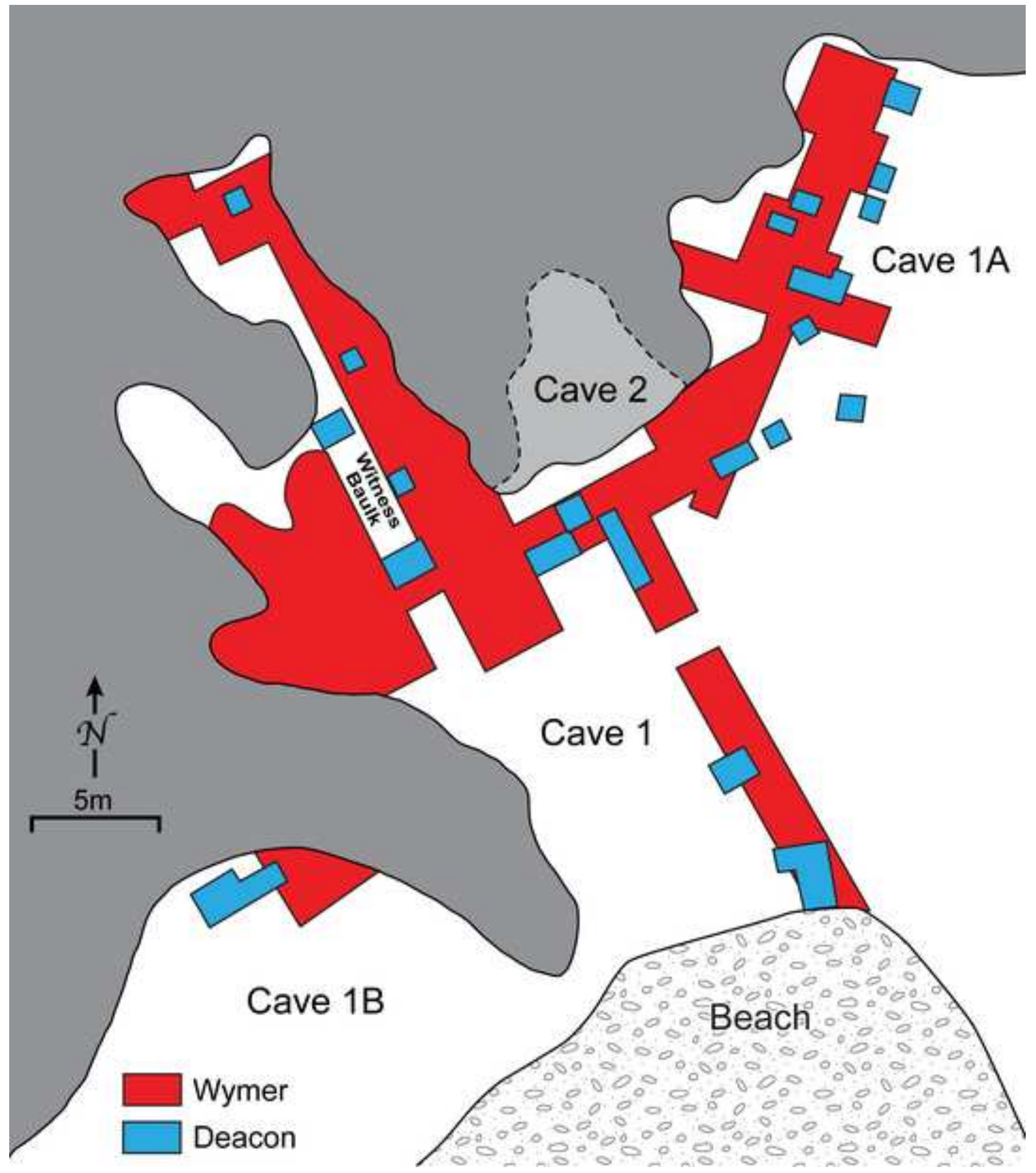




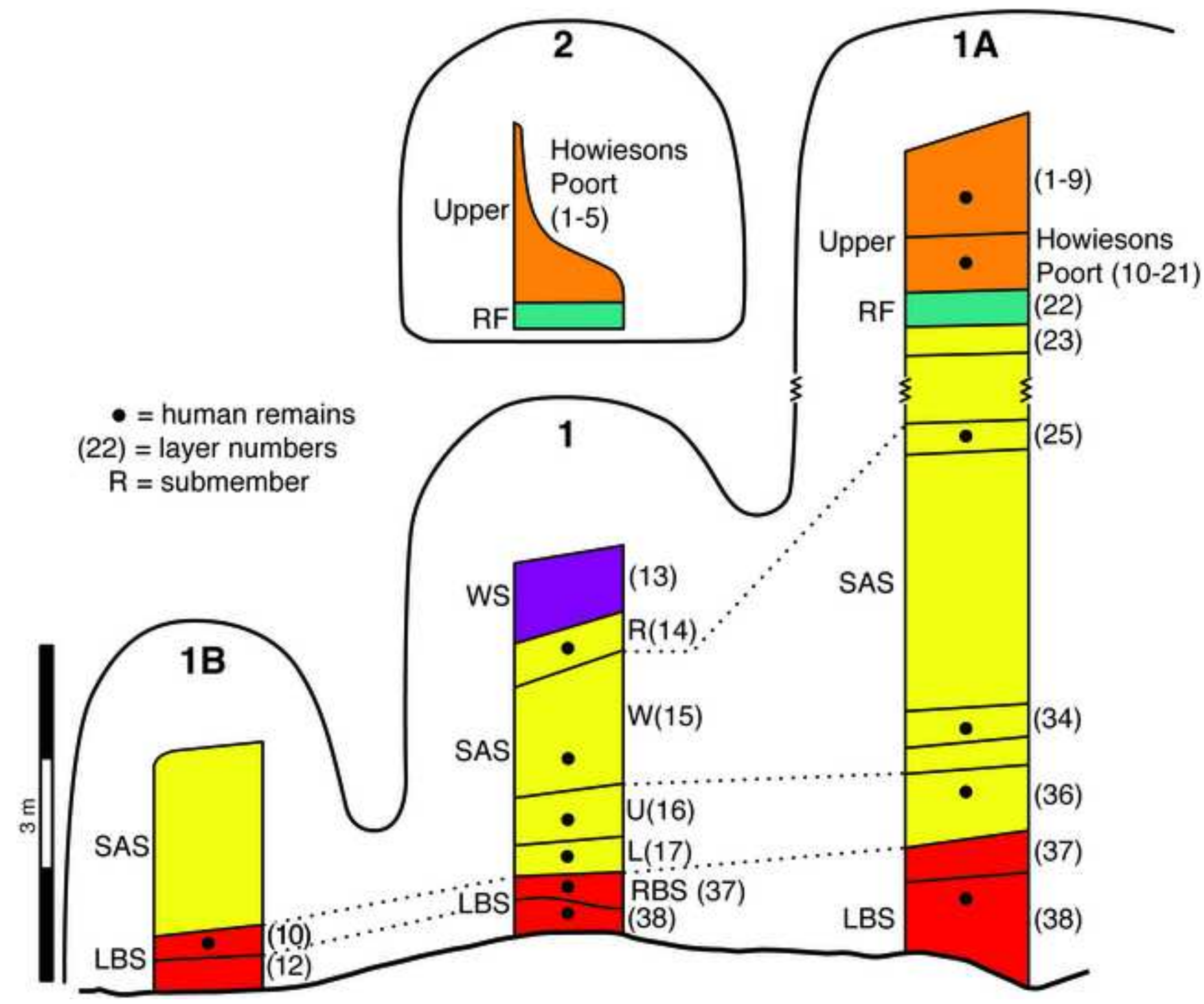




\title{
Figure 5 FINAL
}
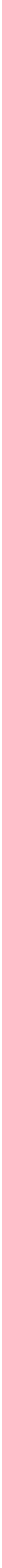

.
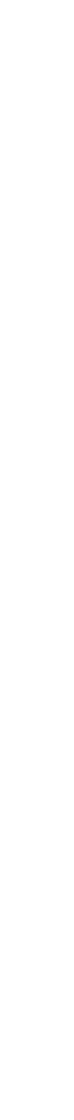

AL

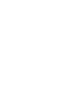


Figure 6 FINAL

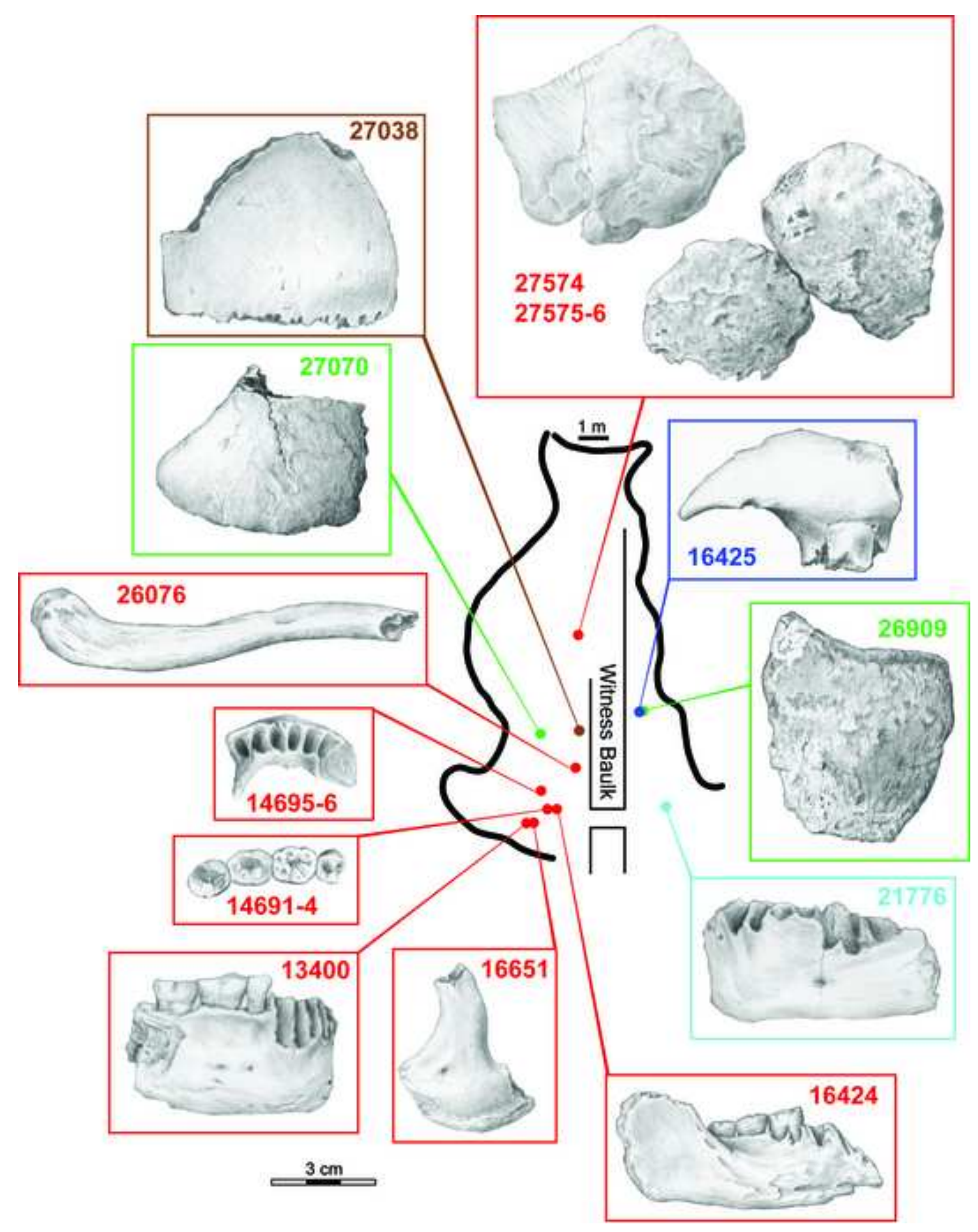



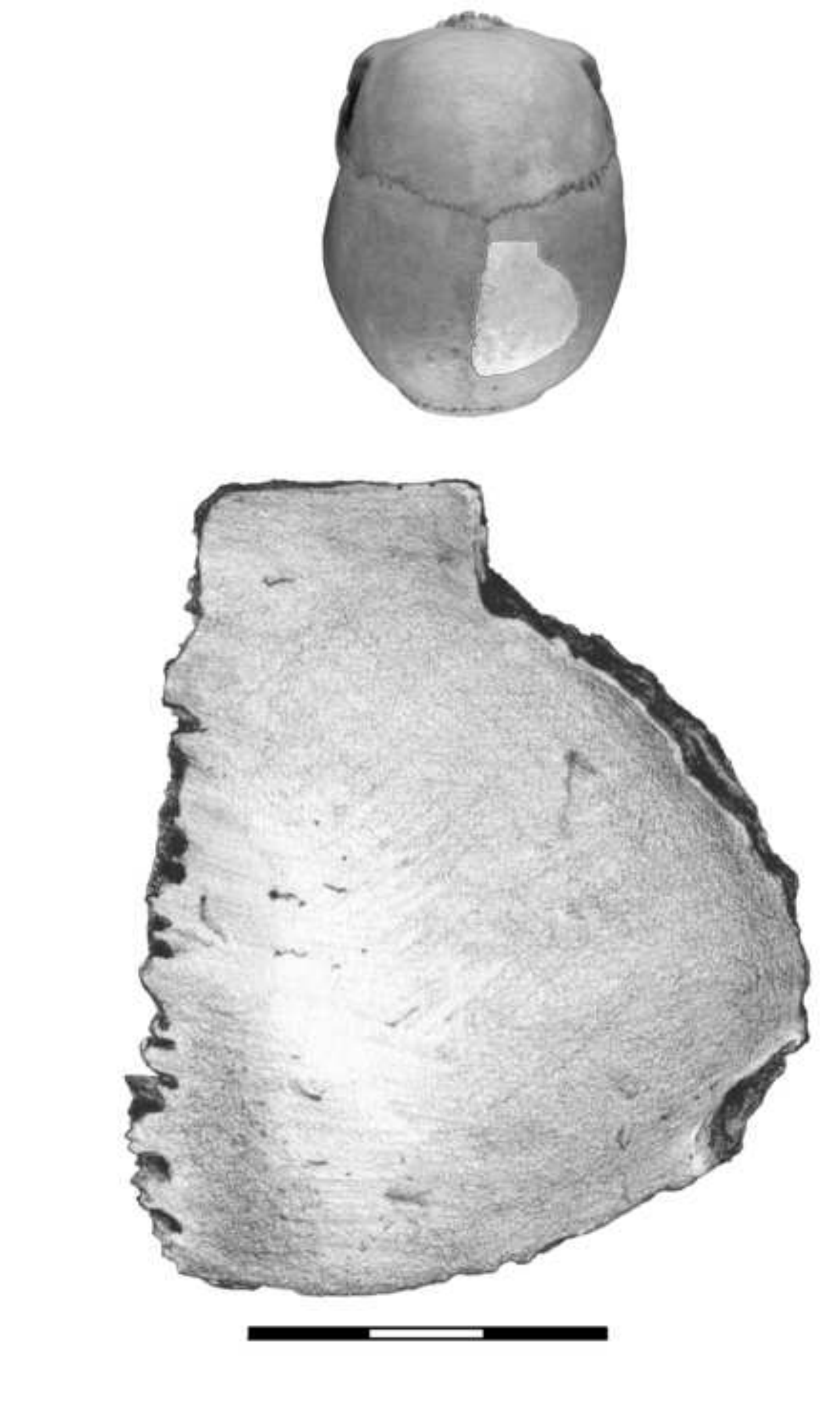

Figure 7 FINAL
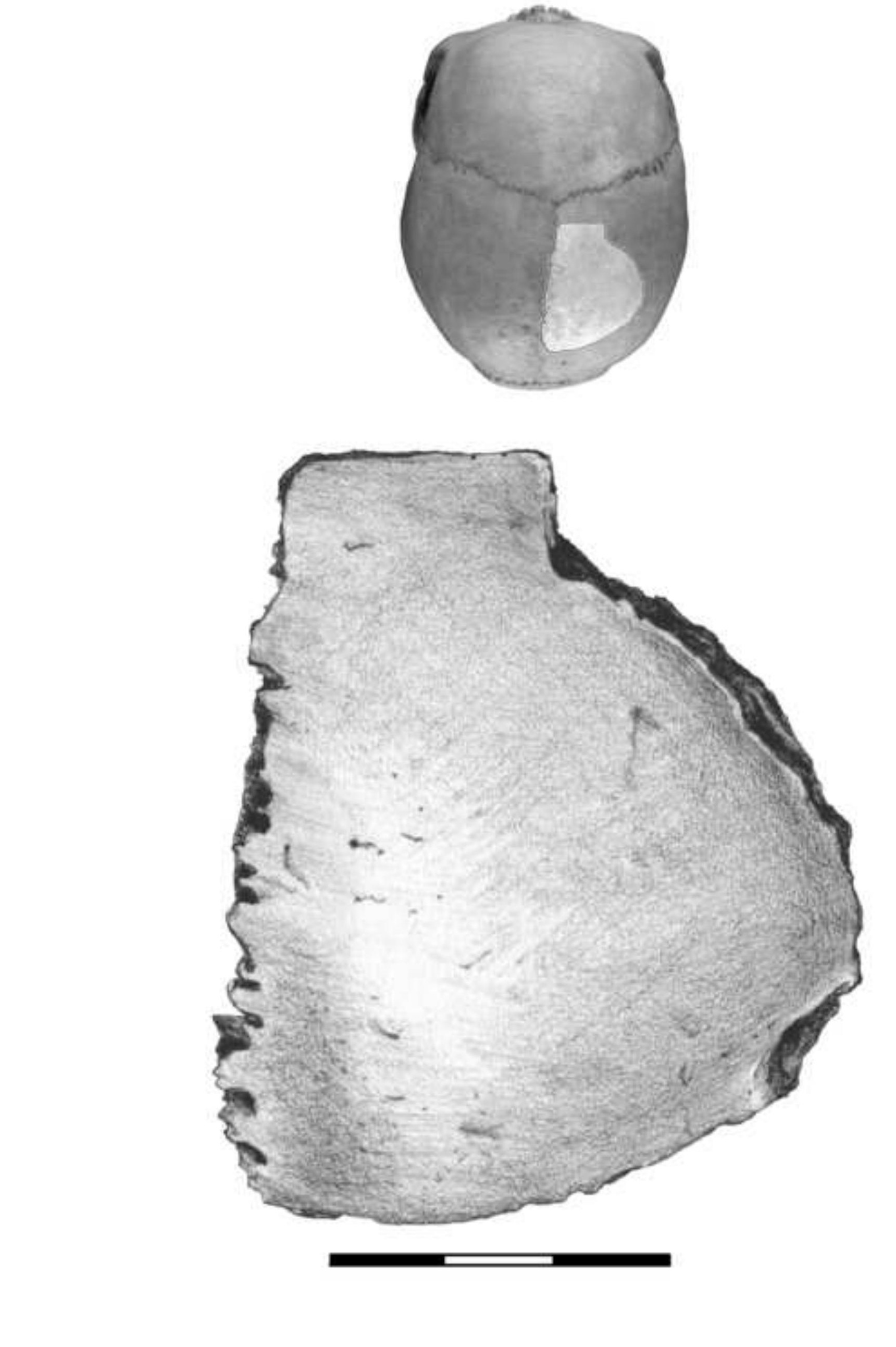
Figure 8 FINAL
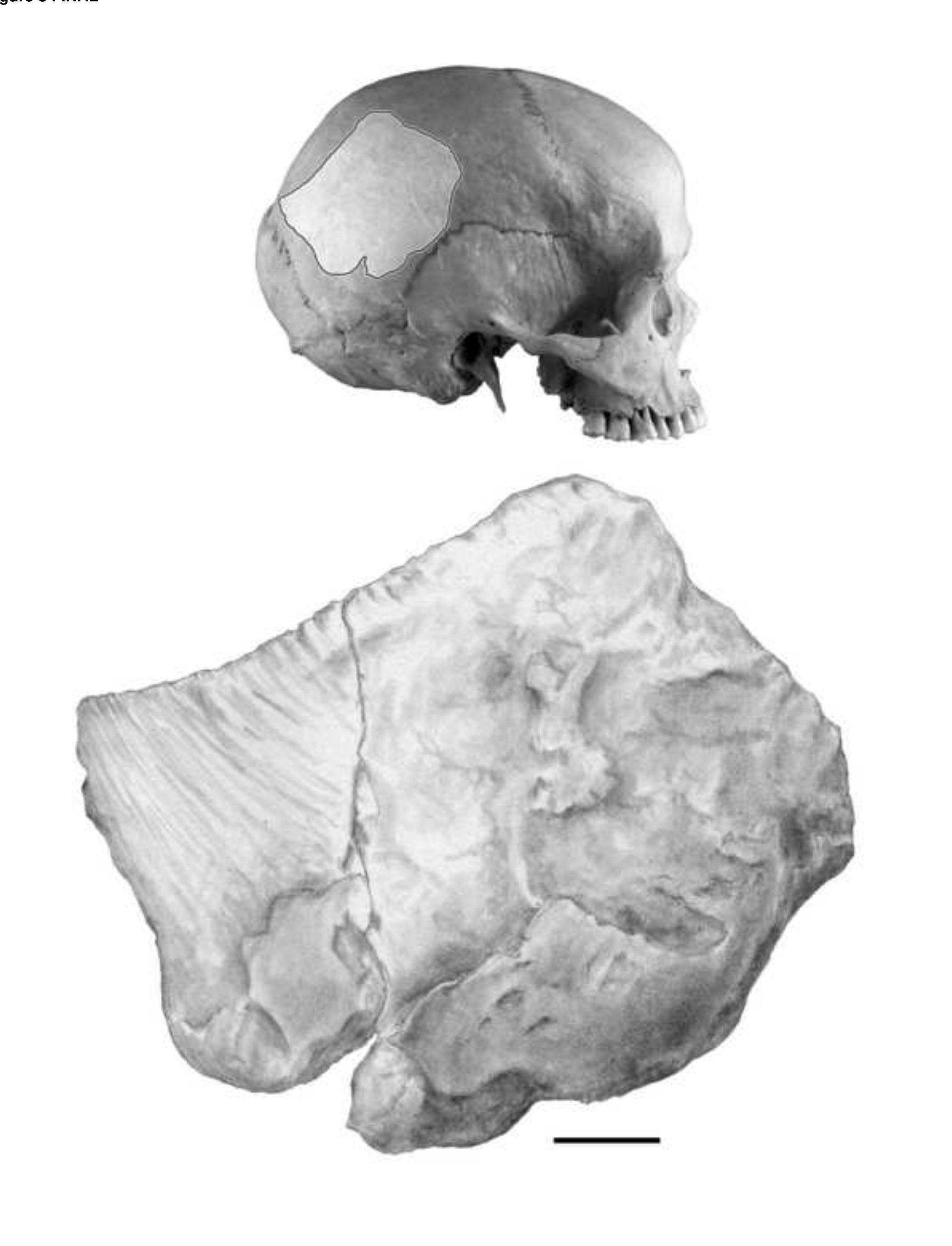


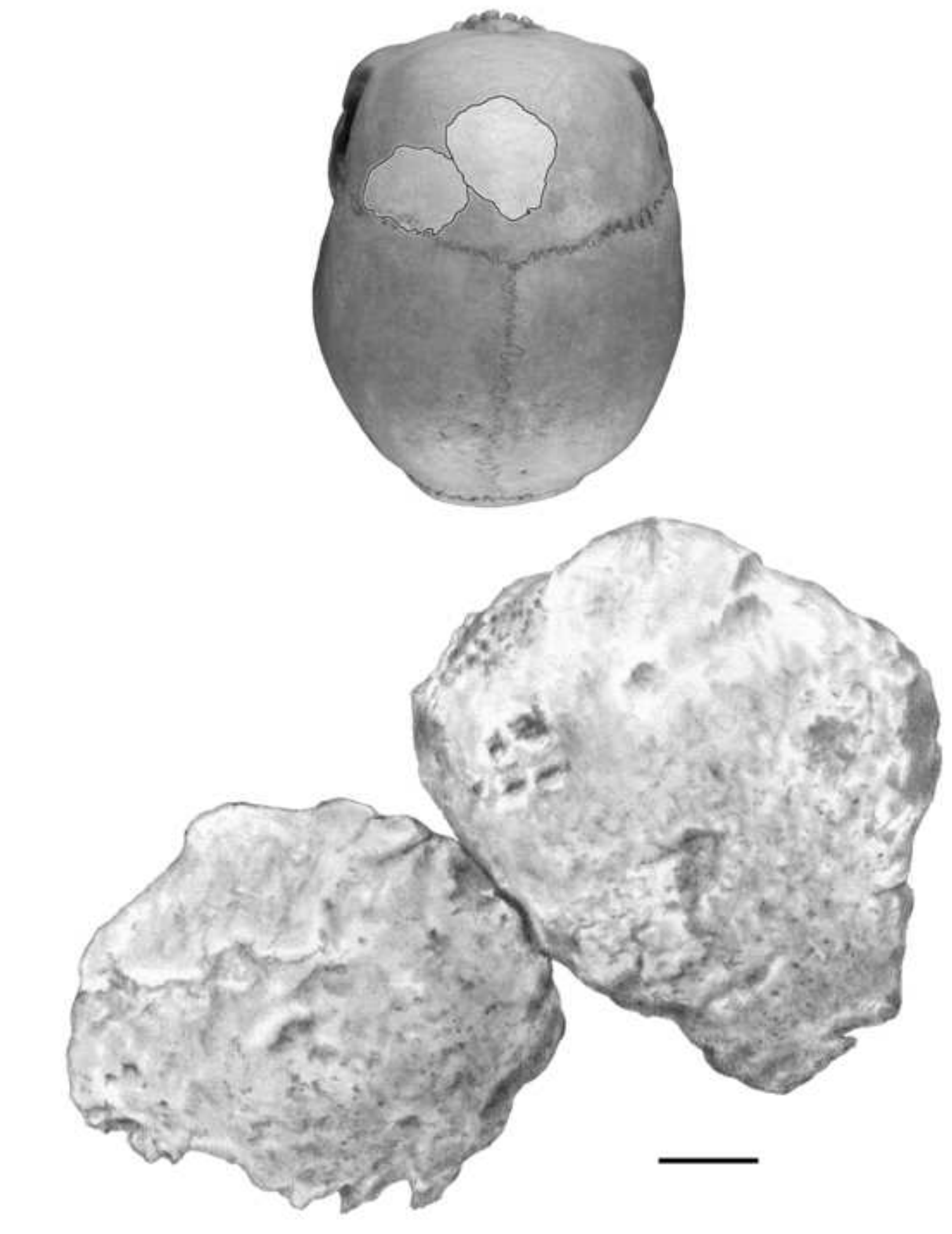

Figure 9 FINAL

\section{Figure g FINAL}
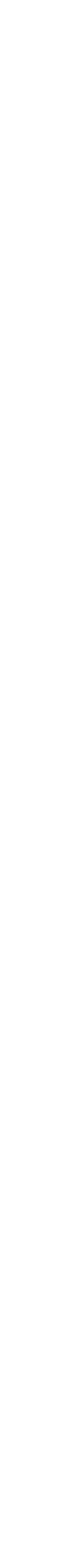

(n)

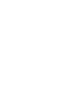


Figure 11 FINAL
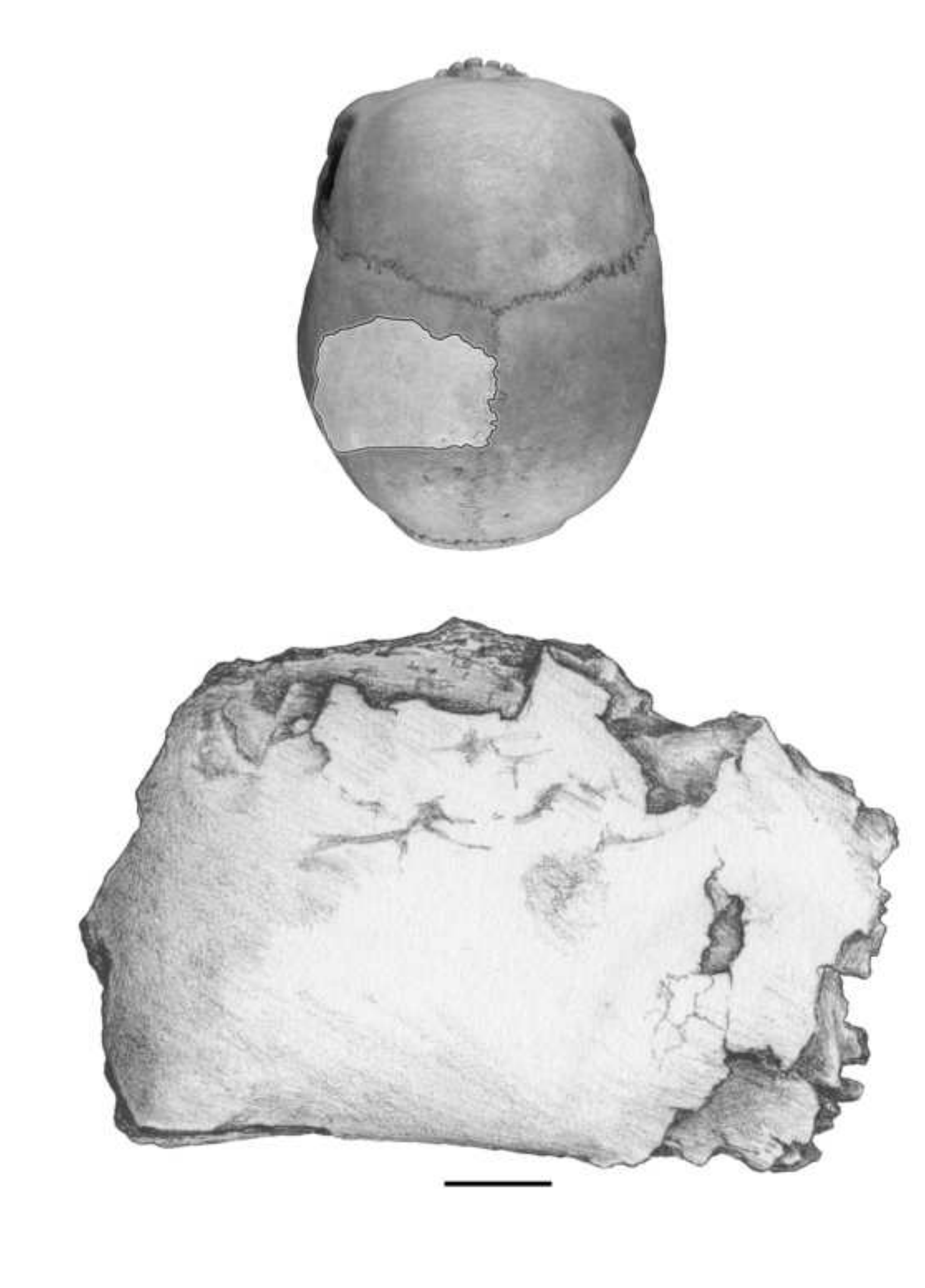

(2)
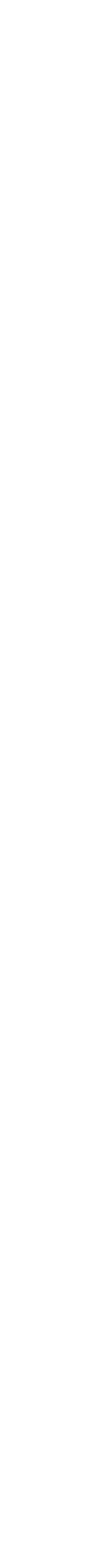


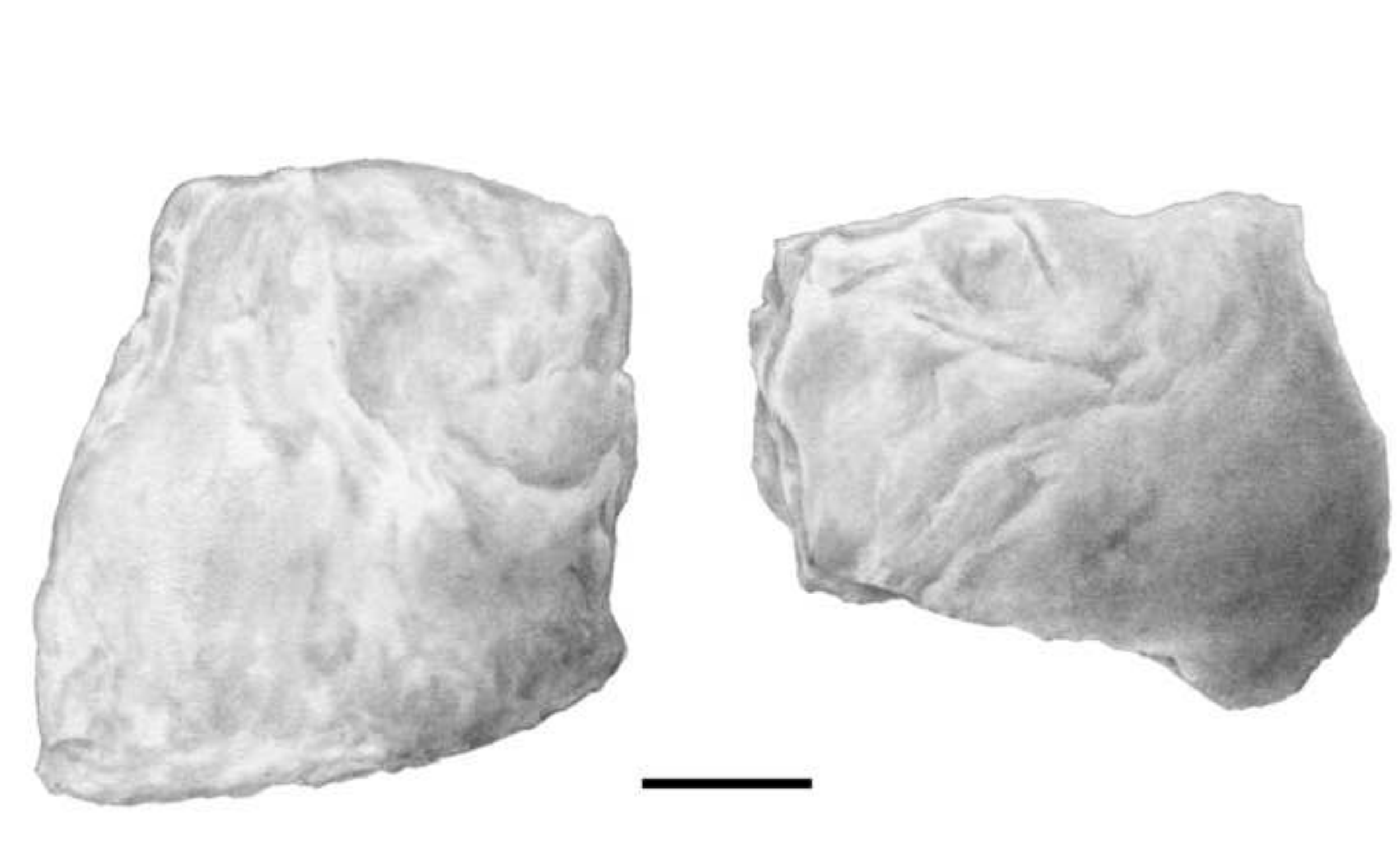

Figure 12 FINAL

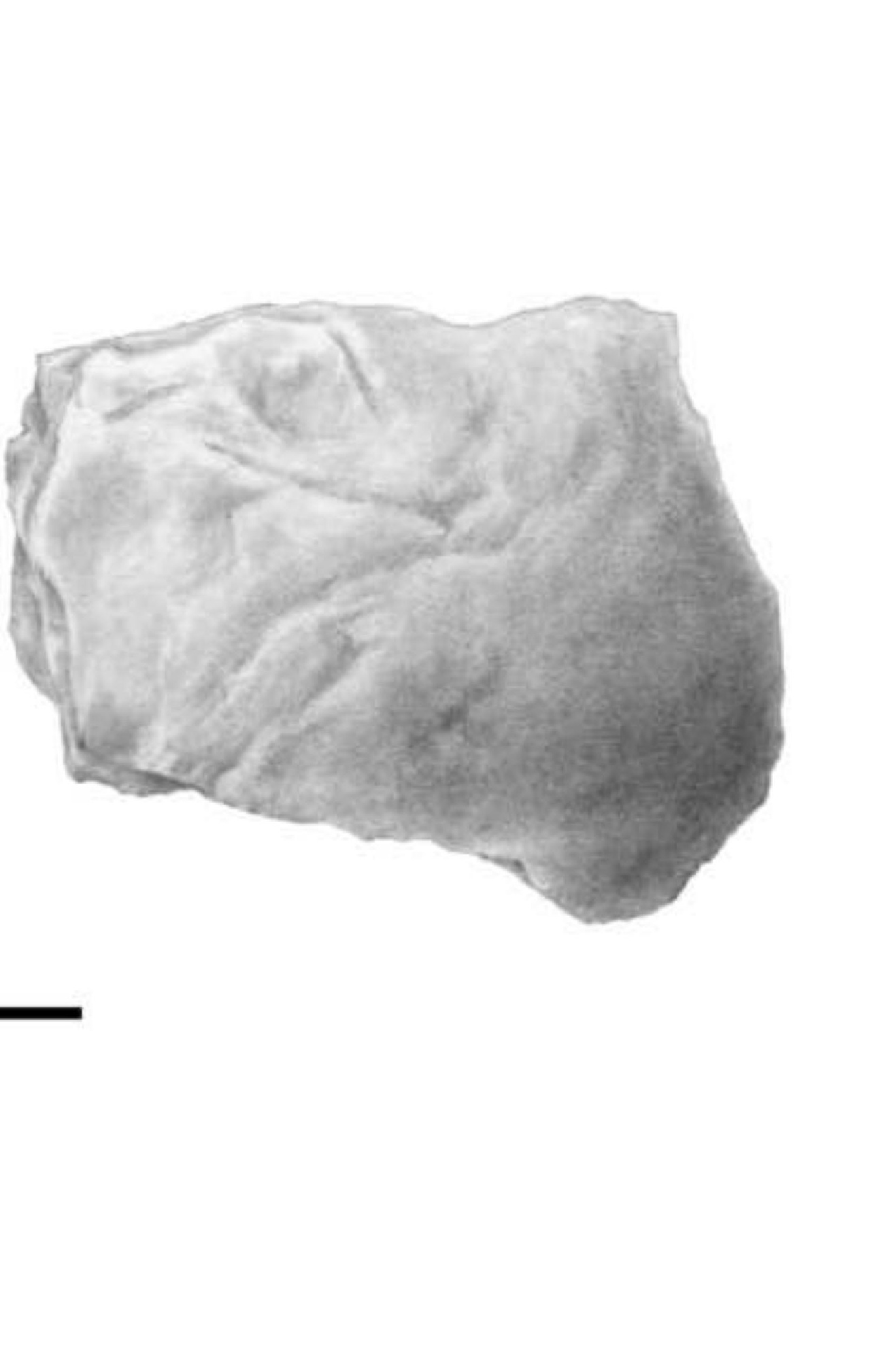

$$
\text { (n) }
$$

\section{Figure 12 FINAL}
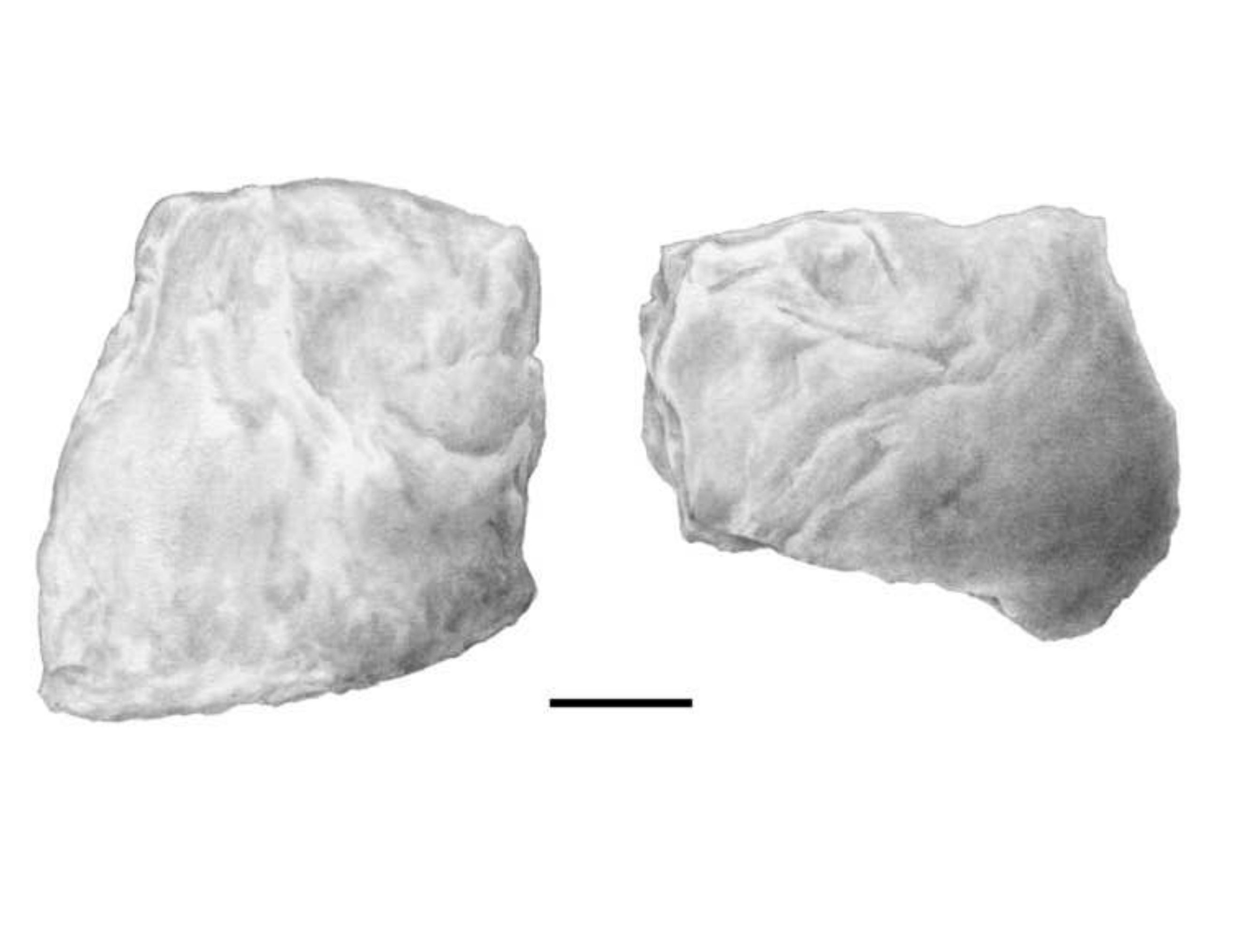
Figure 13 FINAL
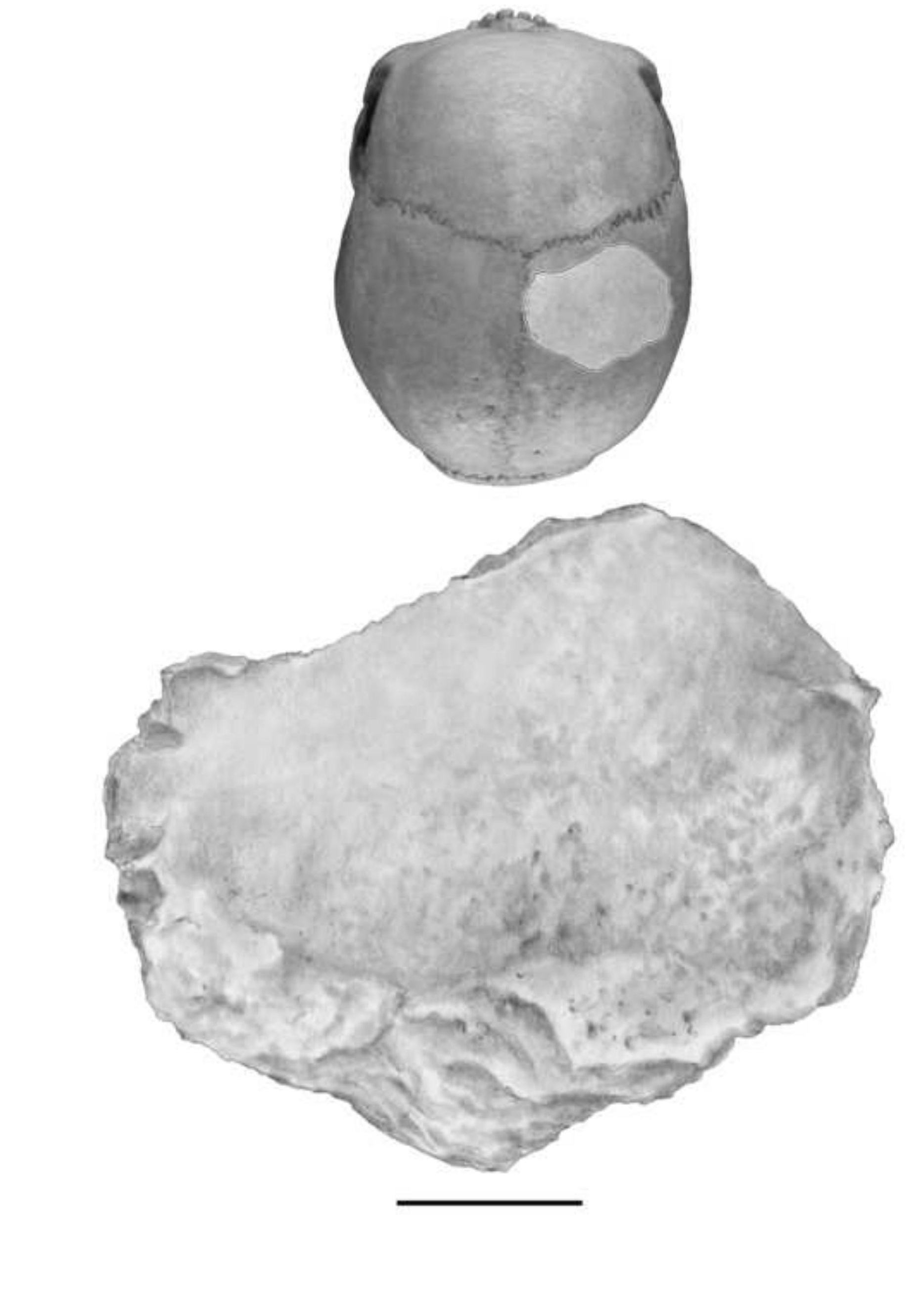

Figure 13 FINAL
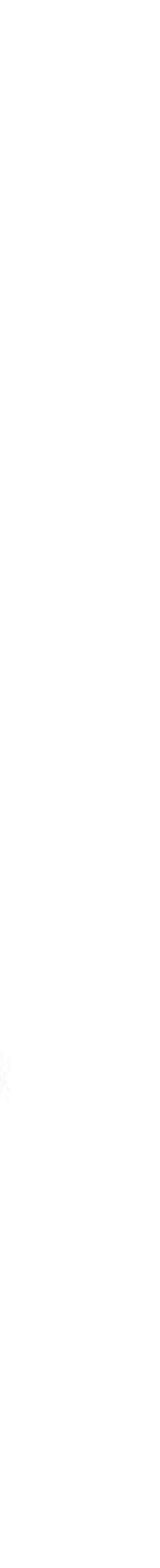
Figure 15 FINAL
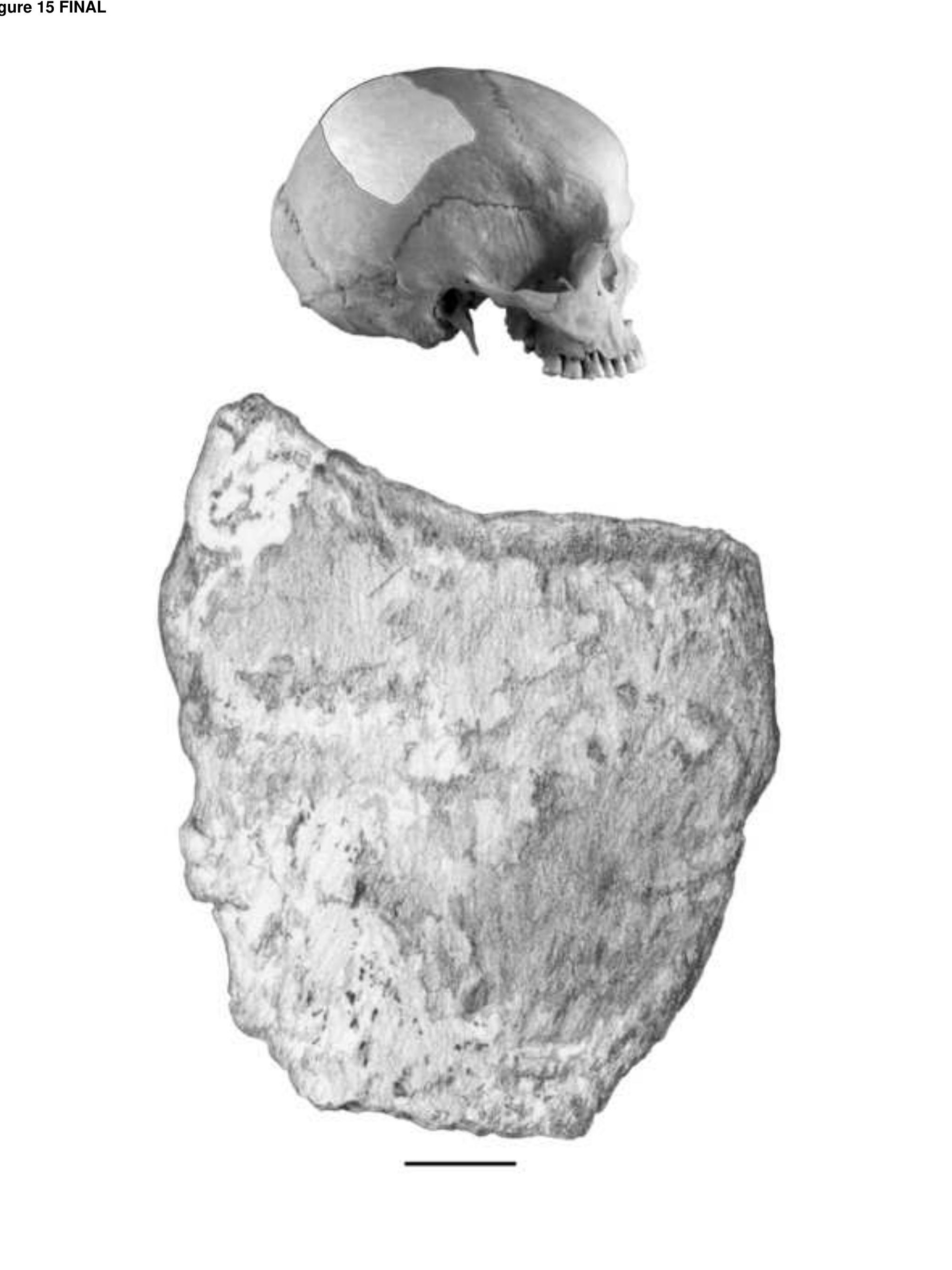

\section{Figure 15 FINAL}

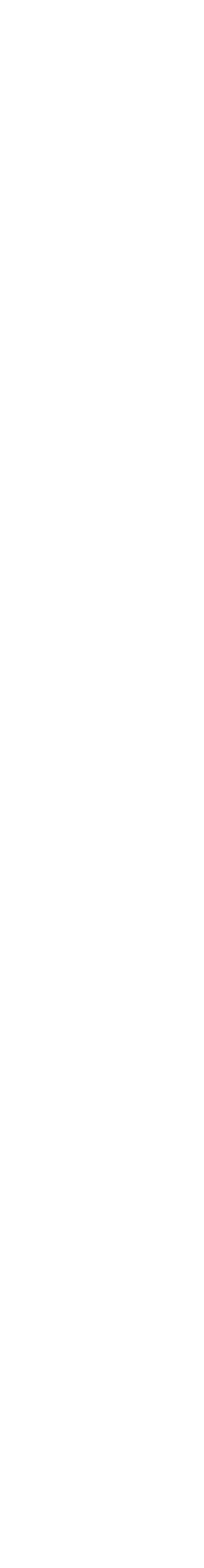


Figure 16 FINAL
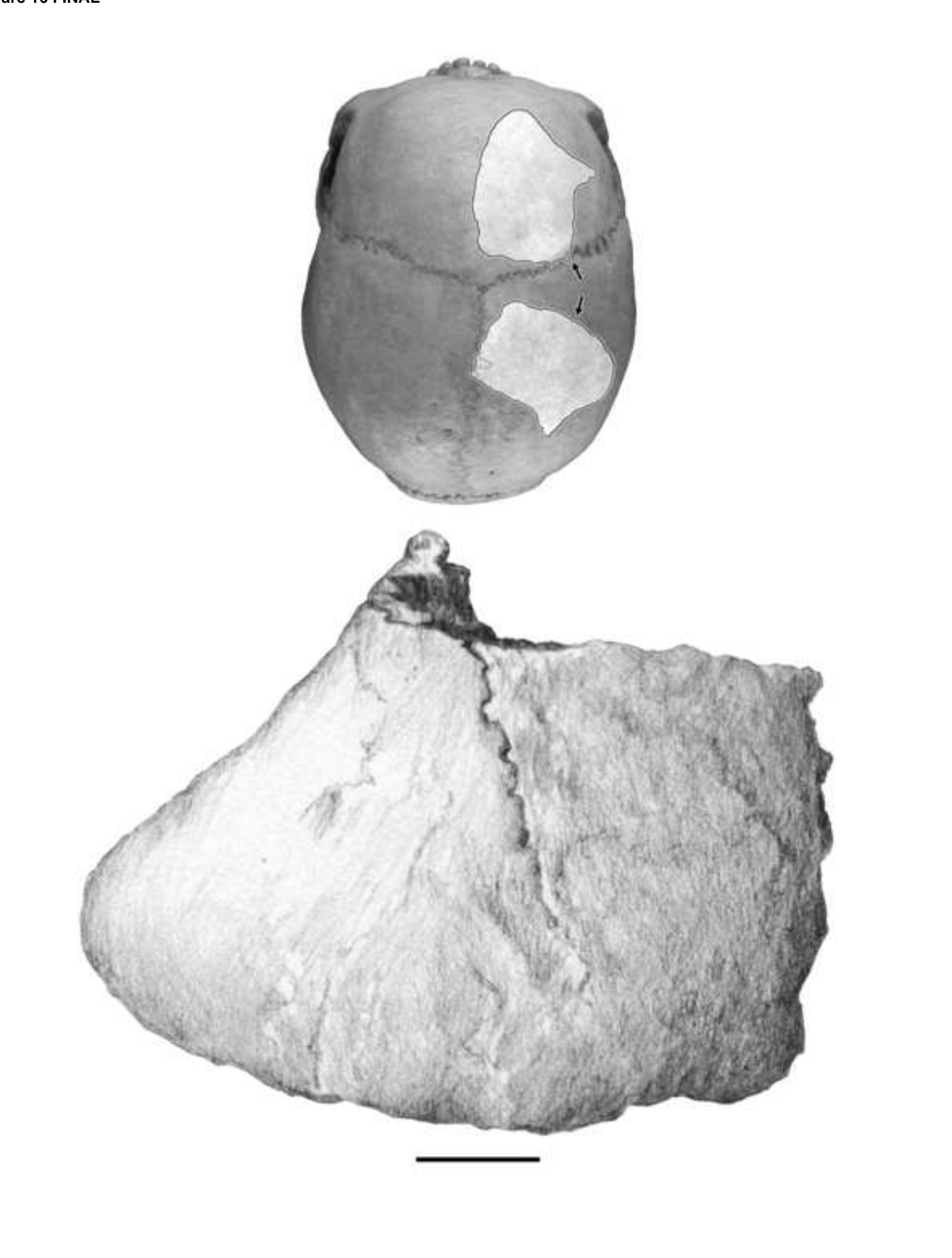
Figure 17 FINAL
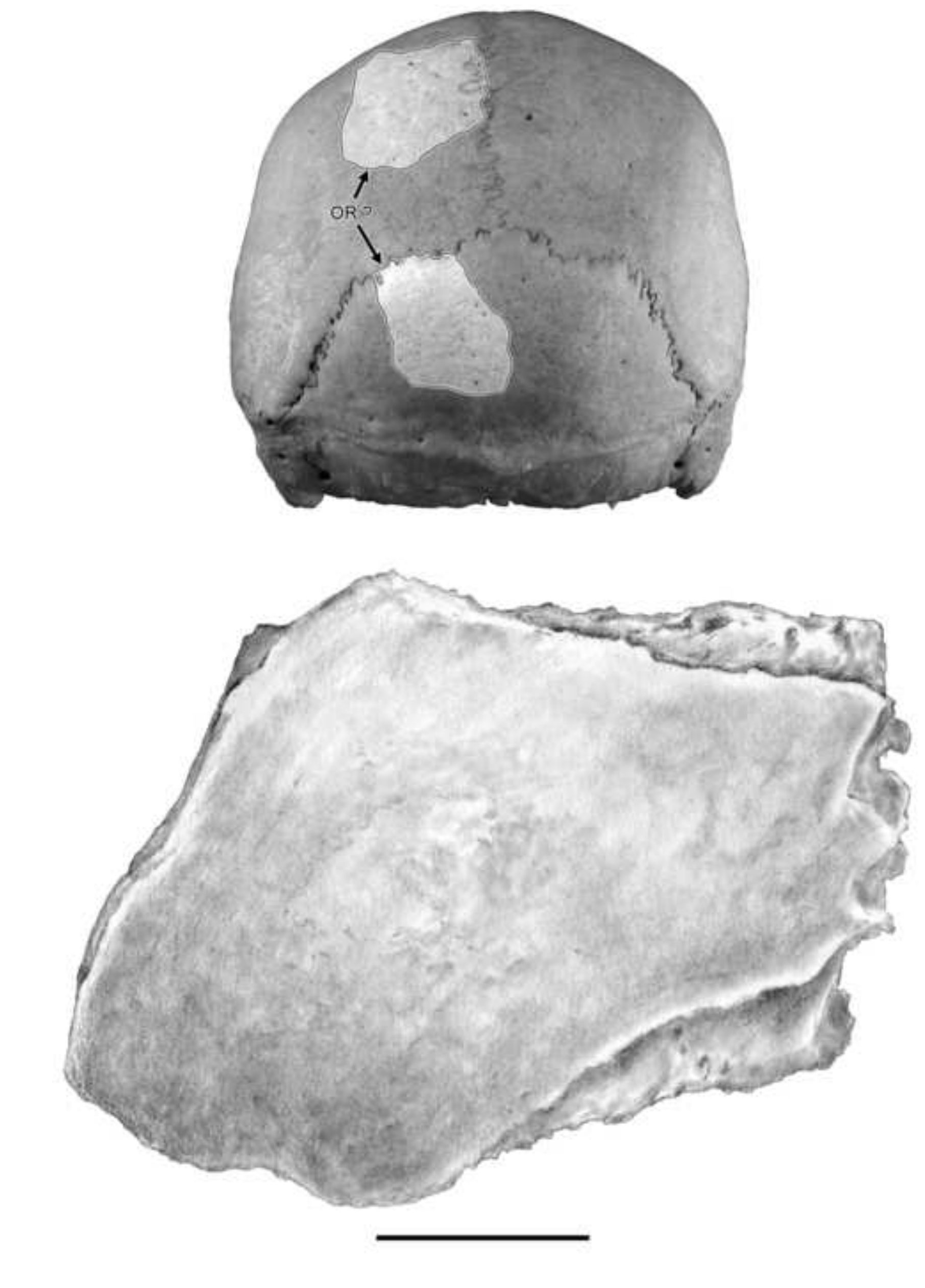

(⿸丆口

.
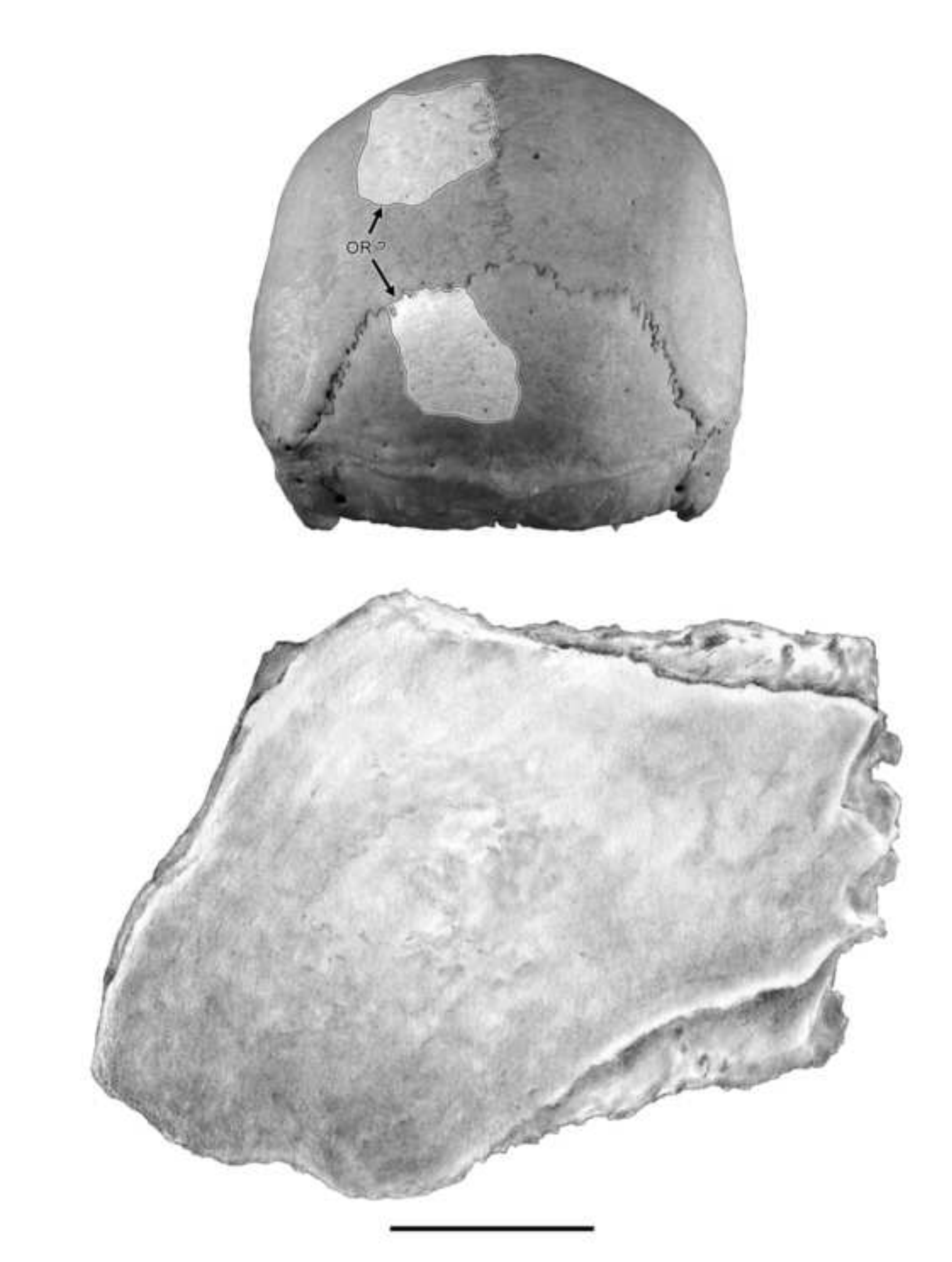

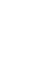

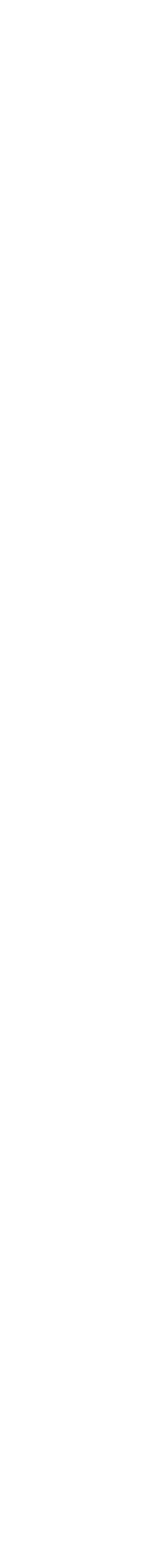



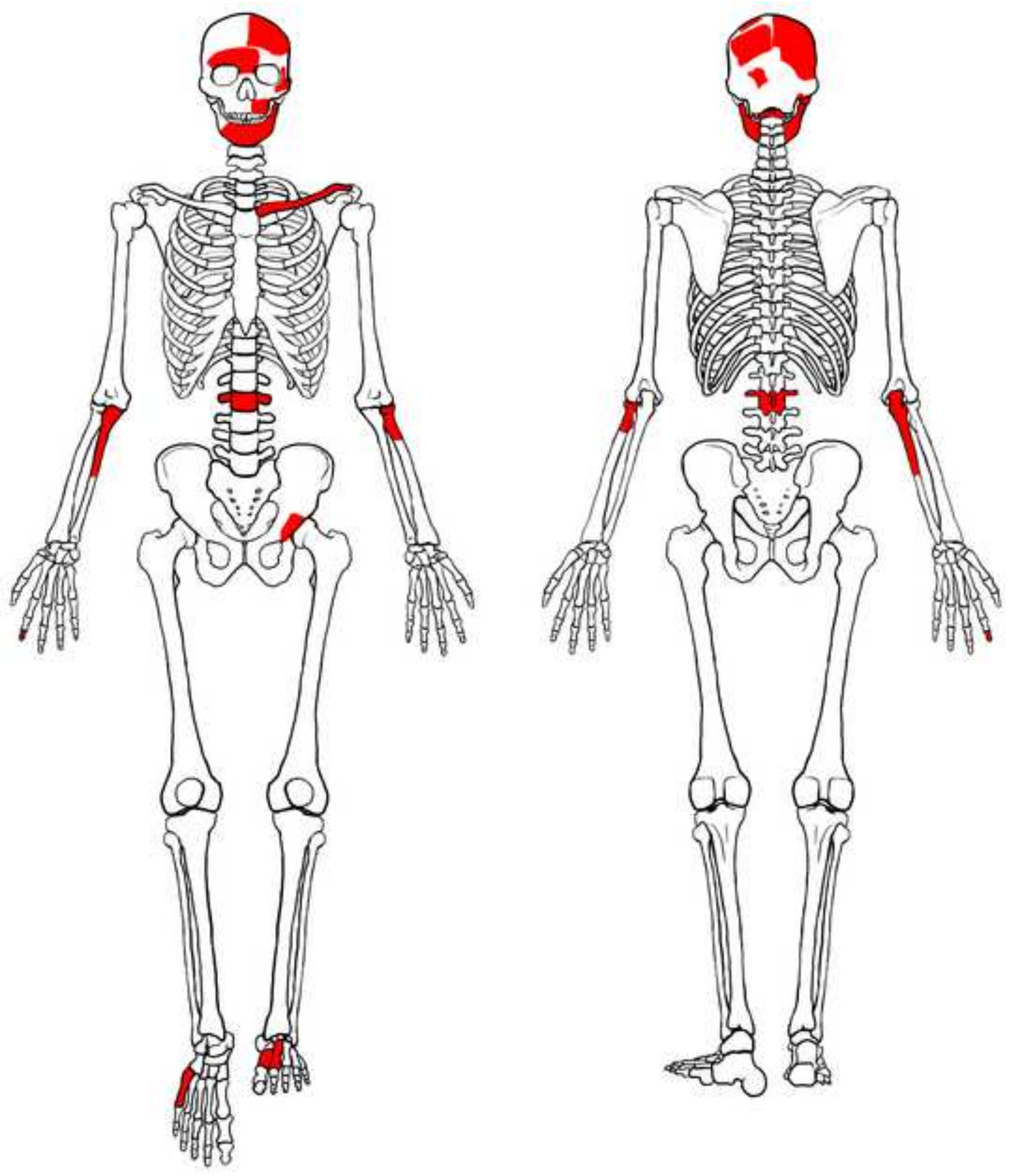